\title{
Patricia Rodrigues Bonazzi
}

\section{Imunogenicidade de doses dobradas da vacina contra o vírus da hepatite $B$ em pacientes cirróticos em lista de espera para transplante de fígado : estudo clínico randomizado}

\author{
Tese apresentada à Faculdade de Medicina da \\ Universidade de São Paulo para obtenção do título de \\ Doutor em Ciências
}

Área de concentração: Doenças Infecciosas e Parasitárias Orientador: Dr. Edson Abdala

São Paulo 


\section{Dados Internacionais de Catalogação na Publicação (CIP)}

Preparada pela Biblioteca da

Faculdade de Medicina da Universidade de São Paulo

Creprodução autorizada pelo autor

\section{Bonazzi, Patricia Rodrigues}

Imunogenicidade de doses dobradas da vacina contra o vírus da hepatite $\mathrm{B}$ em pacientes cirróticos em lista de espera para transplante de fígado : estudo clínico randomizado / Patricia Rodrigues Bonazzi. -- São Paulo, 2010.

Tese(doutorado)--Faculdade de Medicina da Universidade de São Paulo.

Departamento de Moléstias Infecciosas e Parasitárias.

Área de concentração: Doenças Infecciosas e Parasitárias.

Orientador: Edson Abdala.

Descritores: 1.Vacinas contra hepatite B/administração \& dosagem 2.Cirrose hepática 3.Transplante de fígado 4.Ensaio clínico controlado aleatório

USP/FM/SBD-025/10 
Dedicatória

"Aos meus pais,

Duílio e Hortencia" 


\section{Agradecimentos}

Agradeço a Deus por iluminar o meu caminho.

Aos meus pais, sempre incentivando e contribuindo para meu crescimento pessoal e profissional. Companheiros, amigos, a quem agradeço às oportunidades oferecidas ao longo da minha vida, a dedicação e o amor, que nunca me faltaram.

Ao Dr. Edson Abdala, que há alguns anos se tornou meu Mestre, Orientador e Amigo. Uma pessoa honesta, íntegra, dedicada, a quem admiro. Agradeço por ter tido a sorte de trabalhar e crescer ao seu lado.

" O bom mestre faz as pessoas acreditarem nele.

\section{O verdadeiro mestre faz as pessoas acreditarem nelas."}

Às minhas irmãs, Renata e Fernanda, sempre presentes na minha vida, e ao meu cunhado Bruno.

Ao meu namorado Mauro, que esteve ao meu lado com paciência, entendendo minha freqüente ausência.

Às Colegas Profa. Dra. Marta e Dra. Ana Marli, que possibilitaram e muito contribuíram para a realização deste projeto pelo Centro de Imunizações do HCFMUSP, sempre apoiando e estimulando sua concretização.

Aos funcionários do CRIE também pela grande colaboração.

Aos amigos, Débora, Celso, Lígia, Karin e Maristela que me ajudaram muito em diversas etapas deste trabalho.

Aos colegas e funcionários do Serviço de Transplante de fígado pelo apoio no recrutamento dos pacientes, em especial Rosely e enfermeiras Karina, Adriana e Dr. Flávio.

A Roseli e Vânia da pós-graduação pela paciência e apoio durante todos estes anos.

Aos colegas e amigos que um dia faltei para cumprir esta tarefa.

Aos colegas que compuseram minhas bancas de qualificação de mestrado e doutorado, por ter contribuído com o desenvolvimento deste trabalho: Prof. Dr. Bacchella, Dra.Sigrid, Profa. Dra. Marta, Dra. Ana Marli, Dr. Esper.

Ao João Miraglia, que nos orientou quanto à análise estatística deste estudo.

Aos pacientes que aceitaram, mesmo com suas dificuldades, fazer parte de nosso estudo. 
Esta tese está de acordo com as seguintes normas, em vigor no momento desta publicação:

Referências: adaptação de International Committee of Medical Journals Editors (Vancouver)

Universidade de São Paulo. Faculdade de Medicina. Serviço de Biblioteca e Documentação. Guia de apresentação de dissertações, teses e monografias. Elaborado por Anneliese Carneiro da Cunha, Maria Júlia de A. L. Freddi, Maria F. Crestana, Marinalva de Souza Aragão, Suely Campos Cardoso, Valéria Vilhena. $2^{\text {a }}$ ed. São Paulo: Serviço de Biblioteca e Documentação; 2005.

Abreviaturas dos títulos dos periódicos de acordo com List of Journals Indexed in Índex Medicus. 


\section{Sumário}

Lista de tabelas

Lista de figuras

Resumo

Summary

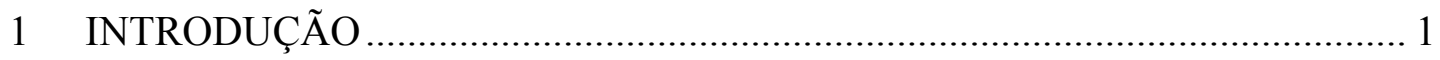

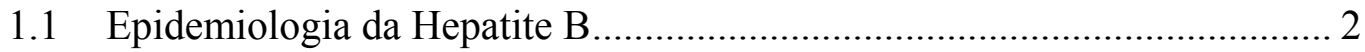

1.2 Vacina Contra o Vírus da Hepatite B ..................................................... 5

1.3 O Cirrótico em Lista de Espera para Transplante de Fígado..................... 13

1.4 Vacina Contra o Vírus da Hepatite B em Cirróticos ................................ 17

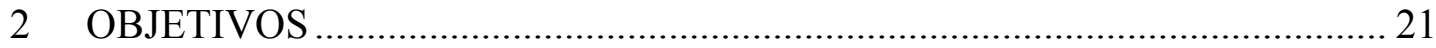

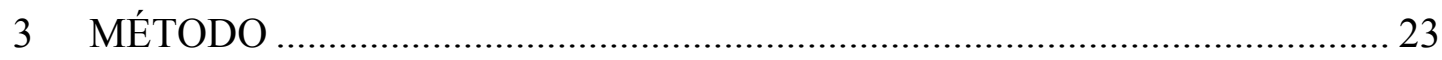

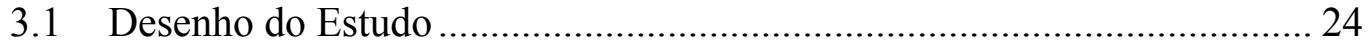

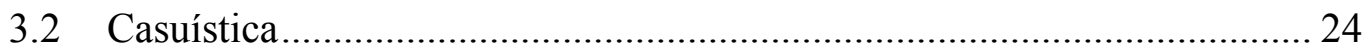

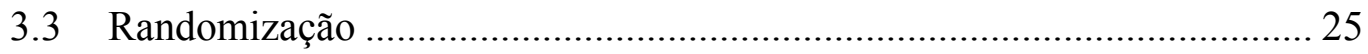

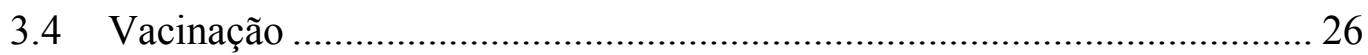

3.5 Exames Laboratoriais ........................................................................... 27

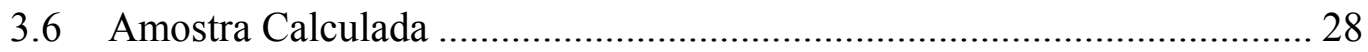

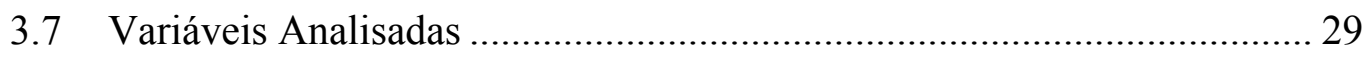

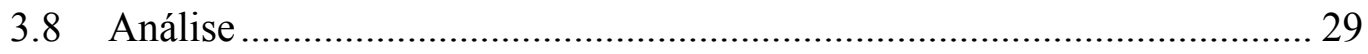

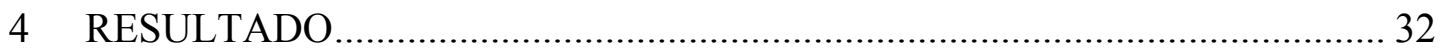

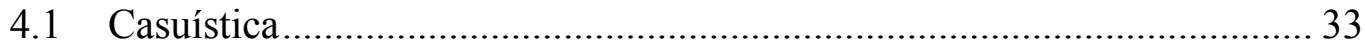

4.2 Análise da resposta após a terceira dose da vacina ................................ 37

4.3 Análise da resposta após a quarta dose da vacina .................................... 44

4.4 Análise comparativa da resposta vacinal após esquema com 3 e 4

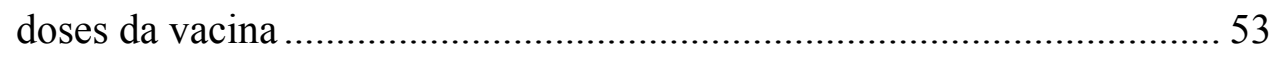

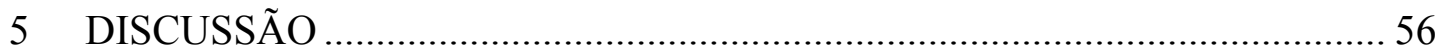

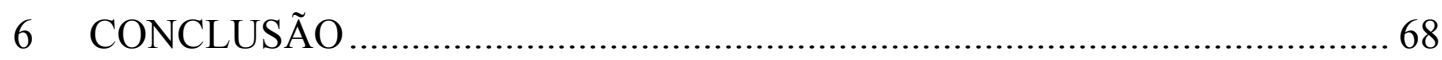

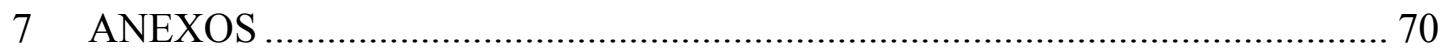

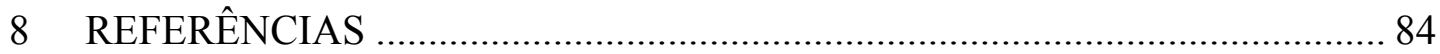




\section{Lista de Tabelas}

Tabela 1 - Avaliação de eficácia de vacina contra VHB: estudos clínicos incluindo cirróticos

Tabela 2 - Causas de exclusão pré-randomização de 506 pacientes.

Tabela 3 - Causas de exclusão pós-randomização de 18 pacientes

Tabela 4 - Descrição das variáveis categóricas dos 214 pacientes randomizados - comparação entre pacientes incluídos e não incluídos na análise após a terceira dose da vacina contra o VHB, conforme dose simples ou dobrada.

Tabela 5 - Descrição das variáveis ordenadas dos 214 pacientes randomizados - comparação entre pacientes incluídos e não incluídos na análise após a terceira dose da vacina contra o VHB, conforme dose simples ou dobrada.

Tabela 6 - Descrição das variáveis categóricas dos 130 pacientes incluídos na análise da resposta vacinal contra o VHB após a terceira dose comparação entre os grupos com dose simples ou dobrada

Tabela 7 - Descrição das variáveis ordenadas dos 130 incluídos na análise da resposta vacinal contra o VHB após a terceira dose - comparação entre os grupos com dose simples ou dobrada

Tabela 8 - Dosagem de anti-HBs após a terceira dose de vacina contra o VHB com doses simples ou dobrada em 130 pacientes

Tabela 9 - Fatores preditivos de resposta vacinal após a terceira dose da vacina: análise multivariada.

Tabela 10 - Probabilidades de soroconversão conforme a idade, após a terceira dose da vacina contra o VHB

Tabela 11 - Descrição das variáveis categóricas dos 214 pacientes randomizados - comparação entre pacientes incluídos e não incluídos na análise após a quarta dose da vacina contra o VHB, conforme dose simples ou dobrada.

Tabela 12 - Descrição das variáveis ordenadas dos 214 pacientes randomizados - comparação entre pacientes incluídos e não incluídos na análise após a quarta dose da vacina contra o VHB, conforme dose simples ou dobrada. 
Tabela 13 - Descrição das variáveis categóricas dos 127 incluídos na análise da resposta vacinal contra o VHB após a quarta dose comparação entre os grupos com dose simples ou dobrada

Tabela 14 - Descrição das variáveis ordenadas dos 127 incluídos na análise da resposta vacinal contra o VHB após a quarta dose - comparação entre os grupos com dose simples ou dobrada.

Tabela 15 - Dosagem de anti-HBs após a quarta dose de vacina contra o VHB com doses simples ou dobrada em 127 pacientes.

Tabela 16 - Grupo sanguíneo como fator preditivo de resposta vacinal após a quarta dose da vacina contra VHB, em análise ajustada para idade e IMC - 127 pacientes

Tabela 17 - IMC como fator preditivo de resposta após a quarta dose da vacina contra o VHB, conforme o tipo sanguíneo, ajustado para idade (média=50anos)

Tabela 18 - Descrição das variáveis categóricas dos 98 pacientes incluídos na análise de comparação entre 3 e 4 doses da vacina contra VHB comparação com os não incluídos

Tabela 19 - Descrição das variáveis ordenadas dos 98 pacientes incluídos na análise de comparação entre 3 e 4 doses da vacina contra VHB comparação com os não incluídos 


\section{Lista de Figuras}

Figura 1 - Número de casos de Hepatite B de acordo com a faixa etária

Figura 2 - Resposta Imune após vacinação contra o VHB 10

Figura 3 - Esquema utilizado de randomização em blocos 26

Figura 4 - Fluxograma do seguimento de pacientes avaliados para análise após a terceira dose da vacina contra o VHB....

Figura 5 - Fluxograma do seguimento de pacientes avaliados para análise após a quarta dose da vacina contra o VHB.

Figura 6 - Gráfico de probabilidade de soroconversão após a terceira dose da vacina contra o VHB, conforme a idade

Figura 7 - Probabilidade de soroconversão após a quarta dose da vacina contra o VHB, conforme tipo sanguíneo e idade, em pacientes com $\mathrm{IMC}=27,5$

Figura 8 - Probabilidade de soroconversão após a quarta dose da vacina contra o VHB, conforme tipo sanguíneo e idade, em pacientes com $\mathrm{IMC}=35$

Figura 9 - Probabilidade de soroconversão após a quarta dose da vacina contra o VHB, conforme tipo sanguíneo e idade, em pacientes com $\mathrm{IMC}=40$ 


\section{Resumo}

Bonazzi PR. Imunogenicidade de doses dobradas da vacina contra o vírus da hepatite $B$ em pacientes cirróticos em lista de espera para transplante de fígado: estudo clínico randomizado [tese]. São Paulo: Faculdade de Medicina, Universidade de São Paulo; 2010. 94p.

INTRODUÇÃO: A vacina contra o vírus da hepatite B é recomendada a todos os pacientes cirróticos, por outra etiologia, em lista de espera para transplante de fígado. Entretanto, a resposta vacinal descrita nesta população é inferior à da população de adultos imunocompetentes. Estratégias para aumentar sua imunogenicidade são discutidas na literatura, como a aplicação de doses dobradas, recomendada a populações de imunodeprimidos. Neste estudo, foi comparada a resposta à vacina contra o vírus da hepatite $\mathrm{B}$ de um esquema com doses simples a um com doses dobradas, e avaliada a influência de outros fatores associados à resposta vacinal no cirrótico em lista de espera para transplante de fígado. MÉTODO: Desenvolveu-se um estudo clínico, prospectivo, randomizado, entre outubro de 2006 e setembro de 2008. Adotando-se intervalo de confiança de $95 \%$ e poder de $80 \%$, o cálculo da amostra resultou em 103 pacientes em cada grupo. Estimou-se uma perda de 10\%, resultando em 113 pacientes a receber o esquema $0,1,2$ e 6 meses com dose simples, e 113 a receber esquema semelhante com dose dobrada. As vacinas utilizadas foram Euvax e Butang. A imunogenicidade da vacina foi avaliada através da dosagem do anti-HBs após a terceira e a quarta dose da vacina. RESULTADO: Foram selecionados 738 pacientes inscritos em lista de espera para transplante de fígado, e incluídos 232. $\mathrm{Na}$ análise de resposta vacinal após a terceira dose, não houve diferença estatisticamente significativa entre os grupos que receberam dose simples ou dobrada $(35,2 \% \times 37,2 \%, p=0,8)$. A soroconversão global após a quarta dose foi $66,9 \%$ (85/127). Também não houve diferença entre o grupo com dose simples e dobrada após a quarta dose $(64,5 \%$ x $69,2 \%, \mathrm{p}=0,57)$, mas ao desenvolver a análise com ajuste para alguns fatores de confusão como idade, IMC, MELD e grupo sanguíneo, encontrou-se uma razão de probabilidade de soroconversão entre os pacientes que receberam a dose dobrada de 2,57 vezes a razão entre os pacientes que receberam a dose simples. Esta diferença foi estatisticamente significante, mas o intervalo de confiança incluiu $1(\mathrm{OR}=2,57$, IC $95 \%=1$ até $6,63, p=0,043)$. Fatores como idade, IMC e grupo sanguíneo $\mathrm{O}$ foram preditivos de resposta vacinal após a quarta dose da vacina. CONCLUSÃO: Não houve diferença na resposta vacinal entre dose simples e dobrada no cirrótico após esquema proposto. A má resposta após o esquema acelerado ( 0,1 e 2 meses) não contribui para que este esquema seja adotado na prática clínica. Provavelmente, o número de doses e o intervalo entre elas têm maior relevância, em relação a dose simples ou dobrada, como estratégia para aumentar a resposta vacinal.

Descritores: 1.Vacinas contra hepatite B/administração \& dosagem 2.Cirrose hepática 3.Transplante de fígado 4.Ensaio clínico controlado aleatório 


\section{Summary}

Bonazzi PR. Immunogenicity of double doses of hepatitis B vaccine in cirrhotic patients in waiting list for orthotopic liver transplantation: a randomized clinical trial [thesis]. São Paulo: Faculdade de Medicina, Universidade de São Paulo; 2010. 94p

BACKGROUND: Vaccine against hepatitis B is recommended for all cirrhotic patients, by another etiology, in waiting list for liver transplantation. However the vaccine response described in this population is lower than in immunocompetent adults. Strategies to increase its immunogenicity are discussed in the literature, as the application of double doses, usually recommended in immunocompromised populations. This study compared response to the vaccine against hepatitis B virus in a single dose regimen with a double dose regimen, and evaluated the influence of other features associated with vaccine response in cirrhotic on the waiting list for liver transplantation. METHOD: A prospective and randomized clinical trial was conducted between October 2006 and September 2008. Adopting confidence interval of $95 \%$ and a power of $80 \%$, calculated sample comprised 103 patients in each group. Considering an estimated mortality of $10 \%$, final calculated sample resulted in 113 patients to receive the scheme 0,1,2 and 6 months with a single dose, and 113 to receive a similar scheme with double doses. Vaccines used were Euvax and Butang. Vaccine immunogenicity was assessed measuring anti-HBs after the third and fourth dose of vaccine. RESULT: We selected 738 patients in waiting list for liver transplantation and included 232. There was no statistically significant difference between the groups that received single or double doses in the analysis of vaccine response after the third dose $(35.2 \%$ vs. $37.2 \%, p=0,8)$. Overall seroconversion after the fourth dose was $66.9 \%$ (85/127). There was no difference between the groups with double and single dose after the fourth dose (64.5\% vs. $69.2 \%, \mathrm{p}=0,57)$, but analysis adjusted for some confounding factors such as age , BMI, MELD and blood group, found odds of seroconversion among patients who received double doses 2.57 times that of patients who received single doses. This difference was statistically significant, but confidence interval included 1 (OR = $2.57,95 \% \mathrm{CI}=1$ to $6.63, \mathrm{p}=0.043$ ). Features as age, BMI and blood group were predictors of vaccine response after the fourth dose of vaccine. CONCLUSION: There was no difference in vaccine response between single and double doses in cirrhotic patients after the proposed scheme. The poor response after accelerated schedule ( 0.1 and 2 months) does not contribute to adopting this scheme in clinical practice. Number of doses and interval between them may be more important to vaccine response than single or double doses.

Descriptors: 1.Hepatitis B Vaccines / administration \& dosage 2.Cirrhosis 3.Liver transplantation 4.Randomized controlled clinical trial 


\section{I ntrodução}


A vacina contra o vírus da hepatite $\mathrm{B}$ (VHB) é recomendada a todos os pacientes cirróticos, por outra etiologia, em lista de espera para transplante de fígado. Entretanto, apesar de pouco estudada, a resposta vacinal descrita nesta população é inferior à população de adultos imunocompetentes. Vários aspectos relacionados à eficácia da vacina e estratégias para aumentar sua imunogenicidade são discutidas na literatura. Neste estudo, avaliamos o impacto de um esquema vacinal com doses dobradas e a influência de outros fatores associados à resposta vacinal no cirrótico em lista de espera para transplante de fígado.

\subsection{Epidemiologia da Hepatite B}

A hepatite B ainda é, atualmente, responsável por cerca de 1 milhão de mortes por ano no mundo, devido a cirrose ou carcinoma hepatocelular $(\mathrm{CHC}),{ }^{1,2} \mathrm{~A}$ Organização Mundial de Saúde (OMS) estima que dois bilhões de pessoas no mundo apresentem algum marcador sorológico para o VHB, e que 360 milhões estejam cronicamente infectadas. $^{3}$

A prevalência da infecção varia com a região estudada. O Sudeste Asiático e a África Sub-Sahara são denominadas áreas de alta endemicidade, pois a hepatite B ocorre em 8 a $20 \%$ da população. ${ }^{2}$ Áreas de endemicidade intermediária, como 
países do Mediterrâneo e Japão, têm uma prevalência de 2 a $8 \%$, e as de baixa endemicidade, como Estados Unidos e Europa, 0,1 a 2\%. ${ }^{2}$

A transmissão do VHB ocorre por via percutânea ou através do contato da mucosa com sangue ou fluidos contaminados. ${ }^{4}$ A prevalência da infecção em determinada área tem influência sobre a freqüência dos mecanismos de transmissão. Uma importante fonte de transmissão em áreas de alta prevalência é a perinatal, podendo ocorrer em até $90 \%$ dos casos em que o vírus está em replicação na gestante. ${ }^{5}$ A transmissão não sexual, pessoa-pessoa, tem sido descrita principalmente entre crianças, provavelmente por contato com sangue ou fluidos não aparentes, através do compartilhamento de escovas de dente, exsudato de lesões dermatológicas, mordeduras e superfícies contaminadas. ${ }^{6}$ Em áreas de menor prevalência, uso de drogas injetáveis e via sexual são as formas de transmissão mais frequentes. ${ }^{6}$ Outras fontes de transmissão descritas são a transfusão de sangue e derivados, e a doação de órgãos. ${ }^{1,2,7}$

Em 1991 a OMS recomenda a integração da vacina contra o VHB ao Programa Nacional de Imunizações (PNI) em todos os países endêmicos. ${ }^{8}$ A vacina foi implementada em aproximadamente 160, diminuindo drasticamente a ocorrência desta infecção e, consequentemente, o número de casos de doença hepática crônica e CHC secundários a este vírus. ${ }^{1,8}$ Entretanto, entre os países com maior prevalência, apenas 44\% relatam ter incluído em seu programa de vacinação a primeira dose da vacina ao nascimento. $^{8}$

No Brasil, há áreas de elevada endemicidade, como a região Amazônica, onde a prevalência da infecção pelo VHB é maior do que 7\%, áreas de endemicidade intermediária, como região Sudeste, e áreas de baixa endemicidade, no sul do país, 
com prevalência menor do que $2 \%$. Desta forma, há também uma variação nas principais vias de transmissão em cada região. ${ }^{9}$

A vacina foi incluída no PNI no Brasil em 1998, para crianças menores de 1 ano. No Estado de São Paulo, a partir de 2001, tornou-se disponível do nascimento até os 19 anos, além da recomendação aos grupos considerados de maior risco de aquisição da infecção, como profissionais de saúde, ou maior risco de gravidade ao adquiri-la, como os portadores de doença hepática crônica. ${ }^{10}$

Com a adoção da vacina contra o VHB e a implementação de triagem sorológica em bancos de sangue em diversos países, as vias de transmissão percutânea e perinatal tornaram-se menos freqüentes. A via sexual passou a ser, então, a principal forma de transmissão nestas regiões, representando $50 \%$ dos casos novos nos EUA. Desta forma, a população de adultos e jovens torna-se a mais exposta (Figura 1), ${ }^{4,6,11}$

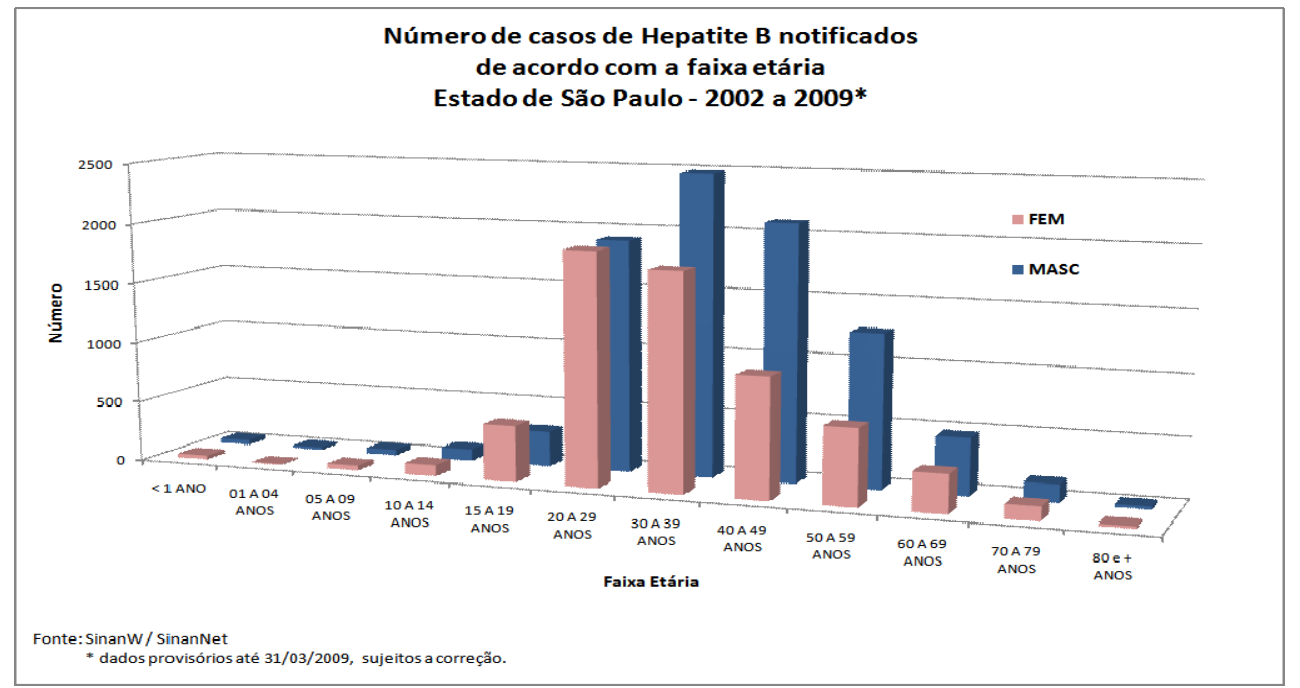

Figura 1 - Número de casos de Hepatite B de acordo com a faixa etária ${ }^{11}$

Fonte: http://www.cve.saude.sp.gov.br/htm/hepatite/hepa_graficos.htm 


\subsection{Vacina Contra o Vírus da Hepatite B}

\subsubsection{O Vírus da Hepatite B}

O VHB é um vírus DNA, hepatotrópico, que pertence à família Hepadnaviridae. Pode ser encontrado no soro de pacientes infectados sob 2 formas: partícula completa (Dane), com $42 \mathrm{~nm}$ de diâmetro, composta por envelope viral e nucleocapsideo com $27 \mathrm{~nm}$; e partículas esféricas ou tubulares de $22 \mathrm{~nm}$, não infecciosas, compostas apenas pelo envelope viral. ${ }^{12}$

O nucleocapsídeo, é uma estrutura icosaédrica, contendo a proteína do core (HBcAg), o antígeno e (HBeAg), e o genoma viral, composto por um DNA de fita dupla e a enzima DNA polimerase. ${ }^{6}$ O HBcAg não é identificado no sangue, mas no tecido hepático dos pacientes infectados. O HBeAg, antígeno solúvel, originado a partir de ação enzimática sofrida pelo $\mathrm{HBcAg}$, pode ser identificado no sangue de pacientes com elevada replicação. Entretanto, existem mutantes não produtores deste antígeno associados a formas graves da doença. O antígeno de superfície (HBsAg) é o principal componente do envelope do VHB, e sua identificação no sangue determina o diagnóstico da infecção pelo VHB. ${ }^{12}$

O genoma do VHB tem aproximadamente 3200 nucleotídeos, codificando 4 diferentes grupos proteicos: gene $\mathrm{S}$ e pré $\mathrm{S}$, codificam as proteínas do envelope viral; gene $\mathrm{C}$, o $\mathrm{HBcAg}$ e o $\mathrm{HBeAg}$; gene $\mathrm{X}$, a proteína $\mathrm{X}$ e gene $\mathrm{P}$, que codifica a DNA polimerase. A molécula de DNA é circular, em parte fita dupla, mas com uma região de fita simples de extensão variável. O Gene $\mathrm{S}$ é dividido em 3 sítios de iniciação denominados regiões pré-S1, pré-S2 e S, responsáveis pela formação de 3 tipos de 
proteínas de superfície: a proteína $\mathrm{S}$ ou HBsAg, de cadeia curta, a pré-S2 ou de cadeia média, e a pré-S1 ou de cadeia longa. As duas últimas podem estar incorporadas ao HBsAg, a proteína predominante, que representa o principal antígeno de superfície, e que pode induzir a produção de anticorpo específico (anti-HBs). As proteínas pré-S1 e pré-S2 também têm um papel no ataque do vírus ao hepatócito. ${ }^{13}$

O HBsAg, é um antígeno complexo, composto por vários determinantes antigênicos. O determinante $a$ é o maior sítio de ligação a anticorpos e é comum a todos os subtipos virais. ${ }^{6}$ Outros 2 pares de determinantes da proteína $\mathrm{S}$ são encontrados: d ou y, w ou r. A combinação destes caracteriza os subtipos. ${ }^{13}$

\subsubsection{A vacina}

Em 1982 foi licenciada a primeira vacina contra o VHB, composta pelo HBsAg purificado, obtido a partir do plasma de portadores crônicos da doença. ${ }^{6}$ Apesar da alta efetividade, sua utilização tornou-se limitada por questões de segurança relacionadas ao potencial de transmissão de agentes infecciosos, como o vírus da imunodeficiência humana (HIV). ${ }^{6}$

Em 1987 foi licenciada a vacina de DNA recombinante contra o VHB, obtida por técnica de engenharia genética. ${ }^{6,14}$ Nesta técnica, um plasmídeo com gene $\mathrm{S}$ e, eventualmente, com genes pré S1 e pré S2, é inserido em levedura, como Saccharomyces cerevisiae. Este, posteriormente, irá expressar uma partícula viral altamente imunogênica e purificada que compõe a vacina, o HBsAg. ${ }^{6} \mathrm{O}$ epítopo $a$ é exposto na partícula artificial do HBsAg, como ocorre na partícula natural. ${ }^{6}$ Estas vacinas são produzidas na Bélgica, França, China, Japão, Coréia do Sul, Estados 
Unidos, Cuba e, recentemente, no Brasil. ${ }^{6}$ Vacinas recombinantes incorporando níveis significantes de epítopos pré-S1 e pré-S2 estão em estudo, trazendo a expectativa de melhor resposta imune. ${ }^{6}$

Nas vacinas disponíveis no país, o HBsAg é adsorvido pelo adjuvante hidróxido de alumínio, e o timerosal é o conservante. ${ }^{5}$ A concentração do HBsAg por dose varia, entre os produtos, de $5 \mu \mathrm{g}$ a $40 \mu \mathrm{g} / \mathrm{ml}$, pela diferença no processo de produção da vacina. ${ }^{6}$ No entanto, as taxas de soroconversão após a terceira dose são semelhantes quando a vacina é utilizada nas doses recomendadas pelos fabricantes. ${ }^{6,15,16}$

Vacinas de diferentes produtores podem ser usadas para cada dose em um mesmo esquema de vacinação. ${ }^{6}$ A dose recomendada varia conforme o produto, a idade do receptor e a presença ou não de imunossupressão. ${ }^{6} \mathrm{O}$ esquema de vacinação consiste na administração de 3 doses, sendo a segunda e a terceira doses realizadas um mês e seis meses após a primeira dose, respectivamente, conhecido como esquema 0,1 e 6 meses. Recomenda-se a aplicação no deltóide, por via intramuscular. ${ }^{1,17}$

\subsubsection{Imunologia da vacina}

\subsubsection{Resposta Inata}

Após a aplicação da vacina, células dendríticas imaturas irão reconhecer o HBsAg administrado através de seu toll like receptor. Estas células passam a expressar o antígeno através de um receptor de superfície, as moléculas de MHC classe II, que permitirão a elas funcionar como células apresentadoras de antígeno 
(CAA). Migram para linfonodos regionais, onde prosseguirá a resposta imune. Como o antígeno não-vivo é, normalmente, pouco imunogênico, frequentemente associamse adjuvantes para prolongar o tempo de exposição do antígeno no sítio de injeção e, consequentemente, às células apresentadoras de antígenos (Figura 2). ${ }^{18}$

\subsubsection{Linfonodo}

\section{A. Reação Extrafolicular:}

Células B naive circulantes encontram o antígeno HBsAg e tornam-se ativadas, migrando para os linfonodos. Nestes, ocorre inicialmente a reação extrafolicular, onde células B antígeno-específicas são expostas às células dendríticas ativadas e iniciam a produção de imunoglobulinas plasmáticas de baixa afinidade, poucos dias após a exposição. ${ }^{18}$

\section{B. Centro Germinativo:}

\section{Resposta Imune Humoral:}

As células B antígeno-específicas, ao atingir a zona de linfócitos $\mathrm{T}$, centros germinativos, são ativadas pelas células dendríticas e também por células $T$ foliculares antígeno-específicas, que tornam a resposta das células B ao estímulo antigênico mais eficiente pela presença de moléculas co-estimuladoras (CD40L, IL10, IL21). Ocorre a diferenciação destas células B em células plasmáticas, que levarão a maciça proliferação clonal e produção de grande quantidade de anticorpos, em 4 a 6 semanas. Há uma maturação progressiva dos anticorpos, que se tornam mais ávidos em 4 a 6 meses, período ideal para o reforço. ${ }^{18}$ 
Durante esta fase, surgem também as células B de memória. Em caso de reexposição, há rápida proliferação e diferenciação destas células em células plasmáticas, sem a necessidade de ativação pelas células T. Ocorre então uma elevada produção de anticorpos de alta afinidade. ${ }^{18,19}$

A produção de células B de memória depende, entretanto, da resposta inicial à vacina e do reforço, que pode ser menos intensa na presença de esquemas acelerados, com intervalos menores do que 4 meses. ${ }^{18}$

Resposta Imune Mediada por Célula:

No linfonodo, as células T CD4 também são ativadas. As células T antígenoespecíficas são ativadas após a ligação do receptor à molécula MHC classe II específica, expressa pelas células apresentadoras de antígenos (sinal 1). Existe um segundo sinal (sinal 2), co-estimulação, necessário para ativar as células T. Esta, ativada, se diferencia em célula TH1, que irá produzir IFN $\gamma, \mathrm{TNF} \alpha$, citocinas associadas à estimulação de linfócitos $\mathrm{T}$ citotóxicos, e TH2, associados com a produção de IL4, IL5, IL13, relacionadas com resposta humoral e produção de anticorpos. Células $\mathrm{T}$ de memória também são produzidas e refletem a magnitude da expansão de células T inicial. ${ }^{18,20}$ 


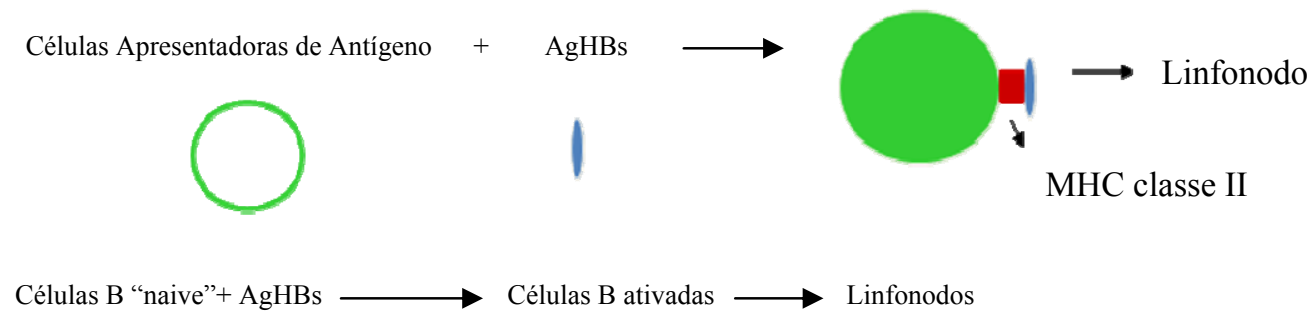

No linfonodo: Extra-Folicular

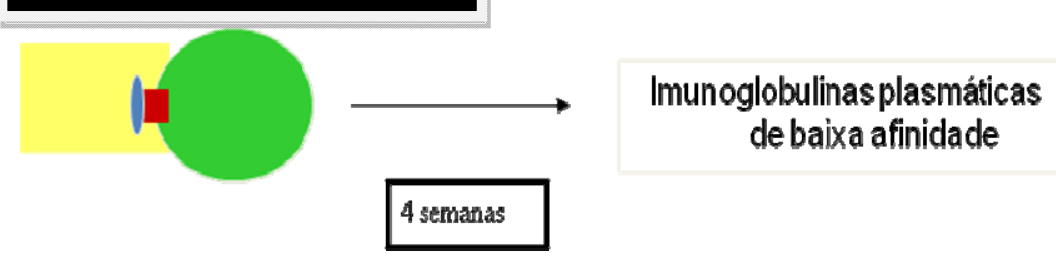

\section{No Centro Germinativo}
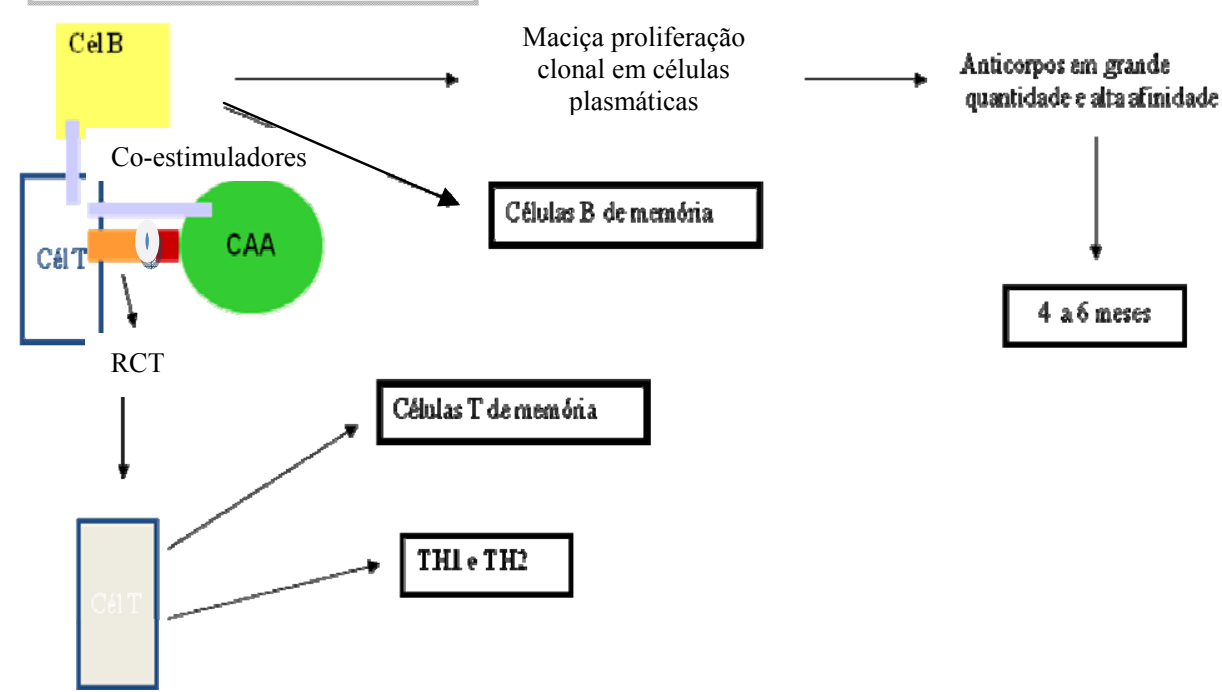

Cel T

Figura 2 - Resposta Imune após vacinação contra o VHB 


\subsubsection{Eficácia e Efetividade da Vacina}

A vacina contra o VHB é segura e atinge eficácia acima de $90 \%$ em adultos com menos de 40 anos, definida como dosagem de anticorpos anti-HBs maior ou igual a $10 \mathrm{mIU} / \mathrm{ml}$, medida através da técnica de ensaio imunoenzimático (ELISA), após esquema composto por três doses aos 0,1 e 6 meses.1,17

A administração da vacina em intervalos mais longos não interfere na proteção, porém a proteção ótima ocorre apenas após a terceira dose. ${ }^{6} \mathrm{O}$ esquema também não precisa ser reiniciado, caso seja interrompido. ${ }^{6,17} \mathrm{O}$ intervalo mínimo entre as doses deve ser sempre respeitado. Um mês entre a primeira e a segunda dose. Entre a segunda e a terceira, no mínimo 2 meses, desde que haja um intervalo de pelo menos 4 meses entre a primeira e a terceira dose. ${ }^{6}$ Normalmente, em adultos, descreve-se soroconversão de 30-55\% após a primeira dose, 75\% após a segunda e maior do que $90 \%$ após a terceira. Uma dose adicional em quem não respondeu ao primeiro esquema de vacinação pode levar a soroconversão em 25 a 50\% dos casos, e 3 doses adicionais, em 44 a 100\%. ${ }^{6}$ Para as pessoas não respondedoras após seis doses de vacina, não existem dados demonstrando a indução de resposta a doses adicionais. ${ }^{6,21}$

A duração da proteção e a necessidade de doses de reforço não estão completamente definidas. ${ }^{22}$ Os títulos de anti-HBs diminuem no decorrer dos anos, mas a memória imunológica permanece indefinidamente. Em adultos, descreve-se redução dos títulos de anti-HBs de 7 a 50\% após cinco anos do esquema de vacinação, e 30 a $60 \%$ após 9 a 11 anos. Entretanto, para os imunocompetentes com soroconversão após 3 doses da vacina, não há recomendação de doses adicionais, uma vez que há um aumento nos títulos de anti-HBs após reexposição ao antígeno em 67 a $76 \%$ dos casos, mesmo após 13 a 23 anos da realização do esquema de vacinação. ${ }^{6,20}$ 
Alguns fatores, como idade acima de 40 anos, sexo masculino, tabagismo, obesidade, sítio e via de aplicação podem diminuir a resposta vacinal. ${ }^{7,23,24,25} \mathrm{O}$ mecanismo exato para esta redução não é bem compreendido. Estudos sugerem que o cigarro estaria relacionado à diminuição da função macrofágica e linfocítica. ${ }^{22,25,26} \mathrm{~A}$ obesidade e a aplicação em região glútea podem dificultar a administração intramuscular da vacina, modificando a exposição do antígeno a fagócitos ou a células apresentadoras de antígenos. ${ }^{26}$

A via de aplicação intradérmica é estudada como uma opção à via intramuscular da vacina. Alguns trabalhos mostram imunogenicidade semelhante, mas pela dificuldade técnica e falta de dados de proteção a longo prazo, não é recomendada rotineiramente. ${ }^{6,22,27}$

Pacientes imunodeprimidos também apresentam menor resposta vacinal, como aqueles portadores do $\mathrm{HIV}^{28}$, pacientes em hemodiálise $(40 \text { a } 67 \%)^{29,30,31}$ ou transplantados de células-tronco hematopoiéticas $(46 \%) .{ }^{17}$ Nesta população, recomenda-se dosar e manter anti-HBs acima de $10 \mathrm{mIU} / \mathrm{ml}$ após o esquema vacinal, pois há descrição de infecção clínica, em pacientes em hemodiálise, após queda dos títulos de anti-HBs abaixo de $10 \mathrm{mIU} / \mathrm{ml}^{6}{ }^{6}$ Em portadores do HIV existe descrição de aparecimento de anti-HBc isolado durante infecção assintomática. ${ }^{6}$

Para aumentar a soroconversão e a duração da imunidade, várias estratégias são discutidas e estudadas na literatura: aumento no número de doses da vacina; aumento na quantidade de antígeno oferecido, como a utilização de doses dobradas; associação com adjuvantes como IL-2; alteração da via de administração e precocidade em oferecer a vacina, principalmente aos pacientes com doenças crônicas. ${ }^{27}$ 
Estudo randomizado em portadores do HIV demonstrou melhor resposta

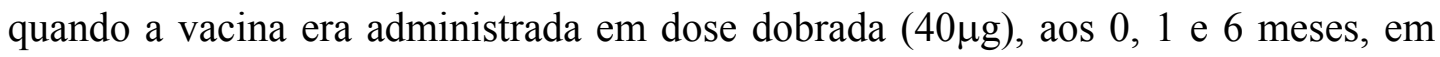
pacientes com CD4 maior ou igual a 350 células $/ \mathrm{mm}^{3}(64,3 \%$ x 39,3\%, p=0,008), ou com carga viral $<10.000$ cópias $/ \mathrm{ml}(58,3 \%$ x 37,3\%, p=0,01), mas não demonstrou diferença quando administrada em pacientes com CD4 $<350$ células $/ \mathrm{mm}^{3}(23,8 \%$ x $26,3 \%, \mathrm{p}=0,8) .{ }^{28}$ Outro trabalho em pacientes em hemodiálise também evidenciou maior eficácia do esquema com dose dobrada. ${ }^{29,30}$

\subsection{O Cirrótico em Lista de Espera para Transplante de Fígado}

\subsubsection{Definição e Classificação Clínica do Cirrótico}

Define-se cirrose todo processo hepático difuso caracterizado por alteração estrutural do fígado, com formação de nódulos envoltos por fibrose. O padrão ouro para seu diagnóstico é o exame anatomopatológico. ${ }^{31} \mathrm{O}$ desarranjo da arquitetura hepática leva à alterações vasculares intra-hepáticas e redução de sua massa funcional, cujas conseqüências são o desenvolvimento de hipertensão portal e a evolução para insuficiência hepática. ${ }^{32}$

Clinicamente, classifica-se a cirrose em compensada quando não há qualquer manifestação clínica da doença, e descompensada quando já existem alterações clínicas como ascite, encefalopatia, hemorragia digestiva e icterícia. ${ }^{31}$ Alterações nas provas de função hepática, métodos de imagens, endoscópicos e alterações de exame físico também podem sugerir o diagnóstico de cirrose hepática. ${ }^{31}$ 
Uma das classificações que melhor avalia a função hepatocelular em cirróticos é a de Child-Turcotte-Pugh (CTP), que analisa parâmetros clínicos e laboratoriais e fornece um bom guia prognóstico a médio prazo dos pacientes (Anexo A). ${ }^{33,34}$ Sabe-se que pacientes com escore 10 ou mais (CTP C) têm uma expectativa de morte em um ano, os com escore 7 a 9 (CTP B) têm sobrevida de $80 \%$ em cinco anos e os com escore 5 a 6 (CTP A), sobrevida maior do que 5 anos. $^{33}$

Outra classificação, mais objetiva e não influenciada pelo observador é o MELD (Model for End-stage Liver Disease), que utiliza uma fórmula matemática para avaliar sobrevida dos pacientes a mais curto prazo (Anexo B). ${ }^{33}$ Este cálculo envolve três variáveis e cada uma tem um peso de acordo com sua influência no prognóstico: bilirrubinas, INR (International Normalized Ratio) e creatinina. Quando o valor do escore MELD é 6, a sobrevida estimada é de 90\% em 3 meses. Quando o MELD é 40, indica mau prognóstico, e a sobrevida passa a $7 \% .^{33}$

Pacientes com escore MELD de 15 ou mais, ou os com escore CTP de 7 ou mais, devem ser avaliados para transplante..$^{33,35}$

\subsubsection{Imunologia do Cirrótico}

O paciente com cirrose hepática sofre alterações imunológicas relacionadas à disfunção sofrida pelo órgão e às comorbidades que frequentemente acompanham a doença, como alcoolismo e desnutrição. Tais alterações trazem repercussões clínicas, favorecendo o aparecimento de infecções. 
Fatores intrínsecos como alteração de flora intestinal, diminuição da função e capacidade de opsonização do sistema retículo-endotelial (SRE) e diminuição na quimiotaxia dos neutrófilos são descritos no paciente cirrótico. ${ }^{31,36}$

O SRE do fígado, que inclui as células de Kupffer, é a maior fração corporal deste sistema fagocítico. A diminuição de sua atividade está associada a vários fatores, como a presença de shunt intra-hepático que ocorre no fígado cirrótico. Desta forma, o sangue e, consequentemente, os patógenos, escapam da atividade fagocítica destas células. A fibronectina, glicoproteína produzida pelo fígado, modula a atividade do SRE, facilitando sua atividade opsonizante. Sua menor produção, no cirrótico, também diminui a atividade do SRE. ${ }^{37}$

A imunidade humoral também está prejudicada. Na cirrose, há uma falência hepática em seqüestrar e remover antígenos bacterianos. O paciente passa a ser hiperimunizado contra sua própria flora intestinal, levando a hiper-reatividade imunológica, com superprodução de anticorpos, porém com atividade alterada. ${ }^{31}$

O fígado também produz certos componentes do complemento. Seus níveis séricos estão associados aos níveis de albumina e tempo de protrombina, indicadores de reserva hepática. A diminuição no complemento relaciona-se, desta forma, com a gravidade da doença hepática, diminuição da capacidade de opsonização e, portanto, maior incidência de infecção. ${ }^{37}$

Quanto à imunidade celular, há uma diminuição nos linfócitos $\mathrm{T}$ circulantes, hiperestimulação e hiperprodução de IL-1, IL-6, IL-8 e TNF; há também um estado de ativação crônica dos linfócitos $\mathrm{T}$ secundários ao aumento de bactérias e toxinas circulantes. ${ }^{31}$

Fatores como alcoolismo, desnutrição, hemorragia digestiva e procedimentos invasivos podem contribuir para a maior incidência de infecções nesta população. ${ }^{31}$ 
Alteração na quimiotaxia dos neutrófilos e depressão na imunidade celular estão associadas ao alcoolismo. ${ }^{37}$ A desnutrição influencia todos os aspectos da imunidade, e sua gravidade está relacionada a uma maior suscetibilidade a infecção. ${ }^{31}$

Diante destas alterações imunológicas, questiona-se também o impacto destas na eficácia de diferentes tipos de vacinas nesta população. Estudo com vacina contra influenza realizado em cirróticos CTP B ou C não mostrou diferença na resposta humoral quando comparada ao grupo controle, mas evidenciou importante diminuição da resposta celular nos pacientes CTP C. ${ }^{38}$ Outro estudo realizado numa população semelhante, vacinada contra o vírus da hepatite $A$, demonstrou presença de títulos de anticorpos protetores em 73\% dos CTP A, mas apenas em 37,1\% dos CTP B ou C. ${ }^{39}$

\subsubsection{O Transplante de Fígado no Brasil}

Atualmente, recomenda-se incluir em lista de espera para transplante de fígado todos os cirróticos, independentemente da etiologia, entre 18 e 70 anos, classificados como CTP A com, pelo menos, uma das seguintes complicações: hemorragia digestiva alta de repetição com necessidade de reposição volêmica, encefalopatia hepática, síndrome hepato-pulmonar; CTP B ou C, independentemente das complicações; e presença de $\mathrm{CHC}$, desde que haja um único nódulo de até $5 \mathrm{~cm}$ ou 3 nódulos de até $3 \mathrm{~cm}$ cada. ${ }^{40}$

No Brasil, até 29 de maio de 2006, o critério de distribuição de fígado de doadores falecidos para transplante era cronológico, ou seja, respeitava a ordem de inclusão em lista de espera para transplante de fígado. Diante do elevado número de 
pacientes em lista, da escassez de doadores de órgãos e consequente elevada mortalidade pré-transplante, a partir desta data o critério de distribuição de órgão passa a ser a gravidade do estado clínico, e o sistema MELD utilizado para classificar estes pacientes. O período em que o paciente aguarda o órgão é bastante variável, de acordo com os valores de MELD obtidos. ${ }^{41}$

No primeiro semestre de 2009, a lista de candidatos a transplante de fígado do Estado de São Paulo incluía 2362 pacientes. Neste mesmo período, foram realizados 311 transplantes de fígado no Estado e 602 no Brasil. ${ }^{42,43}$

Houve um aumento no número de transplantes ao comparar o primeiro semestre de 2008 com o primeiro semestre de 2009 , de $14 \%$, sendo a taxa de transplante de 7 pmp. ${ }^{44}$

\subsection{Vacina Contra o Vírus da Hepatite B em Cirróticos}

Os cirróticos por diversas etiologias em lista de espera para transplante de fígado e os transplantados de fígado são potencialmente expostos ao $\mathrm{VHB}^{45}$ Uma vez adquirida a infecção, pode haver maior risco de descompensação da hepatopatia prévia e menor sobrevida do enxerto, respectivamente. ${ }^{17,23,29}$ Estudos em alcoolistas descrevem maior prevalência de marcadores sorológicos para VHB nesta população e maior risco de CHC quando os dois fatores etiológicos da doença hepática coexistem. ${ }^{46}$ Torna-se importante, portanto, prevenir a infecção pelo VHB em cirróticos suscetíveis enquanto aguardam o transplante de fígado. 
Embora poucos trabalhos descrevam a eficácia do esquema de vacinação convencional contra o VHB (doses simples aos 0,1 e 6 meses) em cirróticos em lista para transplante de fígado, parece haver uma pior resposta ao esquema nesta população. $^{47,48}$ A vacina também é aparentemente segura nesta população, descrevendo-se 7 a 20\% de reação no local de sua aplicação, e 2 a 19\% de sintomas gerais como mal-estar e febre. ${ }^{46}$ Um estudo em cirróticos em lista para transplante de

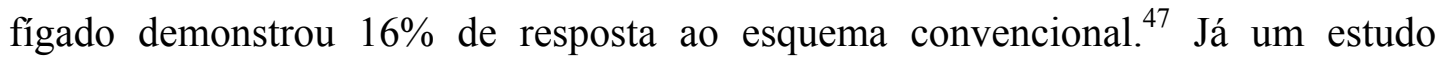
brasileiro, que avaliou eficácia do mesmo esquema em cirróticos portadores de hepatite C e CTP A, evidenciou $70 \%$ de positividade do anti-HBs. ${ }^{48}$ Com o objetivo de melhorar a eficácia da vacina administrada em cirróticos e atingir títulos protetores de anti-HBs mais precocemente, antes da realização do transplante de fígado, alguns estudos nesta população utilizam esquemas acelerados, como 0,7 e 21 dias ou 0, 1 e 2 meses, e/ou esquemas com doses dobradas. Em vários países, incluindo o Brasil desde julho de 2006, o esquema acelerado apresenta maior interesse, uma vez que a distribuição do órgão passa a ser realizada por critérios de gravidade de doença hepática, diminuindo em alguns casos o período pré-transplante disponível para o esquema de vacinação completa.

Por utilizarem amostras com pequeno número de pacientes, além de esquemas e doses bastante variados, torna-se difícil avaliar a eficácia da vacina nesta população. ${ }^{17,45,49,50}$ Apesar disto, a maior parte dos trabalhos prospectivos e controlados demonstra menor resposta dos cirróticos, 36\% a 55\%, em relação aos controles, 92 a 100\%, independentemente do esquema vacinal utilizado. ${ }^{23,29,51,52,53}$ Em recente levantamento realizado no Serviço de Transplante de Fígado do Hospital das Clínicas da Faculdade de Medicina da Universidade de São Paulo (HCFMUSP), 
encontrou-se $67,5 \%$ de resposta vacinal ao esquema com doses dobradas $(40 \mu \mathrm{g})$, aos 0,1 e 6 meses, em cirróticos em lista para transplante de fígado nesta instituição. ${ }^{54} \mathrm{~A}$ Tabela 1 resume os principais estudos de vacina contra o VHB em cirróticos, relacionando soroconversão com dose e esquema utilizados.

Nota-se, portanto, que na literatura não há estudos randomizados em cirróticos comparando a eficácia do esquema vacinal aos 0,1 e 6 meses com dose dobrada, ao esquema com dose convencional. Apenas um estudo comparou doses de 20 com $40 \mu \mathrm{g}$, porém administradas em esquema acelerado (0, 7 e 21 dias) e com inclusão de apenas 34 pacientes. $^{7}$

Um estudo randomizado foi desenvolvido em 100 etilistas, com ou sem doença hepática, comparando a eficácia do esquema da vacina aos 0,1 e 6 meses com dose simples $(20 \mu \mathrm{g})$, ao com dose dobrada $(40 \mu \mathrm{g})$. Houve superioridade estatisticamente significante do segundo esquema em relação ao primeiro ( $75 \%$ versus $46,2 \%$ ), porém apenas 10 pacientes do estudo eram cirróticos, não permitindo a extensão de tal resultado a esta população. ${ }^{55}$

Diante da elevada morbi-mortalidade da doença, do baixo custo e da segurança da vacina, recomenda-se a vacinação contra o VHB aos cirróticos em lista para transplante de fígado. Entretanto, a influência na resposta vacinal da etiologia e da gravidade da doença hepática, e especialmente do esquema e doses da vacina, não estão definidos. Para avaliar alguns destes fatores e, principalmente, estabelecer grau de evidência para adoção de esquemas especiais nesta população, o atual estudo randomizado foi planejado e desenvolvido. 
Tabela 1 - Avaliação de eficácia de vacina contra VHB: estudos clínicos incluindo cirróticos

\begin{tabular}{|c|c|c|c|c|c|c|c|c|c|c|c|}
\hline Tipo de Estudo (Ref) & $\mathrm{DHC}$ & $\begin{array}{l}\text { Cirrótico } \\
\text { (número) }\end{array}$ & $\begin{array}{l}\text { Controles } \\
\text { (número) }\end{array}$ & Etiologia & CTP & Dose $(\mu \mathrm{g})$ & Esquema & $\begin{array}{c}\text { Soroconversão* } \\
\text { DHC (\%) }\end{array}$ & $\begin{array}{c}\text { Soroconversão* } \\
\text { Cirróticos (\%) }\end{array}$ & $\begin{array}{c}\text { Soroconversão* } \\
\text { Controles (\%) }\end{array}$ & $P$ \\
\hline Prospectivo (7) & - & 34 & 39 & Variada & $\begin{array}{c}\mathrm{B} / \mathrm{C} \\
\mathrm{X} \\
\mathrm{A} / \mathrm{B} / \mathrm{C}\end{array}$ & $\begin{array}{c}20 \text { (14 pts) } \\
\text { x } \\
40 \text { (20 pts) }\end{array}$ & $0,7,21$ dias & - & $\begin{array}{c}31 \\
x \\
26\end{array}$ & 100 & NR \\
\hline Retrospectivo (45) & - & 140 & - & Variada & $\mathrm{A} / \mathrm{B} / \mathrm{C}$ & 40 & $0,2,4$ meses & - & 37 & - & NR \\
\hline Prospectivo (23) & 138 & 86 & 26 & Variada & - & $40 \rightarrow 80$ & $0,1,2 \rightarrow 3$ meses & 74 & 42 & 92 & $<0,001$ \\
\hline Retrospectivo (17) & - & 23 & - & $\begin{array}{l}\text { VHC, alcool, } \\
\text { Criptogênica }\end{array}$ & $\mathrm{B} / \mathrm{C}$ & - & - & - & 60,9 & - & NR \\
\hline Prospectiveo (29) & - & 86 & 26 & Variada & - & 40 & $0,1,2$ meses & - & 42 & 92,3 & $<0,001$ \\
\hline Retrospectivo (47) & - & 57 & - & Variada & - & 20 & $0,1,6$ meses & - & 16 & - & NR \\
\hline Prospectivo (48) & 65 & 20 & 46 & VHC & A & 20 & $0,1,6$ meses & 50,8 & 70 & 97,8 & $<0,001$ \\
\hline Prospectivo (53) & - & 20 & 53 & $\begin{array}{l}\text { VHC, CEP, } \\
\text { CBP, alcool }\end{array}$ & $\mathrm{B} / \mathrm{C}$ & 20 & $0,7,21$ dias & - & 36 & 95 & $<0,001$ \\
\hline Prospectivo (51) & 102 & 50 & 26 & VHC & A & $40 \rightarrow 80 * *$ & $0,1,2 \rightarrow 3$ meses & $80,4 \rightarrow 88$ & $54 \rightarrow 74$ & 92 & $<0,01$ \\
\hline \multirow[t]{2}{*}{ Prospectivo (49) } & - & $50(15)$ & - & & $\mathrm{B} / \mathrm{C}$ & 40 & $0,1,2 \rightarrow 0,1,2$ & - & $44 \rightarrow 62$ & - & NR \\
\hline & & & & Variada & & & meses $* * *$ & & & & \\
\hline Prospectivo (50) & - & 24 & - & Variada & - & 40 & $0,1,2$ meses & - & 87 & - & NR \\
\hline Retrospectivo (54) & - & 43 & - & Variada & $\mathrm{A} / \mathrm{B} / \mathrm{C}$ & 40 & $0,1,6$ meses & - & 67,5 & - & NR \\
\hline
\end{tabular}

DHC: doença hepatica crônica; CTP: Classificação de Child-Turcotte-Pugh; Pts: pacientes; NR: não realizado; VHC: vírus da hepatite C; CEP: colangite esclerosante primária; CBP: cirrose biliar primária.

* Soroconversão se anti-HBs $\geq 10 \mathrm{UI} / \mathrm{ml}$. ** Reforço em pacientes sem soroconversão. *** Novo ciclo de vacinação em 15 pacientes não-respondedores ao esquema primário. 


\section{Objetivos}




\section{Objetivo Primário:}

Comparar a imunogenicidade de doses dobradas da vacina contra o VHB a doses convencionais, medida através da dosagem sangüínea do anti-HBs, a partir de 1 mês a 6 meses após a aplicação da quarta dose do esquema proposto $(0,1,2$ e 6 meses), em pacientes cirróticos suscetíveis, incluídos em lista de espera para transplante de fígado.

\section{Objetivos Secundários:}

1. Comparar a imunogenicidade de doses dobradas da vacina contra o VHB a doses convencionais, medida através da dosagem sangüínea do anti-HBs, a partir de 1 mês a 6 meses após a aplicação da terceira dose do esquema proposto $(0,1,2$ e 6 meses), em pacientes cirróticos suscetíveis, incluídos em lista de espera para transplante de fígado.

2. Avaliar fatores associados à resposta após a terceira e após a quarta dose da vacina.

3. Comparar a imunogenicidade do esquema vacinal após 3 doses $(0,1$ e 2 meses), à imunogenicidade após 4 doses (0,1,2 e 6 meses). 


\section{Método}




\subsection{Desenho do Estudo}

Ensaio clínico, prospectivo, duplo-cego, randomizado e controlado.

\subsection{Casuística}

\subsubsection{Critérios de Seleção}

Ensaio clínico, em que foram selecionados prospectivamente, de maneira não sistemática, pacientes cirróticos inscritos em lista para transplante de fígado no Serviço de Transplante de Fígado do HCFMUSP, conforme seu comparecimento para inclusão em lista, para consultas ambulatoriais (médica, psicológica, nutricional) ou para procedimentos como coleta de exames. Estes pacientes, ou responsável legal, foram orientados quanto ao estudo e solicitados a assinar o Termo de Consentimento Livre e Esclarecido (Anexo C). Os pacientes tiveram garantia de absoluto sigilo quanto à sua identidade e aos seus dados clínicos e laboratoriais, assim como de que todo material coletado seria utilizado apenas para as finalidades do presente projeto, aprovado previamente pela Comissão de Análise de Projetos de Pesquisa (CAPPesq) do HCFMUSP (Anexo D). 


\subsubsection{Critérios de Inclusão}

Foram incluídos os pacientes cirróticos de etiologia outra que não o VHB, definida pela sorologia anti-HBc total negativa, entre 18 e 70 anos, que compreenderam, concordaram espontaneamente e assinaram o Termo de Consentimento Livre e Esclarecido.

\subsubsection{Critérios de Exclusão}

- Co-infectados com o HIV

- Pacientes com qualquer marcador sorológico positivo para o VHB

- Pacientes em hemodiálise

- Vacinação prévia contra o VHB

- Neoplasia extra-hepática

- CHC sem critério para transplante (nódulo $>5 \mathrm{~cm}$, ou mais de três nódulos com pelo menos um $>3 \mathrm{~cm})$.

\subsection{Randomização}

Os pacientes elegíveis pelos critérios de inclusão e de exclusão foram randomizados em dois grupos: o primeiro para receber o esquema com dose convencional da vacina contra o VHB aos $0,1,2$ e 6 meses. O segundo grupo para receber dose dobrada da vacina aos $0,1,2$ e 6 meses. 
O método de randomização utilizado foi a permutada em blocos, com o objetivo de manter uma distribuição semelhante do número de pacientes em cada grupo estudado. Blocos de oito pacientes foram criados, com diferentes combinações. Envelopes lacrados e numerados continham o grupo ao qual cada paciente pertencia (A ou B, Figura 3).

A definição dos grupos A e B para doses simples ou dobradas foi determinada pelo centro de aplicação das vacinas. O investigador e o paciente mantiveram-se cegos quanto à dose a ser administrada, até a análise final dos dados.

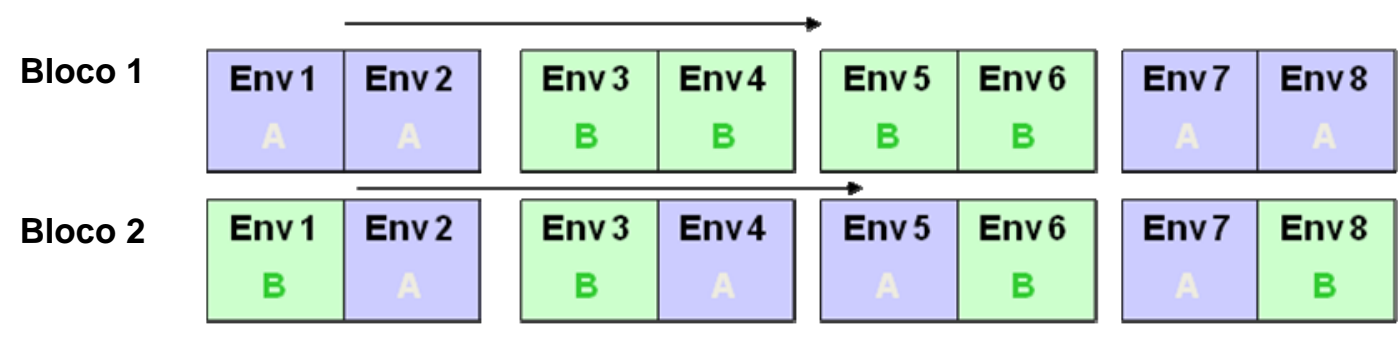

\section{Bloco 3}

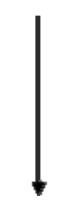

Bloco 29

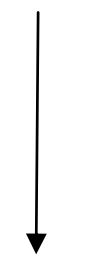

232 envelopes

Figura 3 - Esquema utilizado de randomização em blocos

\subsection{Vacinação}

Foi utilizada a vacina recombinante contra o VHB, que contém o $\mathrm{HBsAg}$ purificado. A administração ocorreu no Centro de Referência de Imunobiológicos 
Especiais do HCFMUSP (CRIE). A vacina foi a disponível para o programa de imunobiológicos especiais do Ministério da Saúde: Euvax B (LG Lifesciences, Jeonbukdo, Korea) para as doses administradas entre outubro de 2006 a janeiro de 2009, e Butang (Instituto Butantã, Brasil) para as doses administradas a partir de fevereiro de 2009. O esquema consistiu em 4 doses de vacina, simples ou dobrada, conforme o grupo selecionado, aplicada por via intramuscular, no deltóide, aos 0,1 , 2 e 6 meses.

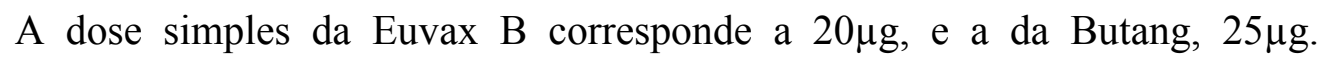
Consequentemente, as doses dobradas, 40 e $50 \mu \mathrm{g}$, respectivamente.

\subsection{Exames Laboratoriais}

\subsubsection{Creatinina, bilirrubina total e frações, tempo de protrombina e albumina}

Foram considerados os exames realizados 2 meses antes a 2 meses após a administração da primeira dose da vacina, na Divisão do Laboratório Central do HCFMUSP - Seção de Bioquímica, para determinação dos escores de CTP e MELD.

\subsubsection{Anticorpos anti-HBc total}


Foram realizados na Divisão do Laboratório Central do HCFMUSP - Seção de Imunologia, nos últimos 2 anos antes de iniciar o esquema vacinal, pelo método ELISA.

\subsubsection{Anticorpos anti-HBs}

Foram realizados na Divisão do Laboratório Central do HCFMUSP - Seção de Imunologia, pelo método ELISA, a partir de um mês a 6 meses após a terceira dose, e a partir de um mês a 6 meses após a quarta dose.

Considerou-se resposta positiva ou soroconversão, o esquema que possibilitou título de anti-HBs maior ou igual a $10 \mathrm{mIU} / \mathrm{ml}$.

Para avaliação de intensidade de soroconversão, consideraram-se títulos de anti-HBs maiores ou iguais a $100 \mathrm{mIU} / \mathrm{ml}$.

\subsection{Amostra Calculada}

O tamanho da amostra foi calculado utilizando-se o programa EpiInfo 3.3.2. Estimou-se $50 \%$ de soroconversão após a quarta dose, baseado em dados da literatura, para pacientes que receberiam a dose simples, e $70 \%$ no grupo com dose dobrada da vacina. Adotando-se intervalo de confiança de $95 \%$ e poder de $80 \%$, o cálculo resultou em 103 pacientes em cada grupo.

Considerando perda de $10 \%$ dos pacientes incluídos, principalmente em conseqüência à elevada gravidade e mortalidade dos pacientes em lista de transplante 
de fígado, calculou-se finalmente uma amostra composta por 113 pacientes a serem randomizados em cada grupo.

\subsection{Variáveis Analisadas}

As seguintes variáveis foram consideradas e analisadas quanto à associação com a resposta vacinal: gênero, idade, tipagem sanguínea $A B O$, etiologia da cirrose, índice de massa corpórea, intervalo entre a primeira e a última dose e gravidade da doença hepática no momento da inclusão em lista de transplante, avaliada através dos critérios de CTP e MELD.

\subsection{Análise}

Para as análises referentes a imunogenicidade da vacina, após a terceira e a quarta dose, incluíram-se apenas os pacientes que completaram o esquema vacinal e submeteram-se à coleta do anti-HBs no período proposto.

Inicialmente, a distribuição das variáveis ordenadas foi avaliada visualmente pela inspeção de gráficos de caixa, e estatisticamente através do teste de SkwenessKurtosis. Foram comparadas entre os grupos de pacientes através do test $\mathrm{t}$ quando sua distribuição foi identificada como normal, e pelo teste da soma dos postos de Wilcoxon quando sua normalidade foi rejeitada. 
As variáveis categóricas foram comparadas entre os grupos de pacientes através do teste do qui-quadrado ou através do teste exato de Fisher quando alguma das suas categorias sendo comparadas apresentava menos de 5 observações.

As proporções de soroconversão, acompanhadas dos seus intervalos de confiança exatos (IC) de 95\%, foram obtidas para os grupos que receberam dose simples e dobrada da vacina após a terceira e a quarta dose. Estas proporções foram comparadas através do teste $\mathrm{Z}$ para proporções, para duas amostras e bicaudal.

Modelos de regressão logística foram construídos para avaliar a associação das diferentes doses da vacina com a soroconversão, ou com a intensidade de soroconversão (anti-HBs $\geq 100 \mathrm{mIU} / \mathrm{mL}$ ), após a terceira e a quarta dose. Os modelos iniciais, para o desfecho soroconversão, foram ajustados para as seguintes variáveis, consideradas como possíveis fatores de confusão: idade, IMC, gênero, CTP (A, B e C), MELD (maior ou igual a 16), grupo sanguíneo, hepatite $\mathrm{C}$, tabagismo e intervalo desde a última dose. Para avaliar a existência de interação entre o efeito da dose da vacina na soroconversão e idade ou valor do MELD, duas variáveis de interação foram criadas e incluídas no modelo incial: dose vacina_idade e dose vacina_MELD.

O modelo inicial, para o desfecho intensidade de soroconversão, foi ajustado para as variáveis idade e gênero, após a terceira dose, e para as variáveis idade, gênero, IMC, grupo sanguíneo e MELD, após a quarta dose, consideradas como possíveis fatores de confusão, e não incluíram variáveis de interação. Estes modelos foram inicialmente ajustados para um número menor de variáveis, pois incluíam apenas os pacientes que soroconverteram, o que restringiu o número total de observações. 
Após a seleção das variáveis de interação, o procedimento de mudança da estimativa, com seleção retrógrada, foi utilizado para a seleção das variáveis, consideradas como possíveis fatores de confusão, incluídas no modelo final.

Regressão logística também foi utilizada na avaliação de fatores associados a soroconversão, ou a intensidade de soroconversão, após a terceira e a quarta dose da vacina, independentemente da dose recebida. Os modelos de regressão logística não incluíram variáveis de interação.

Para a comparação de soroconversão e intensidade de soroconversão entre 3 e 4 doses, foram considerados apenas os pacientes incluídos nas duas análises (após a terceira e a quarta dose). As proporções foram comparadas através do teste $\mathrm{Z}$ para proporções, para uma amostra e bicaudal. Para os pacientes que não soroconverteram após a terceira dose, a chance de soroconversão após a quarta dose foi obtida, juntamente com seu IC exato de $95 \%$.

Todos os testes estatísticos utilizaram um nível de significância $(\alpha)$ igual a 0,05.

Todas as análises foram realizadas utilizando o programa STATA 10.0 (Stata Corporation, Texas). 
4 Resultado 


\subsection{Casuística}

No período de outubro de 2006 a setembro de 2008, foram avaliados 738 pacientes. Destes, 232 foram randomizados. As causas para exclusão antes da randomização encontram-se na Tabela 2.

Tabela 2 - Causas de exclusão pré-randomização de 506 pacientes

\begin{tabular}{lc}
\hline \multicolumn{1}{c}{ Causa de exclusão } & Pacientes - N (\%) \\
\hline Vacinados Previamente contra VHB ${ }^{(1)}$ & $138(27,27)$ \\
Marcador sorológico do VHB ${ }^{(1)}$ & \\
• Anti-HBc total positivo & $48(9,49)$ \\
• Anti-HBc total e Anti-HBs positivos & $84(16,60)$ \\
& \\
Cirrose por VHB & \\
Óbitos & $47(9,29)$ \\
Recusa & $27(5,33)$ \\
Não Cirróticos & $16(3,16)$ \\
Excluídos de Lista de Transplante & $4(0,79)$ \\
Internado em UTI & $5(0,99)$ \\
Transplantados & $1(0,20)$ \\
Não compareceram para inclusão & $2(0,39)$ \\
Não colheram sorologias & $80(15,81)$ \\
Hemodiálise & $51(10,08)$ \\
HIV & $1(0,20)$ \\
Total & $2(0,39)$ \\
\hline
\end{tabular}

${ }^{(1)}$ Vírus da hepatite B; ${ }^{(2)}$ Unidade de terapia intensiva; ${ }^{(3)}$ Vírus da imunodeficiência humana. 
Duzentos e trinta e dois pacientes assinaram o Termo de Consentimento Livre e Esclarecido e foram randomizados. Destes, 18 (7,7\%) foram excluídos. As causas para exclusão pós-randomização estão demonstradas na Tabela 3.

Tabela 3 - Causas de exclusão pós-randomização de 18 pacientes

\begin{tabular}{lc}
\hline \multicolumn{1}{c}{ Causa de exclusão } & Pacientes $\mathbf{- N}(\mathbf{\%})$ \\
\hline Vacinados Previamente contra VHB ${ }^{(1)}$ & $6(33,33)$ \\
Perda do envelope & $5(27,78)$ \\
Diagnóstico de $\mathrm{VHB}^{(1)}$ & $2(11,11)$ \\
Diálise & $1(5,55)$ \\
Não Cirróticos & $4(22,22)$ \\
Total & $\mathbf{1 8 ( 1 0 0 )}$ \\
\hline
\end{tabular}

${ }^{(1)}$ Vírus hepatite B.

Foram, portanto, randomizados e incluídos 214 pacientes, 109 no grupo dose simples e 105 no grupo dose dobrada (Anexo E).

Para a comparação entre dose simples e dobrada, foram analisados 130 pacientes após a terceira dose, e 127 após a quarta dose (Figuras 4 e 5). 




Figura 4 - Fluxograma do seguimento de pacientes avaliados para análise após a terceira dose da vacina contra o VHB 


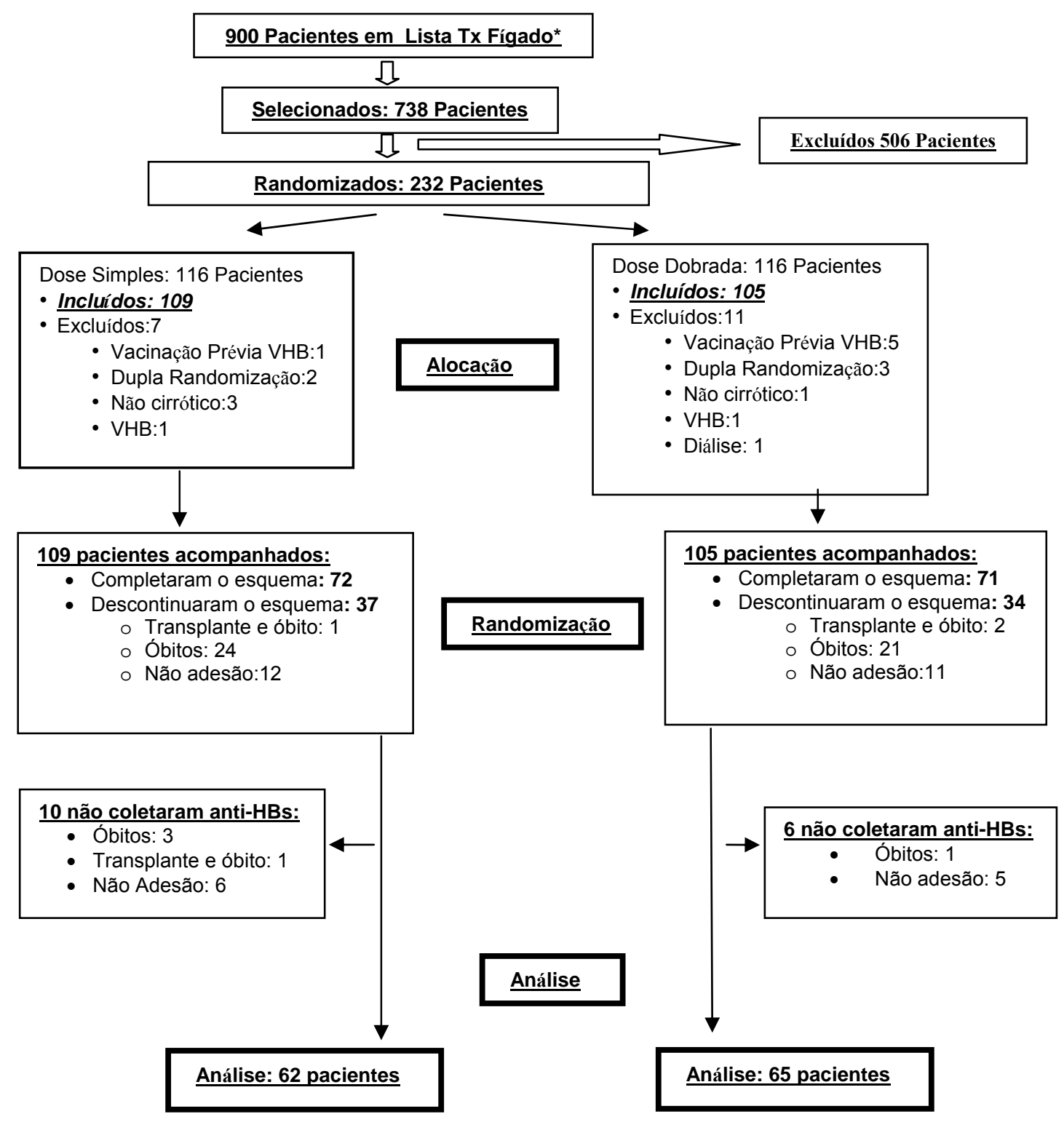

Figura 5 - Fluxograma do seguimento de pacientes avaliados para análise após a quarta dose da vacina contra o VHB 


\subsection{Análise da resposta após a terceira dose da vacina}

\subsubsection{Caracterização dos grupos}

Entre os 214 pacientes, completaram pelo menos as três primeiras doses do esquema vacinal 173 pacientes $(173 / 214-80,8 \%)$, dos quais $130(130 / 214-60,7 \%)$ coletaram o Anti-HBs.

As comparações entre os pacientes incluídos (130) e não incluídos (84) na análise da resposta vacinal após a terceira dose, conforme a dose recebida, encontram-se nas Tabelas 4 e 5. 
Tabela 4 - Descrição das variáveis categóricas dos 214 pacientes randomizados comparação entre pacientes incluídos e não incluídos na análise após a terceira dose da vacina contra o VHB, conforme dose simples ou dobrada

\begin{tabular}{|c|c|c|c|c|c|c|c|c|c|c|}
\hline & \multicolumn{4}{|c|}{ DOSE SIMPLES } & \multicolumn{6}{|c|}{ DOSE DOBRADA } \\
\hline & \multicolumn{2}{|c|}{$\begin{array}{c}\text { Incluídos } \\
\mathbf{N}=71\end{array}$} & \multicolumn{2}{|c|}{$\begin{array}{c}\text { Não } \\
\text { Incluídos } \\
\mathbf{N}=\mathbf{3 8}\end{array}$} & \multirow[b]{2}{*}{$p^{(7)}$} & \multicolumn{2}{|c|}{$\begin{array}{c}\text { Incluídos } \\
\mathbf{N}=\mathbf{5 9}\end{array}$} & \multicolumn{2}{|c|}{$\begin{array}{c}\text { Não } \\
\text { Incluídos } \\
\mathbf{N}=46\end{array}$} & \multirow[b]{2}{*}{$p^{(7)}$} \\
\hline & Total & $\%$ & Total & $\%$ & & Total & $\%$ & Total & $\%$ & \\
\hline Sexo masculino & 44 & 61,97 & 29 & 76,32 & 0,12 & 42 & 71,19 & 30 & 65,22 & 0,51 \\
\hline Tabagismo & 17 & 25,37 & 10 & 29,41 & 0,66 & 9 & 16,36 & 10 & 21,74 & 0,49 \\
\hline Ascite & 40 & 60,61 & 22 & 68,75 & 0,43 & 28 & 52,83 & 31 & 77,50 & 0,01 \\
\hline Encefalopatia & 28 & 42,42 & 14 & 43,75 & 0,90 & 17 & 32,08 & 16 & 40,00 & 0,42 \\
\hline $\operatorname{CTP}^{(1)}$ & & & & & 0,08 & & & & & 0,79 \\
\hline A & 20 & 28,57 & 4 & 10,53 & & 16 & 27,12 & 10 & 21,74 & \\
\hline B & 34 & 48,57 & 25 & 65,79 & & 30 & 50,85 & 26 & 56,52 & \\
\hline $\mathrm{C}$ & 16 & 22,86 & 9 & 23,68 & & 13 & 22,03 & 10 & 21,74 & \\
\hline Etiologia & & & & & $0.09^{(8)}$ & & & & & $0.91^{(8)}$ \\
\hline $\mathrm{CBS}^{(2)}$ & 2 & 2,82 & 0 & 0 & & 4 & 6,78 & 3 & 6,52 & \\
\hline Criptogênica & 7 & 9,86 & 3 & 7,89 & & 9 & 15,25 & 5 & 10,87 & \\
\hline $\mathrm{HAI}^{(3)}$ & 7 & 9,86 & 0 & 0 & & 0 & 0 & 1 & 2,17 & \\
\hline Etilismo & 29 & 40,85 & 14 & 36,84 & & 22 & 37,29 & 19 & 41,30 & \\
\hline $\mathrm{VHC}^{(4)}$ & 14 & 19,72 & 16 & 42,11 & & 17 & 28,81 & 15 & 32,61 & \\
\hline $\mathrm{VHC}^{(4)}+$ Etilismo & 8 & 11,27 & 2 & 5,26 & & 3 & 5,08 & 1 & 2,17 & \\
\hline Outros $^{(5)}$ & 4 & 5,63 & 3 & 7,89 & & 4 & 6,78 & 2 & 4,35 & \\
\hline $\begin{array}{l}\text { Grupo } \\
\text { Sanguíneo }\end{array}$ & & & & & $0.26^{(8)}$ & & & & & $0.87^{(8)}$ \\
\hline A & 29 & 40,85 & 15 & 39,47 & & 27 & 45,76 & 23 & 51,11 & \\
\hline $\mathrm{AB}$ & 0 & 0 & 1 & 2,63 & & 3 & 5,08 & 2 & 4,44 & \\
\hline B & 7 & 9,86 & 7 & 18,42 & & 10 & 16,95 & 5 & 11,11 & \\
\hline $\mathrm{O}$ & 35 & 49,3 & 15 & 39,47 & & 19 & 32,2 & 15 & 33,33 & \\
\hline $\operatorname{MELD}^{(6)} \geq 16$ & 18 & 25,35 & 17 & 44,74 & 0,04 & 24 & 40,68 & 14 & 30,43 & 0,27 \\
\hline
\end{tabular}


Tabela 5 - Descrição das variáveis ordenadas dos 214 pacientes randomizados comparação entre pacientes incluídos e não incluídos na análise após a terceira dose da vacina contra o VHB, conforme dose simples ou dobrada

\begin{tabular}{|c|c|c|c|c|c|c|}
\hline & & DSE SIMPLES & & & SE DOBRADA & \\
\hline & $\begin{array}{l}\text { Incluídos } \\
\mathrm{N}=71\end{array}$ & $\begin{array}{c}\text { Não Incluídos } \\
\mathbf{N = 3 8}\end{array}$ & & $\begin{array}{l}\text { Incluídos } \\
\mathbf{N}=\mathbf{5 9}\end{array}$ & $\begin{array}{l}\text { Não Incluídos } \\
\mathbf{N}=46\end{array}$ & \\
\hline & Média & Média & $p^{(5)}$ & Média & Média & $p^{(5)}$ \\
\hline Idade (anos) & 50,45 & 52,34 & 0,89 & 51,56 & 52,52 & $0.63^{(6)}$ \\
\hline $\mathrm{IMC}^{(1)}$ & 27,07 & 26,94 & 0,75 & 28,26 & 27,09 & 0,08 \\
\hline Creatinina (mg/dL) & 0,96 & 0,97 & 0,98 & 0,89 & 0,91 & 0,71 \\
\hline $\mathrm{BT}^{(2)}$ & 2,72 & 3,93 & 0,06 & 3,48 & 3,05 & 0,78 \\
\hline $\operatorname{INR}^{(3)}$ & 1,31 & 1,42 & 0,27 & 1,37 & 1,36 & 0,92 \\
\hline $\mathrm{AlB}^{(4)}$ & 3,49 & 3,21 & $0.02^{(6)}$ & 3,45 & 3,39 & $0.59^{(6)}$ \\
\hline
\end{tabular}

As variáveis avaliadas tiveram distribuição homogênea entre os grupos de dose simples ou dobrada, nos pacientes incluídos na análise da resposta vacinal após a terceira dose, conforme demonstrado nas Tabelas 6 e 7 . 
Tabela 6 - Descrição das variáveis categóricas dos 130 pacientes incluídos na análise da resposta vacinal contra o VHB após a terceira dose - comparação entre os grupos com dose simples ou dobrada

\begin{tabular}{|c|c|c|c|c|c|}
\hline & \multicolumn{2}{|c|}{ DOSE SIMPLES N=71 } & \multicolumn{2}{|c|}{ DOSE DOBRADA $N=59$} & \multirow[b]{2}{*}{$p^{(7)}$} \\
\hline & Total & $\%$ & Total & $\%$ & \\
\hline Sexo Masculino & 44 & 61,97 & 42 & 71,19 & 0,26 \\
\hline Tabagismo & 17 & 25,37 & 9 & 16,36 & 0,22 \\
\hline Ascite & 40 & 60,61 & 28 & 52,83 & 0,39 \\
\hline Encefalopatia & 28 & 42,42 & 17 & 32,08 & 0,24 \\
\hline $\mathrm{CTP}^{(1)}$ & & & & & 0,96 \\
\hline A & 20 & 28,57 & 16 & 27,12 & \\
\hline B & 34 & 48,57 & 30 & 50,85 & \\
\hline $\mathrm{C}$ & 16 & 22,86 & 13 & 22,03 & \\
\hline Etiologia & & & & & $0.09^{(8)}$ \\
\hline $\mathrm{CBS}^{(2)}$ & 2 & 2,82 & 4 & 6,78 & \\
\hline Criptogênica & 7 & 9,86 & 9 & 15,25 & \\
\hline $\mathrm{HAI}^{(3)}$ & 7 & 9,86 & 0 & 0 & \\
\hline Etilismo & 29 & 40,85 & 22 & 37,29 & \\
\hline $\mathrm{VHC}^{(4)}$ & 14 & 19,72 & 17 & 28,81 & \\
\hline $\mathrm{VHC}^{(4)}+$ Etilismo & 8 & 11,27 & 3 & 5,08 & \\
\hline Outros $^{(5)}$ & 4 & 5,63 & 4 & 6,78 & \\
\hline Grupo Sanguíneo & & & & & $0.06^{(8)}$ \\
\hline A & 29 & 40,85 & 27 & 45,76 & \\
\hline $\mathrm{AB}$ & 0 & 0,00 & 3 & 5,08 & \\
\hline $\mathrm{B}$ & 7 & 9,86 & 10 & 16,95 & \\
\hline $\mathrm{O}$ & 35 & 49,30 & 19 & 32,20 & \\
\hline $\operatorname{MELD}^{(6)} \geq 16$ & 18 & 25,35 & 24 & 40,68 & 0,06 \\
\hline
\end{tabular}

\footnotetext{
${ }^{(1)}$ Critérios de Child-Turcotte-Pugh. ${ }^{(2)}$ Cirrose biliar secundária. ${ }^{(3)}$ Hepatite auto-imune. ${ }^{(4)}$ Vírus da hepatite C. ${ }^{(5)}$ Outros: síndrome de Budd-Chiari, cirrose biliar primária, esteato-hepatite não alcoólica, hemocromatose, hepatite $\mathrm{C}+$ hepatite auto-imune e ductopenia. ${ }^{(6)}$ Model for End-stage Liver Disease. ${ }^{(7)}$ Teste do Qui-Quadrado. ${ }^{(8)}$ Teste exato de Fisher.
} 
Tabela 7 - Descrição das variáveis ordenadas dos 130 incluídos na análise da resposta vacinal contra o VHB após a terceira dose - comparação entre os grupos com dose simples ou dobrada

\begin{tabular}{|c|c|c|c|}
\hline & $\begin{array}{c}\text { DOSE SIMPLES } \\
\mathbf{N}=71\end{array}$ & $\begin{array}{c}\text { DOSE DOBRADA } \\
\mathbf{N}=\mathbf{5 9}\end{array}$ & \\
\hline & Média & Média & $p^{(6)}$ \\
\hline Idade (anos) & 50 & 51,56 & 0,94 \\
\hline $\mathrm{IMC}^{(1)}$ & 27 & 28,26 & 0,15 \\
\hline Creatinina $(\mathrm{mg} / \mathrm{dL})$ & 1 & 0,89 & 0,98 \\
\hline $\mathrm{BT}^{(2)}$ & 3 & 3,48 & 0,19 \\
\hline $\operatorname{INR}^{(3)}$ & 1 & 1,37 & 0,40 \\
\hline $\mathrm{ALB}^{(4)}$ & 3 & 3,45 & $0.67^{(7)}$ \\
\hline $\begin{array}{l}\text { Intervalo entre as } \\
\text { doses (meses) }\end{array}$ & 3,27 & 2,71 & 0,50 \\
\hline
\end{tabular}

${ }^{(1)}$ Índice de massa corpórea $\left(\mathrm{kg} / \mathrm{m}^{2}\right) .{ }^{(2)}$ Bilirrubina total $(\mathrm{mg} / \mathrm{dL}) .{ }^{(3)}$ Razão normalizada internacional. ${ }^{(4)}$ Albumina sérica $(\mathrm{g} / \mathrm{dL}) .{ }^{(5)}$ Intervalo entre a primeira e terceira dose. ${ }^{(6)}$ Teste da soma dos postos de Wilcoxon bicaudal. ${ }^{(7)}$ Teste $t$ de duas amostras bicaudal.

\subsubsection{Proporção de soroconversão}

A taxa de soroconversão global após a terceira dose foi de 35\% (47/130).

As proporções de soroconversão foram de 0,35 (IC 95\%=0,24 até 0,47) e 0,37 (IC $95 \%=0,25$ até 0,5$)$ entre os pacientes que receberam doses simples ou dobradas da vacina, respectivamente. Não houve diferença estatisticamente significante entre estas duas proporções (Tabela 8). 
Tabela 8 - Dosagem de anti-HBs após a terceira dose de vacina contra o VHB com doses simples ou dobrada em 130 pacientes

\begin{tabular}{lccc}
\hline & Anti-HBs & Anti-HBs \\
& $\mathbf{1 0} \mathbf{~ m I U} / \mathbf{m l}$ & $\leq \mathbf{1 0 m I U} / \mathbf{m l}$ & \\
\hline Dose simples & $25(35,21 \%)$ & 46 & $\boldsymbol{p}=\mathbf{0 , \boldsymbol { 8 } ^ { ( \mathbf { 1 } ) }}$ \\
Dose dobrada & $22(37,28 \%)$ & 37 & $\mathbf{8 3}$ \\
Total & $\mathbf{4 7}$ & & \\
\hline
\end{tabular}

${ }^{(1)}$ Teste $Z$ para proporções, para 2 amostras e bicaudal.

O modelo final de regressão logística que avaliou a associação das diferentes doses da vacina com a soroconversão, após a terceira dose, não incluiu as variáveis de interação dose vacina_idade $(p=0,32)$ e dose vacina_MELD $(p=$ 0,51). Segundo o modelo, quando ajustado para idade, IMC, valor do MELD e grupo sanguíneo, a razão de probabilidade de soroconversão após a terceira dose entre os pacientes que receberam a dose dobrada da vacina foi 1,93 vezes à dos que receberam a dose simples, mas esta diferença não foi estatisticamente significante $(\mathrm{OR}=1,93$, IC $95 \%=0,83$ até $5,51, p=0,12)$.

\subsubsection{Intensidade de resposta}

Não se detectou diferença na probabilidade de apresentar títulos de anti-HBs maiores do que $100 \mathrm{mIU} / \mathrm{ml}$ após a terceira dose da vacina entre os pacientes que receberam a dose simples e dobrada, em análises uni e multivariada $(\mathrm{OR}=0,9$, IC $95 \%=0,28$ até $2,84, p=0,8)$. 


\subsubsection{Fatores Preditivos de Resposta Vacinal Após a Terceira Dose}

Para avaliação dos fatores preditivos de resposta vacinal após a terceira dose, independentemente da dose recebida, as variáveis incluídas na análise multivariada por regressão logística foram: gênero, MELD, tabagismo, intervalo entre a primeira e a terceira dose e idade (Tabela 9).

Tabela 9 - Fatores preditivos de resposta vacinal após a terceira dose da vacina: análise multivariada

\begin{tabular}{|c|c|c|c|}
\hline & OR & IC $95 \%$ & $p^{(2)}$ \\
\hline Sexo Masculino & 3,44 & $1,22-9,67$ & 0,01 \\
\hline Meld $<16$ & 5,65 & $1,85-17,21$ & 0,002 \\
\hline Não Fumantes & 3 & $1,06-8,45$ & 0,037 \\
\hline Intervalo $>5$ meses entre doses ${ }^{(1)}$ & 4,02 & $1,04-17,1$ & 0,04 \\
\hline
\end{tabular}

${ }^{(1)}$ Intervalo entre a primeira e a terceira dose. ${ }^{(2)}$ Regressão logística.

As probabilidades de soroconversão por idade (percentil 25, 45 anos; percentil 75, 59 anos), conforme presença de outros fatores preditivos de resposta vacinal, encontram-se na Tabela 10 e na Figura 6.

Tabela 10 - Probabilidades de soroconversão conforme a idade, após a terceira dose da vacina contra o VHB

PROBABILIDADE DE SOROCONVERSÃO

\begin{tabular}{ccc}
\hline Baixa $^{(\mathbf{l})}$ & Intermediária $^{(2)}$ & Alta $^{(3)}$ \\
\hline 0,05 & 0,48 & 0,88 \\
0,02 & 0,29 & 0,77 \\
$3 \%$ & $19 \%$ & $11 \%$ \\
\hline
\end{tabular}

${ }^{(1)}$ Mulheres, tabagistas, MELD $\geq 16$ e intevalo $\leq 5$ meses entre as 2 últimas doses.

${ }^{(2)}$ Mulheres, tabagistas, MELD $<16$ e intevalo $>5$ meses entre as 2 últimas doses.

${ }^{(3)}$ Homens, não tabagistas, MELD $<16$ e intevalo $>5$ meses entre as 2 últimas doses. 


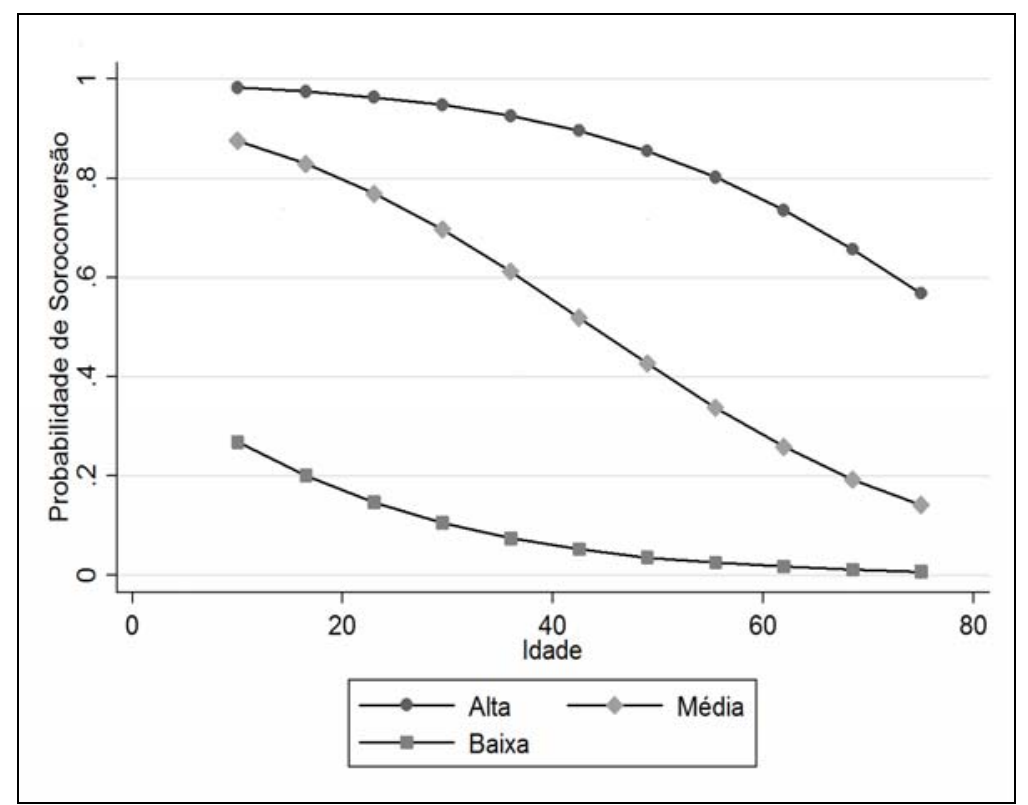

Figura 6 - Gráfico de probabilidade de soroconversão após a terceira dose da vacina contra o VHB, conforme a idade

Não se detectou variável preditiva de soroconversão com títulos de anti-HBs $\geq 100 \mathrm{mIU} / \mathrm{ml}$.

\subsection{Análise da resposta após a quarta dose da vacina}

\subsubsection{Caracterização dos grupos}

Entre os 214 pacientes incluídos para análise, $143(143 / 214$ - 66,8\%) terminaram a quarta dose, dos quais 127 (127/214 - 59,3\%) coletaram o anticorpo anti-HBs, entre 1 e 6 meses após.

As comparações entre os pacientes incluídos (127) e não incluídos (87) na análise da resposta vacinal após a quarta dose, conforme a dose recebida, encontramse nas Tabelas 11 e 12 . 
Tabela 11 - Descrição das variáveis categóricas dos 214 pacientes randomizados comparação entre pacientes incluídos e não incluídos na análise após a quarta dose da vacina contra o VHB, conforme dose simples ou dobrada

\begin{tabular}{|c|c|c|c|c|c|c|c|c|c|c|}
\hline & \multicolumn{4}{|c|}{ DOSE SIMPLES } & \multicolumn{6}{|c|}{ DOSE DOBRADA } \\
\hline & \multicolumn{2}{|c|}{$\begin{array}{c}\text { Incluídos } \\
\mathrm{N}=62\end{array}$} & \multicolumn{2}{|c|}{$\begin{array}{l}\text { Não incluídos } \\
\quad \mathbf{N}=47\end{array}$} & \multirow[b]{2}{*}{$p^{(7)}$} & \multicolumn{2}{|c|}{$\begin{array}{c}\text { Incluídos } \\
\quad \mathrm{N}=65\end{array}$} & \multicolumn{2}{|c|}{$\begin{array}{l}\text { Não incluídos } \\
\mathbf{N}=\mathbf{4 0}\end{array}$} & \multirow[b]{2}{*}{$p^{(7)}$} \\
\hline & Total & $\%$ & Total & $\%$ & & Total & $\%$ & Total & $\%$ & \\
\hline Sexo Masculino & 40 & 64,52 & 33 & 70,21 & 0,50 & 16 & 24,62 & 17 & 42,50 & 0,06 \\
\hline Tabagismo & 15 & 26,32 & 12 & 27,27 & 0,90 & 10 & 16,13 & 9 & 23,08 & 0,38 \\
\hline Ascite & 33 & 58,93 & 29 & 69,05 & 0,30 & 36 & 59,02 & 23 & 71,88 & 0,22 \\
\hline Encefalopatia & 22 & 39,29 & 20 & 47,62 & 0,40 & 16 & 26,23 & 17 & 53,13 & 0,01 \\
\hline $\mathrm{CTP}^{(1)}$ & & & & & 0,25 & & & & & 0,003 \\
\hline A & 17 & 27,42 & 7 & 15,22 & & 23 & 35,38 & 3 & 7,5 & \\
\hline $\mathrm{B}$ & 33 & 53,23 & 26 & 56,52 & & 32 & 49,23 & 24 & 60 & \\
\hline $\mathrm{C}$ & 12 & 19,35 & 13 & 28,26 & & 10 & 15,38 & 13 & 32,5 & \\
\hline Etiologia & & & & & $0.2^{(8)}$ & & & & & $0.35^{(8)}$ \\
\hline $\mathrm{CBS}^{(2)}$ & 2 & 3,23 & 0 & 0 & & 4 & 6,15 & 3 & 7,5 & \\
\hline Criptogênica & 4 & 6,45 & 6 & 12,77 & & 9 & 13,85 & 5 & 12,5 & \\
\hline $\mathrm{HAI}^{(3)}$ & 6 & 9,68 & 1 & 2,17 & & 1 & 1,54 & 0 & 0 & \\
\hline Etilismo & 28 & 45,16 & 15 & 31,91 & & 30 & 46,15 & 11 & 27,5 & \\
\hline $\mathrm{VHC}^{(4)}$ & 13 & 20,97 & 17 & 36,17 & & 15 & 23,08 & 17 & 42,5 & \\
\hline $\mathrm{VHC}^{(4)}+$ Etilismo & 5 & 8,06 & 5 & 10,64 & & 2 & 3,08 & 2 & 5 & \\
\hline Outros $^{(5)}$ & 4 & 6,45 & 3 & 6,38 & & 4 & 6,15 & 2 & 5 & \\
\hline Grupo Sanguíneo & & & & & $0.37^{(8)}$ & & & & & $0.35^{(8)}$ \\
\hline A & 25 & 40,32 & 19 & 40,43 & & 29 & 44,62 & 21 & 53,85 & \\
\hline $\mathrm{AB}$ & 0 & 0 & 1 & 2,13 & & 5 & 7,69 & 0 & 0 & \\
\hline B & 6 & 9,68 & 8 & 17,02 & & 9 & 13,85 & 6 & 15,38 & \\
\hline $\mathrm{O}$ & 31 & 50 & 19 & 40,43 & & 22 & 33,85 & 12 & 30,77 & \\
\hline $\operatorname{MELD}^{(6)} \geq 16$ & 14 & 22,58 & 21 & 44,68 & 0,01 & 23 & 35,38 & 15 & 37,50 & 0,82 \\
\hline
\end{tabular}

(1) Critérios de Child-Turcotte-Pugh. ${ }^{(2)}$ Cirrose biliar secundária. ${ }^{(3)}$ Hepatite auto-imune. ${ }^{(4)}$ Vírus da hepatite C. ${ }^{(5)}$ Outros: síndrome de Budd-Chiari, cirrose biliar primária, esteato-hepatite não alcoólica, hemocromatose, hepatite $\mathrm{C}+$ hepatite auto-imune e ductopenia. ${ }^{(6)}$ Model for End-stage Liver Disease. ${ }^{(7)}$ Teste do Qui-Quadrado. ${ }^{(8)}$ Teste exato de Fisher. 
Tabela 12 - Descrição das variáveis ordenadas dos 214 pacientes randomizados comparação entre pacientes incluídos e não incluídos na análise após a quarta dose da vacina contra o VHB, conforme dose simples ou dobrada

\begin{tabular}{|c|c|c|c|c|c|c|}
\hline & \multicolumn{2}{|c|}{ DOSE SIMPLES } & \multicolumn{4}{|c|}{ DOSE DOBRADA } \\
\hline & $\begin{array}{c}\text { Incluídos } \\
\quad \mathrm{N}=62\end{array}$ & $\begin{array}{l}\text { Não Incluídos } \\
\mathbf{N}=47\end{array}$ & & $\begin{array}{l}\text { Incluídos } \\
\quad \mathrm{N}=65\end{array}$ & $\begin{array}{l}\text { Não Incluídos } \\
\mathbf{N}=\mathbf{4 0}\end{array}$ & \\
\hline & Média & Média & $p^{(5)}$ & Média & Média & $p^{(5)}$ \\
\hline Idade (anos) & 49,50 & 53,23 & 0,15 & 51,55 & 52,68 & $0.58^{(6)}$ \\
\hline $\mathrm{IMC}^{(1)}$ & 27,07 & 26,97 & 0,89 & 27,81 & 27,64 & 0,56 \\
\hline $\begin{array}{l}\text { Creatinina } \\
(\mathrm{mg} / \mathrm{dL})\end{array}$ & 0,91 & $<0.001$ & 0,28 & 0,90 & 0,89 & 0,33 \\
\hline $\mathrm{BT}^{(2)}$ & 2,74 & 3,66 & 0,14 & 2,79 & 4,10 & 0,02 \\
\hline $\operatorname{INR}^{(3)}$ & 1,30 & 1,42 & 0,07 & 1,36 & 1,38 & 0,68 \\
\hline $\mathrm{ALB}^{(4)}$ & 3,53 & 3,22 & $0.01^{(6)}$ & 3,52 & 3,27 & $0.2^{(6)}$ \\
\hline
\end{tabular}

As variáveis avaliadas tiveram distribuição homogênea entre os grupos de dose simples ou dobrada, nos pacientes incluídos na análise da resposta vacinal após a quarta dose, conforme demonstrado nas Tabelas 13 e 14 . 
Tabela 13 - Descrição das variáveis categóricas dos 127 incluídos na análise da resposta vacinal contra o VHB após a quarta dose - comparação entre os grupos com dose simples ou dobrada

\begin{tabular}{|c|c|c|c|c|c|}
\hline & \multicolumn{2}{|c|}{ DOSE SIMPLES N $=62$} & \multicolumn{2}{|c|}{ DOSE DOBRADA N=65 } & \multirow[b]{2}{*}{$P^{(7)}$} \\
\hline & Total & $\%$ & Total & $\%$ & \\
\hline Sexo Masculino & 40 & 64,52 & 49 & 75,38 & 0,18 \\
\hline Tabagismo & 15 & 26,32 & 10 & 16,13 & 0,17 \\
\hline Ascite & 33 & 58,93 & 36 & 59,02 & 0,99 \\
\hline Encefalopatia & 22 & 39,29 & 16 & 26,23 & 0,13 \\
\hline CTP $^{(1)}$ & & & & & 0,59 \\
\hline A & 17 & 27,42 & 23 & 35,38 & \\
\hline B & 33 & 53,23 & 32 & 49,23 & \\
\hline $\mathrm{C}$ & 12 & 19,35 & 10 & 15,38 & \\
\hline
\end{tabular}

Etiologia

$0.28^{(8)}$

$\begin{array}{lcccc}\mathrm{CBS}^{(2)} & 2 & 3,23 & 4 & 6,15 \\ \text { Criptogênica } & 4 & 6,45 & 9 & 13,85 \\ \mathrm{HAI}^{(3)} & 6 & 9,68 & 1 & 1,54 \\ \text { Etilismo } & 28 & 45,16 & 30 & 46,15 \\ \mathrm{VHC}^{(4)} & 13 & 20,97 & 15 & 23,08 \\ \mathrm{VHC}^{(4)}+\text { Etilismo } & 5 & 8,06 & 2 & 3,08 \\ \text { Outros }^{(5)} & 4 & 6,45 & 4 & 6,15\end{array}$

Tipo Sanguíneo

$0.06^{(8)}$

$\begin{array}{lcccc}\text { A } & 25 & 40,32 & 29 & 44,62 \\ \mathrm{AB} & 0 & 0,00 & 5 & 7,69 \\ \mathrm{~B} & 6 & 9,68 & 9 & 13,85 \\ \mathrm{O} & 31 & 50,00 & 22 & 33,85\end{array}$

$\operatorname{MELD}^{(6)} \geq 16$

14

22,58

23

35,38

0,11

${ }^{(1)}$ Critérios de Child-Turcotte-Pugh. ${ }^{(2)}$ Cirrose biliar secundária. ${ }^{(3)}$ Hepatite auto-imune. ${ }^{(4)}$ Vírus da hepatite C. ${ }^{(5)}$ Outros: síndrome de Budd-Chiari, cirrose biliar primária, esteato-hepatite não alcoólica, hemocromatose, hepatite $\mathrm{C}+$ hepatite auto-imune e ductopenia. ${ }^{(6)}$ Model for End-stage Liver Disease. ${ }^{(7)}$ Teste do Qui-Quadrado. ${ }^{(8)}$ Teste exato de Fisher. 
Tabela 14 - Descrição das variáveis ordenadas dos 127 incluídos na análise da resposta vacinal contra o VHB após a quarta dose - comparação entre os grupos com dose simples ou dobrada

\begin{tabular}{|c|c|c|c|}
\hline & $\begin{array}{c}\text { DOSE SIMPLES } \\
\mathrm{N}=62\end{array}$ & $\begin{array}{c}\text { DOSE DOBRADA } \\
\mathrm{N}=65\end{array}$ & \\
\hline & Média & Média & $p^{(6)}$ \\
\hline Idade (anos) & 50 & 51,55 & $0,3^{(7)}$ \\
\hline $\operatorname{IMC} C^{(1)}$ & 27 & 27,81 & 0,45 \\
\hline Creatinina (mg/dL) & 1 & 0,90 & 0,98 \\
\hline $\mathrm{BT}^{(2)}$ & 3 & 2,79 & 0,81 \\
\hline $\operatorname{INR}^{(3)}$ & 1 & 1,36 & 0,25 \\
\hline $\mathrm{ALB}^{(4)}$ & 4 & 3,52 & $0.92^{(7)}$ \\
\hline $\begin{array}{l}\text { Intervalo } \\
\text { entre doses (meses) }\end{array}$ & 8,26 & 8,42 & 0,72 \\
\hline
\end{tabular}

${ }^{(1)}$ Índice de massa corpórea $\left(\mathrm{kg} / \mathrm{m}^{2}\right) .{ }^{(2)}$ Bilirrubina total $(\mathrm{mg} / \mathrm{dL}) .{ }^{(3)}$ Razão normalizada internacional. ${ }^{(4)}$ Albumina sérica $(\mathrm{g} / \mathrm{dL}) .{ }^{(5)}$ Intervalo entre a primeira e a quarta dose ${ }^{(6)}$ Teste da soma dos postos de Wilcoxon bicaudal. ${ }^{(7)}$ Teste $t$ de duas amostras bicaudal.

\subsubsection{Proporção de soroconversão}

A taxa de soroconversão global foi de $66,9 \%$ (85/127 pacientes).

As proporções de soroconversão foram de 0,64 (IC 95\%=0,51 até 0,76) e de 0,69 (IC $95 \%=0,56$ até 0,8 ) entre os pacientes que receberam doses simples ou dobradas, respectivamente. Não se detectou diferença estatisticamente significante entre estas duas proporções (Tabela 15). 
Tabela 15 - Dosagem de anti-HBs após a quarta dose de vacina contra o VHB com doses simples ou dobrada em 127 pacientes

\begin{tabular}{cccc}
\hline & Anti-HBs & Anti-HBs \\
& $\mathbf{1 0 m I U} / \mathbf{m l}$ & $\leq \mathbf{1 0 m I U} / \mathbf{m l}$ & \\
Dose simples & $40(64,51 \%)$ & 22 & $\boldsymbol{p}=\mathbf{0 , 5 7 ^ { ( 1 ) }}$ \\
Dose dobrada & $45(69,23 \%)$ & 20 & \\
Total & $\mathbf{8 5}$ & $\mathbf{4 2}$ & \\
\hline
\end{tabular}

${ }^{(1)}$ Teste $Z$ para proporções, para 2 amostras e bicaudal.

O modelo final de regressão logística que avaliou a associação das diferentes doses da vacina com a soroconversão, após a quarta dose, não incluiu as variáveis de interação dose vacina_idade $(p=0,61)$ nem dose vacina_meld $(p=0,19)$. O modelo ajustado por idade, IMC, MELD e grupo sanguíneo encontrou uma razão de probabilidade de soroconversão entre os pacientes que receberam a dose dobrada da vacina de 2,57 vezes a razão entre os pacientes que receberam a dose simples. Esta diferença foi estatisticamente significante, mas o intervalo de confiança incluiu 1 $(\mathrm{OR}=2,57, \mathrm{IC} 95 \%=1$ até $6,63, p=0,043)$.

\subsubsection{Intensidade de resposta}

O modelo final de regressão logística que avaliou a associação das diferentes doses da vacina com os títulos de anti-HBs, após a quarta dose, foi ajustado apenas pela variável grupo sanguíneo. Segundo o modelo, a razão de probabilidade de apresentar títulos de anti-HBs maiores do que $100 \mathrm{mIU} / \mathrm{ml}$ após a quarta dose entre os pacientes que receberam a dose dobrada da vacina é 1,63 vezes a razão dos 
pacientes que receberam a dose simples, diferença não estatisticamente significante $(\mathrm{OR}=1,63, \mathrm{IC} 95 \%=0,63$ até $4,19, \mathrm{p}=0,3)$.

\subsubsection{Fatores Preditivos de Resposta Vacinal}

Para avaliação dos fatores preditivos de resposta vacinal após a quarta dose, independentemente da dose recebida, as variáveis incluídas no modelo final da análise multivariada por regressão logística foram: idade, IMC e grupo sanguíneo.

A tabela 16 demonstra as razões de soroconversão entre os pacientes de acordo com o tipo sanguíneo, em análise ajustada para idade e IMC.

Tabela 16 - Grupo sanguíneo como fator preditivo de resposta vacinal após a quarta dose da vacina contra VHB, em análise ajustada para idade e IMC - 127 pacientes

\begin{tabular}{lccc}
\hline & OR de Soroconversão & IC 95\% & $\boldsymbol{P}^{(\mathbf{1})}$ \\
\hline Grupo O x Grupo A & 3,93 & $1,63-10,33$ & 0,006 \\
Grupo O x Grupo B & 4,26 & $1,14-15,94$ & 0,031 \\
\hline
\end{tabular}

${ }^{(1)}$ Regressão logística

As figuras 7,8 e 9 demonstram a probabilidade de soroconversão para pacientes com IMC de 27,5, 35 e 40, conforme a idade e o tipo sanguíneo. 


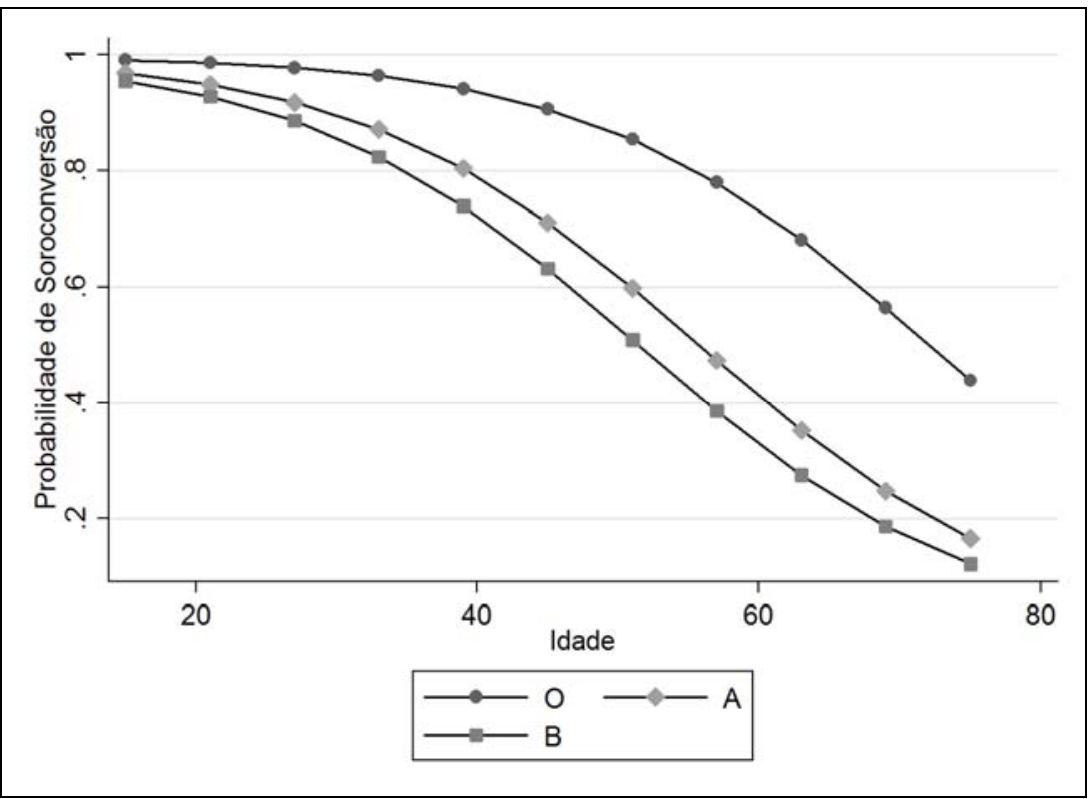

Figura 7 - Probabilidade de soroconversão após a quarta dose da vacina contra o VHB, conforme tipo sanguíneo e idade, em pacientes com IMC $=\mathbf{2 7 , 5}$

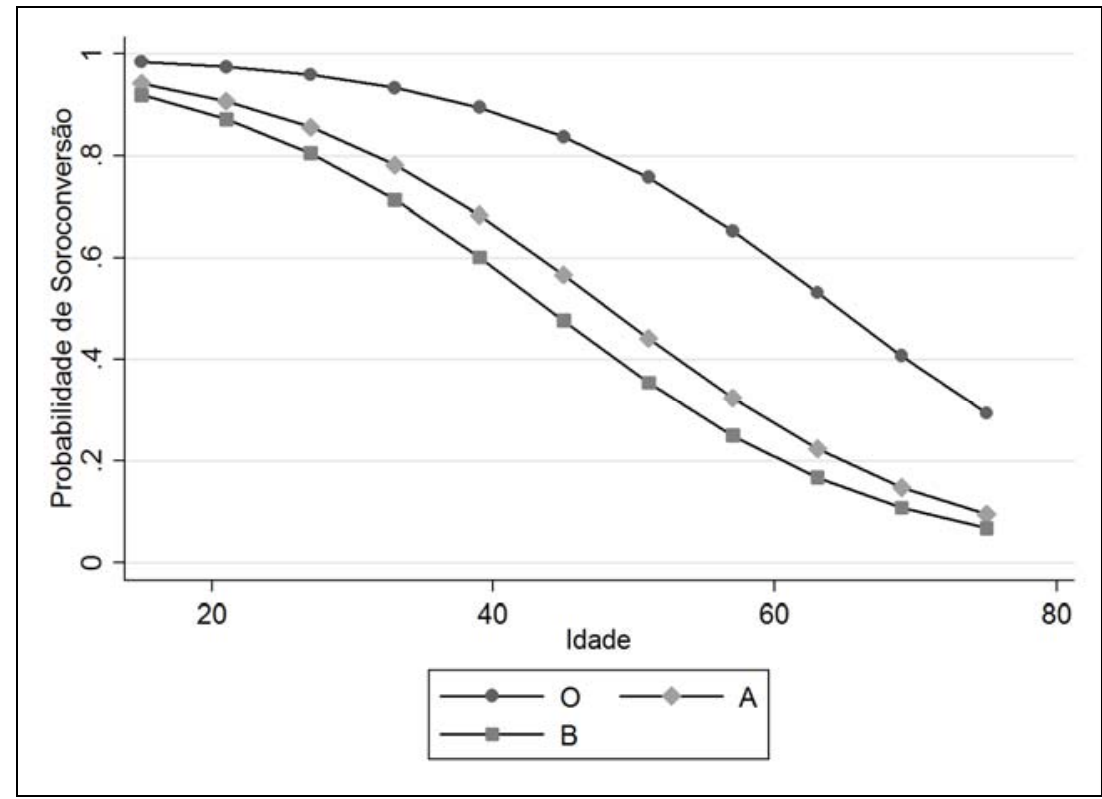

Figura 8 - Probabilidade de soroconversão após a quarta dose da vacina contra o VHB, conforme tipo sanguíneo e idade, em pacientes com IMC $=35$ 


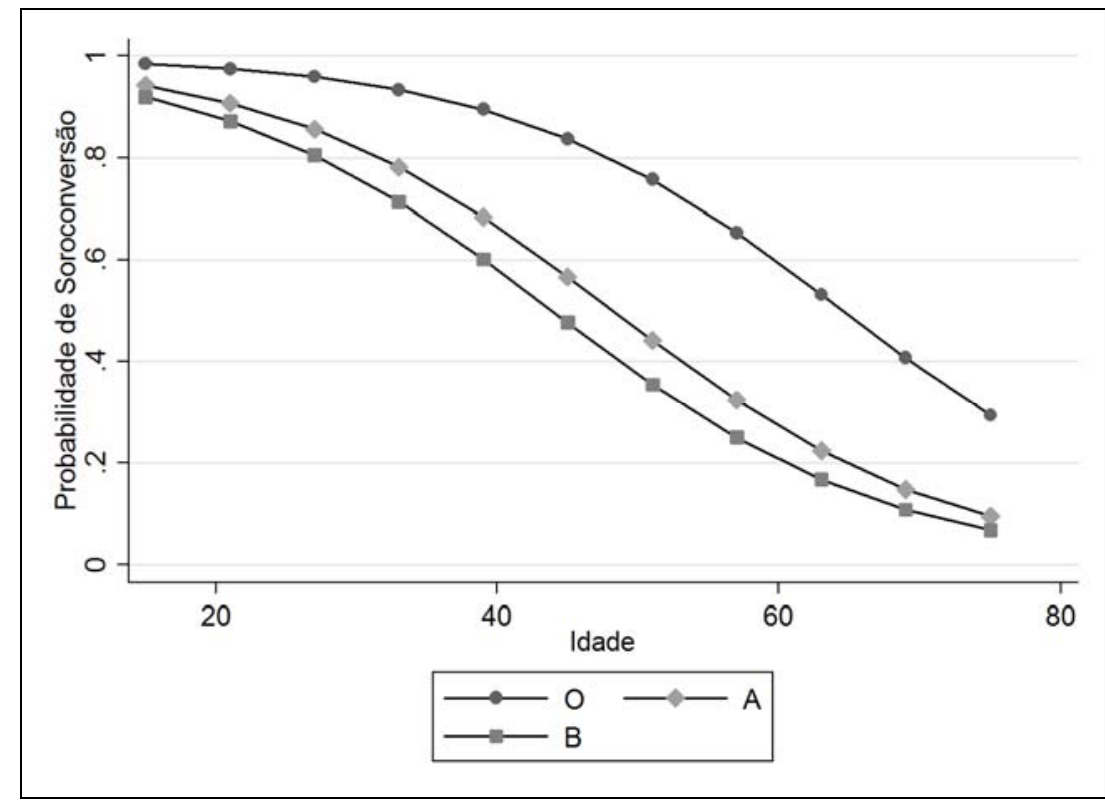

Figura 9 - Probabilidade de soroconversão após a quarta dose da vacina contra o VHB, conforme tipo sanguíneo e idade, em pacientes com IMC=40

As probabilidades de soroconversão para diferentes valores de IMC, por grupo sanguíneo, mantendo a idade em sua média (50 anos), estão descritas na Tabela 17.

Tabela 17 - IMC como fator preditivo de resposta após a quarta dose da vacina contra o VHB, conforme o tipo sanguíneo, ajustado para idade (média=50anos)

\begin{tabular}{cccc}
\hline & \multicolumn{2}{c}{ PROBABILIDADE DE SOROCONVERSÃO } \\
\cline { 2 - 4 } IMC & $\begin{array}{c}\text { GRUPO } \\
\text { SANGUÍNEO O }\end{array}$ & $\begin{array}{c}\text { GRUPO } \\
\text { SANGUÍNEO A }\end{array}$ & $\begin{array}{c}\text { GRUPO } \\
\text { SANGUÍNEO B }\end{array}$ \\
\hline IMC 27,5 (Sobrepeso) & 0,85 & 0,6 & 0,51 \\
IMC 35 (Obesidade Grau II) & 0,76 & 0,45 & 0,36 \\
IMC 40(Obesidade Grau III) & 0,67 & 0,35 & 0,27 \\
\hline
\end{tabular}

Nenhuma variável conseguiu prever, de forma estatisticamente significante, a intensidade de soroconversão (anti-HBs $\geq 100 \mathrm{mIU} / \mathrm{ml}$ ) entre os pacientes que soroconverteram após a quarta dose da vacina. 


\subsection{Análise comparativa da resposta vacinal após esquema com 3 e 4 doses da vacina}

Noventa e oito pacientes completaram o esquema com três e quatro doses, e realizaram a coleta da sorologia após a terceira e a quarta dose do esquema vacinal. Estes pacientes foram submetidos a análise comparativa de soroconversão após 3 e 4 doses. As características deste grupo, comparadas aos 116 pacientes não incluídos nesta análise, estão demonstradas nas Tabelas 18 e 19. 
Tabela 18 - Descrição das variáveis categóricas dos 98 pacientes incluídos na análise de comparação entre 3 e 4 doses da vacina contra VHB - comparação com os não incluídos

\begin{tabular}{|c|c|c|c|c|}
\hline & \multicolumn{2}{|c|}{$\begin{array}{c}\text { INCLUÍDOS } \\
\mathrm{N}=98\end{array}$} & \multicolumn{2}{|c|}{$\begin{array}{c}\text { NÃO INCLUÍDOS } \\
\mathrm{N}=116 \\
\end{array}$} \\
\hline & Total & $\%$ & Total & $\%$ \\
\hline Sexo Masculino & 69 & 69,39 & 76 & 66,0 \\
\hline Tabagismo & 19 & 20,88 & 27 & 24 \\
\hline Ascite & 51 & 56,04 & 69 & 69,7 \\
\hline Encefalopatia & 31 & 34,07 & 43 & 43,4 \\
\hline $\operatorname{CTP}^{(1)}$ & & & & \\
\hline A & 31 & 31,63 & 19 & 16,6 \\
\hline B & 45 & 45,92 & 69 & 60,5 \\
\hline $\mathrm{C}$ & 22 & 22,45 & 26 & 22 \\
\hline
\end{tabular}

Etiologia

$0.3^{(8)}$

$\begin{array}{lcccc}\mathrm{CBS}^{(2)} & 5 & 5,1 & 4 & 3,48 \\ \text { Criptogênica } & 10 & 10,20 & 14 & 12,17 \\ \mathrm{HAI}^{(3)} & 6 & 6,12 & 2 & 1,74 \\ \text { Etilismo } & 44 & 43,88 & 40 & 34,78 \\ \mathrm{VHC}^{(4)} & 22 & 22,45 & 40 & 34,78 \\ \mathrm{VHC}^{(4)}+\text { Etilismo } & 6 & 6,12 & 8 & 6,96 \\ \text { Outros }^{(5)} & 6 & 6,12 & 7 & 6,09\end{array}$

Grupo Sanguíneo

$0.98^{(8)}$

\begin{tabular}{|c|c|c|c|c|c|}
\hline A & 45 & 44,9 & 49 & 42,98 & \\
\hline $\mathrm{AB}$ & 3 & 3,06 & 3 & 2,63 & \\
\hline B & 13 & 13,27 & 16 & 14,04 & \\
\hline $\mathrm{O}$ & 38 & 38,78 & 46 & 40,35 & \\
\hline $\operatorname{MELD}^{(6)} \geq 16$ & 30 & 30,61 & 43 & 37,39 & 0,29 \\
\hline
\end{tabular}


Tabela 19 - Descrição das variáveis ordenadas dos 98 pacientes incluídos na análise de comparação entre 3 e 4 doses da vacina contra VHB - comparação com os não incluídos

\begin{tabular}{|c|c|c|c|}
\hline & $\begin{array}{c}\text { INCLUÍDOS } \\
\qquad \mathbf{N}=\mathbf{9 8}\end{array}$ & $\begin{array}{c}\text { NÃO INCLUÍDOS } \\
\text { N=116 }\end{array}$ & \\
\hline & Média & Média & $p^{(5)}$ \\
\hline Idade (anos) & 50 & 52,82 & 0,08 \\
\hline $\mathrm{IMC}^{(1)}$ & 28 & 27,14 & 0,40 \\
\hline Creatinina (mg/dL) & 1 & 0,96 & 0,52 \\
\hline $\mathrm{BT}^{(2)}$ & 3 & 3,46 & 0,16 \\
\hline $\operatorname{INR}^{(3)}$ & 1 & 1,38 & 0,47 \\
\hline $\mathrm{ALB}^{(4)}$ & 4 & 3,31 & $0.01^{(6)}$ \\
\hline
\end{tabular}

${ }^{(1)}$ Índice de massa corpórea $\left(\mathrm{kg} / \mathrm{m}^{2}\right) .{ }^{(2)}$ Bilirrubina total $(\mathrm{mg} / \mathrm{dL}) .{ }^{(3)}$ Razão normalizada internacional. ${ }^{(4)}$ Albumina sérica $(\mathrm{g} / \mathrm{dL}) .{ }^{(5)}$ Teste da soma dos postos de Wilcoxon bicaudal. ${ }^{(6)}$ Teste $\mathrm{t}$ de duas amostras bicaudal.

A soroconversão ocorreu em 37 dos 98 pacientes após a terceira dose, resultando em uma proporção de 0,37 (IC 95\%=0,27 até 0,47), e em 65 após a quarta dose, resultando em uma proporção de 0,66 (IC 95\%=0,56 até 0,75), diferença estatisticamente significante $(\mathrm{p}<0,001)$.

Entre os 62 pacientes não-respondedores após a terceira dose, 29 tornaram-se anti-HBs positivo após a quarta dose, resultando em uma chance de soroconversão de 0,47 (IC $95 \%=0,34$ até 0,6 ).

$\mathrm{Na}$ avaliação de intensidade de soroconversão, detectaram-se 18 pacientes com títulos acima de 100mIU/ml após a terceira dose, resultando numa proporção de 0,48 (IC $95 \%=0,32$ até 0,65 ), e 31 após a quarta dose, resultando numa proporção de 0,83 (IC $95 \%=0,68$ até 0,94$)$. A diferença entre estas proporções foi estatisticamente significante $(p<0,001)$. 


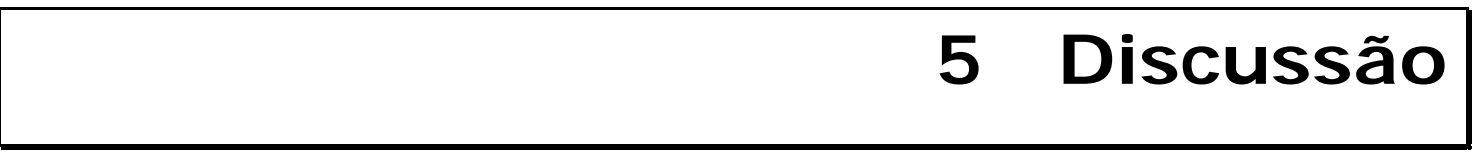


A infecção pelo VHB em cirrótico por outra etiologia em lista de espera para transplante de fígado está associada a maior morbidade e mortalidade tanto pré quanto pós-transplante (VHB de novo), pois a aquisição da infecção leva a maior risco de descompensação clínica em cirróticos e a menor sobrevida do enxerto em transplantados de fígado. ${ }^{17,20,22}$

Em áreas de alta endemicidade da doença, é freqüente a oferta de doadores com algum marcador sorológico para o VHB. ${ }^{56} \mathrm{O}$ doador com anticorpo anti-Hbc total positivo é aceito nestas regiões, apesar do risco de transmissão ao receptor. ${ }^{56} \mathrm{~A}$ incidência de VHB de novo pós-transplante, nesta situação, varia conforme o perfil sorológico do receptor, entre 25 e $95 \%$, sendo maior nos receptores sem marcador sorológico para VHB e menor nos receptores com anticorpos anti-Hbc total e antiHbs. ${ }^{57}$ Algumas medidas, como uso de anti-viral, imunoglobulina específica contra VHB pós-transplante e/ou vacinação pré-transplante, são utilizadas para diminuir esta transmissão. ${ }^{56}$

Para prevenir a infecção pelo VHB pré e pós-transplante e, consequentemente, as complicações associadas, a vacina contra o VHB no paciente com cirrose, em lista de espera para transplante de fígado, é uma estratégia segura e de menor custo, recomendada a esta população. ${ }^{1,17}$ Entretanto, questões sobre sua eficácia ainda não estão bem estabelecidas.

Em imunocompetentes, a eficácia da vacina contra o VHB é relacionada a títulos de anti-HBs $\geq 10 \mathrm{mUI} / \mathrm{ml}$, atingindo $95 \% .{ }^{6}$ Em cirróticos, estudos evidenciam 
menor eficácia da vacina quando comparada a controles sadios. Além disso, alguns autores sugerem títulos de anti-HBs $\geq 200 \mathrm{mUI} / \mathrm{ml}$ ou $\geq 1000 \mathrm{mUI} / \mathrm{ml}$ como títulos protetores nesta população, uma vez que há relatos de transmissão de VHB póstransplante ao paciente vacinado, com anti-HBs $\geq 10 \mathrm{mUI} / \mathrm{ml}$, que recebeu um fígado de doador anti-HBc total positivo. ${ }^{58,59,60}$ Alguns casos descritos, entretanto, são de transmissão de vírus que sofrem mutações no determinante $a$ do $\mathrm{HBsAg}$, não permitindo o reconhecimento deste vírus pelo anticorpo específico produzido após a vacinação. ${ }^{58,61,62,63}$

Por ocorrer queda progressiva dos títulos de anticorpo, alguns autores sugerem também que seja realizado reforço periodicamente pós-transplante, para que se mantenham altos títulos de anticorpos. ${ }^{56,59}$ Entretanto, o papel da imunidade celular na eficácia da vacina contra VHB nesta e em outras populações não está bem definido, e deve ser melhor estudado. Estudo em crianças transplantadas de fígado demonstrou a manutenção da imunidade celular mesmo após queda dos títulos de anti-HBs pós- transplante, induzindo ao questionamento da necessidade de reforço. ${ }^{64}$

Com o objetivo de aumentar a imunogenicidade da vacina, alguns estudos desenvolvidos em populações de pacientes imunodeprimidos, como pacientes HIV positivos ou com insuficiência renal crônica dialítica, evidenciam maior imunogenicidade do esquema vacinal com doses dobradas quando comparado ao esquema com doses convencionais. ${ }^{28,29,30}$ Desta forma, recomenda-se a dose dobrada a todos os pacientes imunodeprimidos. ${ }^{5,65}$ Apesar de não haver referência especificamente aos cirróticos, tal conduta também é recomendada a este grupo de pacientes em vários centros de transplante. ${ }^{54}$ 
Estratégias para aumentar a imunogenicidade da vacina especificamente em cirróticos são pouco estudadas. Há trabalhos comparando diferentes doses e diferentes intervalos entre elas, mas não são randomizados, possuem pequeno número de pacientes incluídos e populações heterogêneas. Os estudos com esquemas convencionais, dose simples da vacina aos 0,1 e 6 meses, demonstram resultados discrepantes, variando entre $16 \%$ e $70 \%$ a resposta vacinal nos cirróticos. Em recente levantamento realizado em nosso serviço, a resposta vacinal ao esquema com doses dobradas aos 0,1 e 6 meses foi de $67,5 \%$, superior a algumas séries relatadas com dose simples. ${ }^{54}$

O esquema acelerado, 0,1 e 2 meses ou 0,7 e 21 dias, é proposto em alguns estudos e teria uma vantagem diante do critério de gravidade para o transplante de fígado. Frequentemente os pacientes apresentam-se com a primeira descompensação da doença hepática, são rapidamente incluídos em lista de transplante e podem ser transplantados num período menor do que 6 meses. O esquema ideal deveria ser, portanto, altamente eficaz em curto espaço de tempo. Entretanto, a maioria dos estudos com esquema acelerado apresenta resultado aquém do ideal, e não parece ser superior ao esquema convencional, com resposta variando de 26 a 54\%. ${ }^{48,53}$

Desenvolvemos, portanto, para melhor compreensão da resposta vacinal no cirrótico e estratégia para melhorar esta resposta, um estudo clínico, randomizado, comparando a imunogenicidade com doses e esquemas variados nesta população.

O esquema proposto consistiu em 4 doses, aos 0,1,2 e 6 meses, com avaliação da imunogenicidade de diferentes doses da vacina realizada após a terceira dose, para eventualmente validar o esquema acelerado, e após a quarta dose.

Os pacientes incluídos no estudo foram cirróticos em lista de transplante de fígado, independentemente da gravidade. Entretanto, excluímos do estudo os 
pacientes que pudessem apresentar qualquer outra doença imunossupressora já conhecida, que interferisse na resposta vacinal, como HIV e insuficiência renal dialítica. As neoplasias extra-hepáticas e as hepáticas, sem critério para transplante, também foram fatores de exclusão do estudo, pois além de poderem agravar ou descompensar a doença hepática e diminuir a sobrevida, são fatores de exclusão da lista de transplante.

Por questões de custo e para que fosse possível incluir nossos pacientes na rotina do laboratório, consideramos apenas a realização do anti-HBc total como exame de triagem sorológica para inclusão no estudo. Com isto, podem ter sido incluídos pacientes com infecção pelo VHB, apresentando um perfil sorológico com anti-HBc total negativo, mas $\mathrm{HBsAg}$, não realizado em nossa triagem, positivo. Entretanto, este perfil é bastante incomum. ${ }^{66}$ Também, pelo mesmo motivo, não se repetiu a sorologia completa para VHB no final do seguimento, quando realizamos apenas a dosagem do anti-HBs.

Pelas dificuldades para que o paciente compareça mais uma ou duas vezes ao hospital, optou-se também por considerar as sorologias realizadas nos últimos 2 anos para inclusão no estudo.

A randomização em blocos foi escolhida para que a distribuição entre os grupos permanecesse estável durante todo o período de inclusão do estudo.

A perda de casos pós-randomização foi expressivamente maior do que os $10 \%$ inicialmente previstos. Óbito foi a principal causa, sendo associado a mais da metade destas perdas. Isto ocorreu provavelmente pela mudança dos critérios de transplante de fígado durante o estudo. No princípio, com a lista cronológica, eram incluídos pacientes relativamente menos graves, qualquer MELD, desde que CTP $\geq$ 
7. Após a mudança para gravidade, incluíam-se apenas pacientes com MELD $\geq 16$ ou com alguma complicação maior, como sangramento, peritonite bacteriana e encefalopatia. Desta forma, os pacientes selecionados para inclusão passaram a ser mais graves.

A não adesão ao protocolo também contribuiu para as perdas e ocorreu, provavelmente, pelo baixo nível sócio-econômico-cultural dos pacientes em nosso serviço. Em geral não possuíam recursos financeiros ou verba para comparecer ao serviço apenas para vacina ou coleta de exame. Além disso, foi muito frequente o fornecimento de dados errados quanto à vacinação prévia, ou de dados para contato, o que impediu a localização do paciente e o reforço sobre datas de vacina e coleta.

Para melhor validar o estudo, comparamos as características entre os pacientes incluídos e excluídos da análise após a terceira e a quarta dose. Detectaram-se indicadores de maior gravidade e/ou de pior função hepática entre os excluídos de ambos os grupos, o que pode ter resultado na avaliação de pacientes menos graves. No entanto, outras variáveis associadas às complicações da cirrose não foram diferentes entre os grupos, e evidenciaram a inclusão de pacientes graves na análise.

Neste estudo, não encontramos diferença estatisticamente significante na resposta vacinal (anti-HBs $\geq 10 \mathrm{mIU} / \mathrm{ml}$ ), nem na intensidade da resposta (anti-HBs $\geq 100 \mathrm{mIU} / \mathrm{ml}$ ) entre o esquema com dose simples e o com dobrada após a terceira e após a quarta dose.

O fato de haver maior número de pacientes graves entre os excluídos da análise poderia interferir no resultado. Entretanto, ao se comparar as características apenas entre os pacientes incluídos que receberam a dose simples ou dobrada da vacina, não houve diferença entre os grupos, tanto após a terceira quanto após a 
quarta dose. Os grupos analisados mantiveram-se com distribuição semelhante e homogênea em relação às variáveis, não invalidando o estudo, embora variáveis como tipo sanguíneo $\mathrm{O}$ e MELD menor que 16, apesar de não diferentes estatisticamente, tenham sido mais freqüentes no grupo dose simples.

Ao se ajustar a análise para alguns fatores de confusão, como idade, MELD, IMC e grupo sanguíneo, houve diferença estatística da dose dobrada em relação à dose simples, mas o intervalo de confiança incluiu 1 . O número de pacientes pode não ter sido suficiente para demonstrar verdadeiramente esta diferença.

Um importante fator a se considerar foi o uso, durante o estudo, de dois produtos diferentes. De outubro de 2006 a janeiro de 2009, utilizamos a Euvax B, e a partir de fevereiro de 2009, passamos a utilizar a Butang, produzida no Brasil. Pelo curto período durante o qual esta vacina foi utilizada entre os pacientes que completaram o protocolo, apenas 1 recebeu a terceira dose e 17 receberam a quarta dose da Butang (7 no grupo dose simples e 10 no grupo dose dobrada), sendo pouco provável que este fator tenha interferido nos resultados. Esta mudança se deve ao fato de, no estudo, utilizarmos a vacina oferecida nos CRIES. Há um ofício da Secretaria Municipal de Saúde, publicado em junho de 2008, autorizando o uso da Butang a todas as pessoas às quais a vacina estiver indicada (Anexo F). Entretanto, não há estudos em imunodeprimidos, e os realizados comparando a imunogenicidade desta com outras vacinas contra o VHB, sugerem inferioridade da Butang em populações com mais de 30 anos

Em imunodeprimidos, há a recomendação de dose dobrada da vacina contra o VHB, entretanto não existe evidência para todas as causas de imunodeficiência, e dados contraditórios ou mostrando eficácia apenas em subpopulações existem na literatura, 
podendo reforçar os resultados encontrados neste estudo. Em HIV, houve superioridade da dose dobrada em estudo randomizado, porém apenas o subgrupo de pacientes com CD4 maior ou igual a $350 \mathrm{cell} / \mathrm{mm}^{3}$ ou carga viral menor ou igual a 10.000 cópias $/ \mathrm{ml}^{28}$ Em pacientes dialíticos, relatos com dose simples apresentavam soroconversão máxima de $58 \%$, enquanto atingia $72 \%$ em esquemas com dose dobrada. ${ }^{25,67}$ Entretanto, a maioria destas diferenças foi demonstrada em estudos distintos.

Em imunocompetentes, um estudo comparou resposta após uma dose de reforço, simples ou dobrada, aos não respondedores ao esquema convencional $(0,1$ e 6 meses), e não encontraram diferença. ${ }^{68}$

Apesar de haver um estudo randomizado em etilistas evidenciando superioridade do esquema com dose dobrada, apenas um pequeno número tinha o diagnóstico de cirrose, o que não nos permite aplicar tal achado a esta população. ${ }^{55} \mathrm{O}$ estudo que comparou dose simples com dose dobrada em cirróticos, após esquema acelerado, aos 0 , 7 e 21 dias, não demonstrou diferença entre as doses (31 versus $26 \%)^{7}$

Reforçam os resultados do atual estudo o fato de ter sido randomizado e da amostra analisada ser importante quando comparada a outros estudos da literatura nesta população. Há a possibilidade de realmente não haver influência destas diferentes doses na imunogenicidade da vacina, mas de haver outros fatores, peculiares ou não aos cirróticos, que possam interferir na resposta vacinal. Provavelmente, o número e o intervalo entre as doses são mais importantes do que a dose a ser administrada, simples ou dobrada, na indução da resposta vacinal.

Destaca-se ainda, neste estudo, a elevada taxa de soroconversão encontrada após a quarta dose, 66,92\% (85/127), resultado superior ao encontrado na maioria das publicaçõe. Isto pode se dever à análise dos pacientes que 
realmente se comprometeram e terminaram as doses e coleta adequadamente, ou por terem sido analisados apenas pacientes em lista para transplante que sobrevivem o período necessário para completar o esquema vacinal proposto, ou seja, pacientes de menor gravidade.

O esquema com 4 doses (0,1,2 e 6 meses) também pode ter contribuído para a esta boa resposta, embora resultado semelhante tenha ocorrido em estudo descritivo com 3 doses nesta população (0,1 e 6 meses). Entretanto, favorecendo esta hipótese, dois estudos em cirróticos, com mais de três doses, evidenciaram aumento significante nos títulos de anticorpos após uma quarta dose (54 para 74\% e 44 para $62 \%){ }^{49,51}$ Em pacientes em diálise, também foi realizada a comparação entre um esquema com 3 doses dobradas ( 0,1 e 6 meses) e um com 4 doses dobradas (0,1,2 e 6 meses), demonstrando superioridade do segundo (55 versus $79 \%) .{ }^{30}$

Realizou-se uma subanálise, em que foi feita a comparação entre a soroconversão após 3 e 4 doses, independentemente da dose recebida, no grupo de pacientes que realizou as 2 coletas adequadamente. Embora o estudo não tenha sido desenhado com este objetivo, demonstrou-se diferença estatisticamente significante, com maior proporção de soroconversão e maior intensidade de soroconversão após a quarta dose.

Diante destes dados, pode-se questionar a importância do número de doses e do intervalo entre a segunda e terceira doses, na resposta vacinal. Pelas baixas taxas de soroconversão após a terceira dose, o esquema acelerado não produziu impacto, o que pode ser compreendido pelo mecanismo de ação da vacina, pois no momento da terceira dose não houve o intervalo mínimo de tempo para que tenha ocorrido a maturação das células B e, consequentemente, maior produção de anticorpo. ${ }^{18}$ 
Variáveis foram analisadas neste estudo, independentemente da dose recebida, como fator preditivo de resposta vacinal e como fator associado à intensidade de soroconversão, após a terceira e a quarta doses.

$\mathrm{Na}$ análise multivariada após a terceira dose encontramos, assim como na literatura, tabagismo como um fator de pior resposta vacinal. Este poderia estar associado à diminuição da função macrofágica e linfocítica. Uma vez que a resposta imune após a vacina contra o VHB é dependente de células T, qualquer diminuição em sua função relacionada à nicotina poderia interferir na produção de anticorpos. ${ }^{25,26}$ Entretanto, após a quarta dose, este fator não foi identificado no estudo.

A idade também interferiu, inversa e progressivamente, na probabilidade de soroconversão após a terceira e a quarta dose. Fator já conhecido na literatura, em recente meta-análise, sua interferência aparece na grande maioria dos trabalhos avaliando fator associado com resposta vacinal, após 40 anos, o que é biologicamente adequado diante do envelhecimento do sistema imunológico. ${ }^{69}$

Embora nenhum estudo tenha avaliado diretamente o MELD como fator preditivo de resposta, a maioria sugere a relação de gravidade da doença com a eficácia da vacina. Como já descrito anteriormente, o cirrótico apresenta diminuição na quimiotaxia dos neutrófilos, além de alteração na função linfocítica, o que poderia justificar esta relação. Entretanto, o principal parâmetro para avaliar o impacto da alteração imunológica na redução de resposta vacinal não está bem estabelecido: CTP, MELD, grau de desnutrição, ou a associação de fatores. Em cirróticos, estudos em pacientes CTP B e C parecem apresentar pior resposta a vacina contra o VHB e VHA. ${ }^{39}$ Em nosso estudo, demonstramos que MELD menor do que 16 foi um fator 
de melhor resposta vacinal após a terceira dose. Isto não ocorreu após a quarta dose, o que pode se dever ao maior número de perdas por óbito neste momento da análise.

Outro fator encontrado, preditivo de melhor resposta, estatisticamente significante, que reforça a hipótese de que o intervalo entre as doses é bastante importante na resposta vacinal, é o intervalo entre a primeira e a terceira doses maior do que cinco meses, o que ocorreu em uma pequena parcela dos pacientes que atrasou a tomada das doses. Este dado reforça a dúvida gerada sobre a superioridade do esquema $0,1,2$ e 6 meses ao 0,1 e 6 meses.

O alto índice de massa corpórea como fator de má resposta, também conhecido na literatura, foi significante em nosso estudo após a quarta dose. No cirrótico, a interpretação deste fator tem alguns aspectos peculiares. A primeira consideração é quanto este valor é representativo, pois muitas vezes o paciente com cirrose é desnutrido e seu elevado peso pode ser decorrente da retenção de sódio e água, apresentando-se clinicamente como edema e ascite. Além disto, os pacientes desnutridos têm uma diminuição da resposta humoral e celular, o que poderia interferir na interpretação do resultado encontrado. ${ }^{70} \mathrm{~A}$ obesidade no cirrótico poderia levar à aplicação da vacina em tecido adiposo ao invés de intramuscular. ${ }^{26}$ Na região muscular há maior número de CAA, maior absorção de antígenos para a corrente sanguínea e, consequentemente, resposta imune mais eficaz que a primeira. ${ }^{26} \mathrm{O}$ elevado IMC também poderia estar associada ao fígado "gorduroso", intolerância à glicose e até diabetes. ${ }^{71}$

Sabe-se que a resposta vacinal contra o VHB sofre interferência de fatores genéticos, como algumas variantes de HLA-DR. ${ }^{72,73}$ Entretanto, não encontramos descrição de sua associação com tipo sanguíneo na literatura. Estudo com vacina de 
raiva já avaliou, mas não demonstrou relação entre sua resposta e tipo sanguíneo. ${ }^{74}$ Em nosso trabalho, o tipo sanguíneo $\mathrm{O}$ foi um fator de melhor resposta quando comparado ao grupo A e B. Avaliação com o tipo $\mathrm{AB}$ não foi possível, pelo pequeno número de pacientes com este tipo sanguíneo.

A soroconversão global após a quarta dose foi elevada quando comparada aos dados da literatura. Entretanto, a resposta vacinal ao VHB ainda está aquém do ideal nesta população. A dose dobrada no cirrótico não parece ser uma alternativa para aumentar a imunogenicidade da vacina. A administração precoce na doença hepática, antes do aparecimento ou em estágios iniciais da cirrose, poderia ser uma alternativa tanto para aumentar a soroconversão quanto para que o paciente consiga completar o esquema vacinal, com 3 ou 4 doses, mas com intervalo mínimo de 4 a 5 meses entre a segunda e a terceira doses, antes do transplante. A via de administração, como intradérmica ou subcutânea, também poderia ser uma opção a ser estudada nesta população.

Estudos nesta população, com novos adjuvantes, como IL-2 e monophosphoryl lipid A, e com novas vacinas incluindo as porções Pré-S1 e Pré-S2 em sua composição, são necessários para o desenvolvimento de vacina altamente eficaz, com esquemas mais acelerados. ${ }^{75}$ Há, ainda, uma escassez de estudos para que se possa medir e compreender o papel da imunidade celular na eficácia desta vacina em pacientes imunodeprimidos. 


\section{Conclusão}


1. A taxa de soroconversão global da vacina contra o VHB em cirróticos em lista de espera para transplante de fígado, após a quarta dose, em esquema com doses aos $0,1,2$ e 6 meses, foi superior à maioria dos trabalhos realizados nesta população.

2. Não houve diferença na resposta vacinal (anti-HBs $\geq 10 \mathrm{mIU} / \mathrm{ml}$ ) entre dose simples e dobrada em cirróticos, avaliada após esquema acelerado, 0,1 e 2 meses, e esquema com 4 doses, aos 0,1,2 e 6 meses.

3. Não houve diferença na intensidade de soroconversão (anti-HBs $\geq 100 \mathrm{mIU} / \mathrm{ml}$ ) entre dose simples e dobrada em cirróticos, avaliada após esquema acelerado, 0,1 e 2 meses, e esquema com 4 doses, aos 0,1,2 e 6 meses.

4. Fatores preditivos de resposta vacinal após o esquema acelerado, aos 0,1 e 2 meses, foram: idade, sexo masculino, não fumantes, MELD $<16$ e intervalo entre a primeira e terceira dose maior do que 5 meses.

5. Fatores preditivos de resposta vacinal após o esquema com 4 doses, aos 0,1, 2 e 6 meses, foram: idade, IMC e grupo sanguíneo O.

6. A resposta vacinal após 4 doses, com esquema 0,1,2 e 6 meses, foi estatisticamente superior à resposta após 3 doses, 0,1 e 2 meses, independentemente da dose, nos pacientes que realizaram e coletaram o exame nos dois momentos. 


\section{Anexos}


Anexo A: Critérios de Child-Turcotte-Pugh

\begin{tabular}{cccc}
\hline $\begin{array}{c}\text { Dados Clínicos e } \\
\text { Laboratoriais }\end{array}$ & 1 Ponto & 2 Pontos & 3 Pontos \\
\hline Encefalopatia & Ausente & $1-2$ & $3-4$ \\
Ascite & Ausente & $\begin{array}{c}\text { Discreta ou } \\
\text { diuréticos }\end{array}$ & $\begin{array}{c}\text { Ao menos } \\
\text { moderada apesar } \\
\text { do uso de } \\
\text { diuréticos }\end{array}$ \\
INR & $<1,7$ & $1,7-2,3$ & $>2,3$ \\
Albumina $(\mathrm{g} / \mathrm{dl})$ & $>3,5$ & $2,8-3,5$ & $<3,5$ \\
$\begin{array}{c}\text { Bilirrubinas } \\
(\mathrm{mg} / \mathrm{d} \mathrm{l})\end{array}$ & $<2$ & $2-3$ & $>3$ \\
\hline
\end{tabular}

(A): 5-6. (B): 7-9. (C): 10-15. 
Anexo B: Fórmula para o cálculo do MELD (Model for End-stage Liver Disease)

$\operatorname{MELD}=9,57 \times \log _{\mathrm{e}}$ creatinina $(\mathrm{mg} / \mathrm{dl})+3,78 \times \log _{\mathrm{e}}$ bilirrubina total $(\mathrm{mg} / \mathrm{dl})+11,20$

$$
\mathrm{x} \log _{\mathrm{e}} \mathrm{INR}+6,42
$$




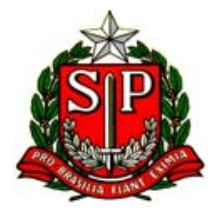

Hospital das ClíNICAS

da Faculdade de Medicina da Universidade de São PaUlo

Caixa Postal, 8091 - SÃo PaUlo - Brasil

TERMO DE CONSENTIMENTO LIVRE E ESCLARECIDO

(Instruções para preenchimento no verso)

I - DADOS DE IDENTIFICAÇÃO DO SUJEITO DA PESQUISA OU RESPONSÁVEL LEGAL

1. NOME DO PACIENTE .

DOCUMENTO DE IDENTIDADE N ${ }^{\circ}$ : SEXO : .M $\mathrm{F}$

DATA NASCIMENTO:

$\mathrm{N}^{\circ}$

APTO:

BAIRRO:

CIDADE

CEP:

TELEFONE: DDD (. ...)

2.RESPONSÁVEL LEGAL

NATUREZA (grau de parentesco, tutor, curador etc.)

DOCUMENTO DE IDENTIDADE N ${ }^{\circ}$ :

SEXO : .M $F$

DATA NASCIMENTO: .........................

ENDEREÇO

$\mathrm{N}^{\circ}$

CIDADE

BAIR.

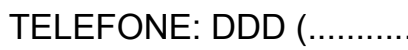
.)

APTO:

CEP

\section{II - DADOS SOBRE A PESQUISA CIENTÍFICA}

\section{TÍTULO DO PROTOCOLO DE PESQUISA :}

"Eficácia de doses dobradas da vacina contra o vírus da hepatite B em pacientes cirróticos em lista para transplante de fígado: estudo clínico randomizado."

2.

- PESQUISADOR: Patrícia Rodrigues Bonazzi

- CARGO/FUNÇÃO: Médica Infectologista.

- INSCRIÇÃO CONSELHO REGIONAL NN 98.250

- UNIDADE DO HOSPITAL: Serviço de Transplante e Cirurgia do Fígado 
3. AVALIAÇÃO DO RISCO DA PESQUISA:

SEM RISCO
RISCO MÍNIMO

RISCO MÉDIO

\author{
RISCO BAIXO X \\ RISCO MAIOR \\ (probabilidade de que o indivíduo sofra algum dano como consequência imediata ou tardia do estudo)
}

4.DURAÇÃO DA PESQUISA : 18 meses

\title{
III - REGISTRO DAS EXPLICAÇÕES DO PESQUISADOR AO PACIENTE OU SEU
} REPRESENTANTE LEGAL SOBRE A PESQUISA CONSIGNANDO:

\section{Justificativa e os objetivos da pesquisa:}

A transmissão do vírus da hepatite $B$ ocorre principalmente por contato sexual, por transfusão de sangue e doação de órgão infectado. Os cirróticos que pegam o vírus têm maior risco de piorar a doença do seu fígado. Além disso, o paciente pode pegarr o vírus após o transplante, prejudicando o órgão recebido. Torna-se importante, então, prevenir a infecção pelo vírus da hepatite $\mathrm{B}$, o que pode ser conseguido através da vacinação. Por isso, todos os pacientes que estão na lista para o transplante de fígado devem receber esta vacina. Mas, pelos estudos científicos já realizados, parece que o efeito desta vacina nos pacientes com cirrose não é tão bom quanto na população em geral. Por isso, vamos usar doses maiores para tentar melhor proteção contra este vírus. Isto já foi feito em outros grupos de pacientes, com bons resultados e sem aumentar efeitos colaterais.

2. Procedimentos que serão utilizados e propósitos, incluindo a identificação dos procedimentos que são experimentais

Um grupo de pacientes entrando em lista de transplante de fígado será submetido a doses da vacina normalmente utilizadas, ou seja, 20 nos meses $0,1,2$ e 6 . Um outro grupo receberá as doses dobradas: 40 nos meses $0,1,2$ e 6 . A inclusão em um grupo ou outro será por sorteio.Cada paciente receberá, então, 4 doses da vacina, que será administrada por via intramuscular (injeção no músculo), na região do deltóide (braço). Um mês após a terceira dose da vacina e um mês após a quarta dose, os pacientes deverão colher sangue, para que possamos realizar a dosagem do anticorpo e ver se a vacina funcionou.

\section{Desconfortos e riscos esperados}

Os pacientes que forem receber doses dobradas da vacina terão o mesmo desconforto durante a aplicação da injeção que os demais. Reação no local como dor, vermelhidão, inchaço, hematoma pode ocorrer nos dois grupos. Outros efeitos raros podem ocorrer como reação alérgica, febre, dores pelo corpo, dor de cabeça, dor nas articulações. Doenças graves relacionadas com a vacina não tem sido descritas. De acordo com o que levantamos na literatura médica, pacientes que recebem doses dobradas da vacina não parecem ter mais efeitos colaterais que os que recebem doses simples. 
A necessidade de coleta de sangue em dois momentos durante o estudo traz ainda o desconforto ao paciente da locomoção até o serviço e da punção venosa para coleta.

\section{Benefícios que poderão ser obtidos}

Com este estudo poderemos avaliar qual a melhor dose e ou esquema para vacinar os cirróticos em lista de transplante. Além disso, poderemos avaliar qual a característica dos pacientes relacionada a maior produção de anticorpo protetor (qual a idade ou sexo ou doença hepática que respondem melhor) e definir quem deverá receber a vacina e quando.

\section{Procedimentos alternativos que possam ser vantajosos para o indivíduo}

Não há, hoje, procedimento alternativo à vacina. Quando a vacina não funcionar, independentemente da dose, o esquema poderá ser repetido.

\section{IV - ESCLARECIMENTOS DADOS PELO PESQUISADOR SOBRE GARANTIAS DO SUJEITO DA PESQUISA CONSIGNANDO:}

1. acesso, a qualquer tempo, às informações sobre procedimentos, riscos e benefícios relacionados à pesquisa, inclusive para dirimir eventuais dúvidas.

Em caso de dúvida sobre os procedimentos a serem realizados, riscos e benefícios referentes à pesquisa, os pacientes poderão entrar em contato com Dra Patrícia, investigadora principal, ou com a enfermeira Karina, no telefone 30696250 ou 30697940.

2. liberdade de retirar seu consentimento a qualquer momento e de deixar de participar do estudo, sem que isto traga prejuízo à continuidade da assistência.

O paciente tem total liberdade para participar ou não do estudo. Caso seja incluído, poderá deixar de participar do estudo em qualquer momento, sem que haja qualquer prejuízo em seu acompanhamento no serviço.

3. salvaguarda da confidencialidade, sigilo e privacidade.

As informações obtidas neste estudo são confidenciais, sigilosas, e não haverá qualquer exposição dos dados de pacientes individualmente.

4. disponibilidade de assistência no HCFMUSP, por eventuais danos à saúde, decorrentes da pesquisa.

Todos os pacientes estarão incluídos no Ambulatório do Serviço de Transplante e Cirurgia do Fígado, e assistência no HC-FMUSP será disponível em caso de evento adverso grave decorrente da pesquisa, que necessite de internação.

5. viabilidade de indenização por eventuais danos à saúde decorrentes da pesquisa. 
Não há indenização prevista.

V. INFORMAÇÕES DE NOMES, ENDEREÇOS E TELEFONES DOS RESPONSÁVEIS PELO ACOMPANHAMENTO DA PESQUISA, PARA CONTATO EM CASO DE INTERCORRÊNCIAS CLÍNICAS E REAÇÕES ADVERSAS.

Patrícia Rodrigues Bonazzi, pesquisador responsável. Av. Dr. Arnaldo, 455 3A. Fones: 30697940, 30696250

Karina Tiemi Osaki Av. Dr. Arnaldo, 455 3A. Fones: 30697940, 30696250

VI. OBSERVAÇÕES COMPLEMENTARES:

\section{VII - CONSENTIMENTO PÓS-ESCLARECIDO}

Declaro que, após convenientemente esclarecido pelo pesquisador e ter entendido o que me foi explicado, consinto em participar do presente Protocolo de Pesquisa

São Paulo, de de 19 


\section{Anexo D: Aprovação da CAPPesq}

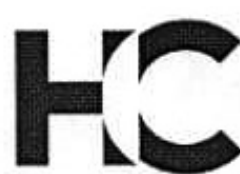

HOSPITHL DAS GLIMUChS

DA FACULOADE DE WIEDICINA
DA UMYESTIPADE DE SAO PAUTD

\section{APROVAÇÃO}

A Comissão de Ética para Análise de Projetos de Pesquisa - CAPPesq da Diretoria Clínica do Hospital das Clínicas e da Faculdade de Medicina da Universidade de São Paulo, em sessão de 12/07/06, APROVOU o Protocolo de Pesquisa $n^{\circ}$ 618/06, intitulado: "Eficácia de doses dobradas da vacina contra o vírus da hepatite B em pacientes cirróticos em lista de espera para transplante de fígado:estudo clínico randomizado." apresentado pelo Departamento de Molétias Infeciosas e paraditárias, inclusive Termo de Consentimento Livre e Esclarecido.

$$
\text { Cabe ao pesquisador elaborar e apresentar à }
$$

CAPPesq, os relatórios parciais e final sobre a pesquisa (Resolução do Conselho Nacional de Saúde ${ }^{\circ} 196$, de 10.10.1996, inciso IX. 2, letra "c")

\section{Pesquisador(a) Responsável: Patricia Rodrigues Bonazzi}

CAPPesq, 12 de julho de 2006.

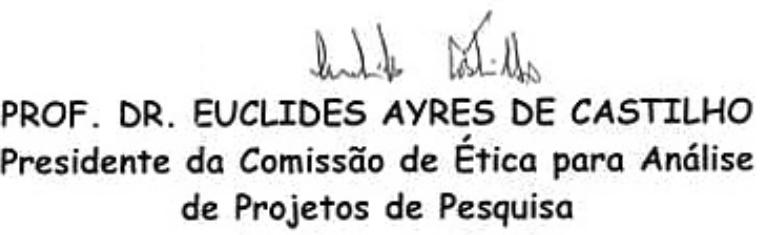

Comissða de Ética para Análise de Projetos de Pesquisa do HCFMUSP e da FMUSP Diretoria Clírica do Hospital das Clínicos da Faculdade de Medicina da Universidade de Sðo Poulo Rua Ovídio Pires de Compos. 225, $5^{\circ}$ andar - CEP 05403010 - Så Poulo - SP Fone: 011 - 30696442 fax : 011 - 30696492 - e-mail i coppesq@henetusp.br/ secretariocappesq2@henet usp.br 
Anexo E: Descrição das características e acompanhamento dos 214 pacientes incluídos no estudo

\begin{tabular}{|c|c|c|c|c|c|c|c|c|c|c|c|c|c|c|c|c|c|c|c|c|c|c|}
\hline Bloco & Envelope & RG & Idade & Sexo & Etiologia & TS & IMC & Tabagista & CTP & MELD & $\begin{array}{c}\text { Dose } \\
\text { dobrada }\end{array}$ & $\begin{array}{c}\text { Intervalo entre } \\
3 \text { doses } \\
\text { (meses) }\end{array}$ & $\begin{array}{c}\text { Soroconversão } \\
3 \text { doses } \\
(\geq 10 \mathrm{mlU} / \mathrm{ml})\end{array}$ & $\begin{array}{c}\text { Soroconversão } \\
3 \text { doses } \\
(\geq 10 \mathrm{mll} / \mathrm{ml})\end{array}$ & $\begin{array}{c}\text { Titulo após } \\
3 \text { doses }\end{array}$ & $\begin{array}{r}\text { Perdas } \\
3 \text { doses }\end{array}$ & $\begin{array}{l}\text { Intervalo entre } \\
4 \text { doses } 7 \mathrm{~m}\end{array}$ & $\begin{array}{c}\text { Soroconversão } \\
4 \text { doses } \\
(\geq 10 \mathrm{mlU} / \mathrm{ml})\end{array}$ & $\begin{array}{c}\text { Soroconversão } \\
4 \text { doses } \\
(\geq 100 \mathrm{mlU} / \mathrm{ml})\end{array}$ & $\begin{array}{c}\text { Titulo após } \\
4 \text { doses }\end{array}$ & $\begin{array}{l}\text { Perdas } \\
4 \text { doses } \\
\end{array}$ & $\begin{array}{l}\text { Colheu após } \\
3 \text { e } 4 \text { doses }\end{array}$ \\
\hline$\overline{1}$ & 1 & 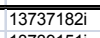 & 53 & $\bar{F}$ & Cripto & $\bar{A}$ & 32,0 & 0 & $\begin{array}{l}\mathrm{C} 10 \\
\end{array}$ & 18 & 0 & 2 & 0 & 0 & 0 & $\overline{0}$ & & & & & 1 & 0 \\
\hline 1 & 2 & 13739151i & 64 & $\mathrm{~F}$ & $\mathrm{VHC}$ & A & 27,8 & 0 & A6 & 11 & 1 & & & & & 1 & 7 & 1 & 1 & 509 & 0 & 0 \\
\hline 1 & 4 & $5127524 \mathrm{~h}$ & 52 & M & VHC & A & 36,3 & 0 & B7 & 12 & 0 & & & & & 1 & & & & & 1 & 0 \\
\hline 1 & 5 & $13738215 \mathrm{~g}$ & 36 & M & $\mathrm{OH}$ & A & 23,2 & 1 & A6 & 11 & 0 & 2 & 1 & 1 & 271 & 0 & 7 & 1 & 1 & $>1000$ & 0 & 1 \\
\hline 1 & 6 & $13741762 \mathrm{~d}$ & 58 & M & VHC & 0 & 28,1 & 0 & A6 & 13 & 1 & 2 & 0 & 0 & 2 & 0 & 8 & 1 & 1 & 103 & 0 & 1 \\
\hline$\frac{1}{1}$ & 7 & $\begin{array}{l}13737451 \mathrm{~g} \\
13723665\end{array}$ & 51 & $M$ & $\mathrm{OH}$ & 0 & 24,4 & 1 & B7 & 11 & 1 & & & & & 1 & 7 & 1 & 0 & 12 & 0 & 0 \\
\hline $\begin{array}{l}1 \\
2\end{array}$ & $\begin{array}{l}8 \\
1\end{array}$ & $\begin{array}{l}1372336655 \\
137320739\end{array}$ & $\begin{array}{l}69 \\
41\end{array}$ & $\begin{array}{l}\mathrm{M} \\
\mathrm{F}\end{array}$ & $\begin{array}{l}\mathrm{VHC} \\
\mathrm{OH}\end{array}$ & $\begin{array}{l}0 \\
0\end{array}$ & $\begin{array}{l}23,9 \\
21,5\end{array}$ & 1 & $\begin{array}{l}\mathrm{A} 6 \\
\mathrm{~A} 6\end{array}$ & $\begin{array}{l}11 \\
11\end{array}$ & $\begin{array}{l}1 \\
1\end{array}$ & & & & & $\begin{array}{l}1 \\
1\end{array}$ & 8 & $\begin{array}{l}1 \\
1\end{array}$ & $\begin{array}{l}1 \\
0\end{array}$ & $\begin{array}{l}646 \\
20\end{array}$ & $\begin{array}{l}0 \\
0\end{array}$ & $\begin{array}{l}0 \\
0\end{array}$ \\
\hline 2 & 2 & $13736518 \mathrm{~b}$ & 45 & M & $\mathrm{OH}$ & 0 & $\begin{array}{l}21,5 \\
20,8\end{array}$ & 1 & $\begin{array}{l}\mathrm{A6} \\
\mathrm{B} 7\end{array}$ & $\begin{array}{l}11 \\
10\end{array}$ & 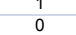 & 2 & 1 & 1 & 162 & 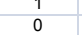 & $\begin{array}{l}6 \\
7\end{array}$ & $\begin{array}{l}1 \\
1\end{array}$ & 1 & $\begin{array}{r}20 \\
380\end{array}$ & 0 & 1 \\
\hline 2 & 3 & $13589891 \mathrm{~h}$ & 25 & $\mathrm{~F}$ & ductopênica & A & 20,5 & 0 & B7 & 14 & 0 & 2 & 1 & 1 & 197 & 0 & 7 & 1 & 1 & $>1000$ & 0 & \\
\hline 2 & 5 & 13752297j & 54 & M & VHC & 0 & 28,4 & 0 & $\mathrm{C} 10$ & 19 & 1 & & & & & 1 & & & & & 1 & 0 \\
\hline 2 & & $13742635 i$ & 44 & M & 0 & 0 & 29,7 & & B7 & 12 & 1 & & & & & 1 & & & & & 1 & 0 \\
\hline 2 & 7 & $13751672 j$ & 54 & M & $\mathrm{OH}$ & A & 26,3 & 0 & $\mathrm{C} 12$ & 22 & 0 & & & & & 1 & & & & & 1 & 0 \\
\hline 2 & 8 & $13757773 \mathrm{~h}$ & 64 & M & VHC & A & 32,8 & 0 & C10 & 13 & 1 & & & & & 1 & & & & & 1 & 0 \\
\hline 3 & 1 & $13758894 \mathrm{c}$ & 59 & $\mathrm{~F}$ & VHC & A & 30,1 & 0 & B8 & 14 & 0 & 2 & 0 & 0 & 0 & 0 & 7 & 0 & 0 & 4 & 0 & 1 \\
\hline 3 & 2 & $13761778 \mathrm{e}$ & 50 & M & $\mathrm{OH}$ & A & 22,7 & 1 & B7 & 12 & 0 & & & & & 1 & 6 & 1 & 0 & 54 & 0 & 0 \\
\hline & 3 & $3215677 \mathrm{k}$ & 60 & $F$ & $\begin{array}{c}\text { CBS } \\
V H C+O H\end{array}$ & B & $\begin{array}{l}23,6 \\
250\end{array}$ & 0 & B8 & 20 & 1 & 2 & 0 & 0 & 0 & 0 & 7 & 0 & 0 & 0 & 0 & 1 \\
\hline$\frac{3}{3}$ & $\begin{array}{l}4 \\
5\end{array}$ & $\begin{array}{l}\text { 13733210d } \\
13758430 \mathrm{~h}\end{array}$ & $\begin{array}{l}44 \\
58\end{array}$ & $\begin{array}{l}M \\
M\end{array}$ & $\begin{array}{l}\mathrm{VHC}+\mathrm{OH} \\
\mathrm{OH}\end{array}$ & $\begin{array}{l}0 \\
0\end{array}$ & $\begin{array}{l}25,9 \\
25,2\end{array}$ & $\begin{array}{l}0 \\
0\end{array}$ & $\begin{array}{l}\text { B9 } \\
\text { C11 }\end{array}$ & $\begin{array}{l}18 \\
18\end{array}$ & $\begin{array}{l}1 \\
1\end{array}$ & 2 & 0 & 0 & 0 & $\begin{array}{l}1 \\
0\end{array}$ & $\begin{array}{l}10 \\
7\end{array}$ & $\begin{array}{l}1 \\
1\end{array}$ & $\begin{array}{l}1 \\
1\end{array}$ & $\begin{array}{l}112 \\
218\end{array}$ & $\begin{array}{l}0 \\
0\end{array}$ & $\begin{array}{l}0 \\
1\end{array}$ \\
\hline 3 & 6 & $13752189 \mathrm{~d}$ & 57 & M & $\mathrm{OH}$ & A & 24,3 & 1 & C12 & 22 & 0 & & & & & 1 & & & & & 1 & 0 \\
\hline 3 & 7 & $13765984 k$ & 53 & M & VHC & A & 24,2 & 0 & B8 & 12 & 1 & & & & & 1 & & & & & 1 & 0 \\
\hline 3 & 8 & $13750477 \mathrm{~g}$ & 57 & M & $\mathrm{OH}$ & 0 & 25,3 & 1 & C10 & 17 & 0 & 2 & 0 & 0 & 0 & 0 & 7 & 0 & 0 & 0 & 0 & 1 \\
\hline $\begin{array}{l}4 \\
4\end{array}$ & $\begin{array}{l}1 \\
2\end{array}$ & $\begin{array}{l}890239900 \mathrm{c} \\
31399398 \mathrm{~b}\end{array}$ & $\begin{array}{l}55 \\
42\end{array}$ & $M$ & $\begin{array}{l}\mathrm{OH} \\
\text { Cripto }\end{array}$ & $\begin{array}{l}O \\
B\end{array}$ & & $\begin{array}{l}1 \\
0\end{array}$ & $\begin{array}{l}\text { B7 } \\
\text { B8 }\end{array}$ & $\begin{array}{l}13 \\
14\end{array}$ & $\begin{array}{l}1 \\
0\end{array}$ & $\begin{array}{l}2 \\
3\end{array}$ & 1 & $\begin{array}{l}0 \\
0\end{array}$ & $\begin{array}{l}80 \\
18\end{array}$ & $\begin{array}{l}0 \\
0\end{array}$ & $\begin{array}{l}7 \\
8\end{array}$ & 1 & 1 & $\begin{array}{l}769 \\
>1000\end{array}$ & 0 & 1 \\
\hline $\begin{array}{l}4 \\
4\end{array}$ & $\begin{array}{l}2 \\
3\end{array}$ & $\begin{array}{l}313993986 \mathrm{~b} \\
1378071 \mathrm{e}\end{array}$ & $\begin{array}{l}42 \\
49\end{array}$ & $\begin{array}{l}M \\
M\end{array}$ & $\begin{array}{c}\text { Cripto } \\
\text { OH }\end{array}$ & O & $\begin{array}{l}25,3 \\
33,0\end{array}$ & 0 & $\begin{array}{l}\text { B8 } \\
\text { B9 }\end{array}$ & $\begin{array}{l}14 \\
16\end{array}$ & 0 & $\begin{array}{l}3 \\
2\end{array}$ & $\begin{array}{l}1 \\
0\end{array}$ & 0 & $\begin{array}{c}18 \\
3\end{array}$ & 0 & $\begin{array}{l}8 \\
7\end{array}$ & $\begin{array}{l}1 \\
1\end{array}$ & $\begin{array}{l}1 \\
0\end{array}$ & $>1000$ & $\begin{array}{l}0 \\
0\end{array}$ & $\begin{array}{l}1 \\
1\end{array}$ \\
\hline 4 & 4 & $13757730 \mathrm{a}$ & 50 & M & $\mathrm{OH}$ & 0 & 32,5 & 0 & $\mathrm{C} 12$ & 23 & 0 & & & & & 1 & & & & & 1 & 0 \\
\hline 4 & 5 & $13762768 \mathrm{c}$ & 33 & M & VHC & 0 & 27,4 & 0 & C11 & 20 & 1 & 2 & 1 & 1 & 149 & 0 & 7 & 1 & 1 & $>1000$ & 0 & 1 \\
\hline $\begin{array}{l}4 \\
4\end{array}$ & 6 & $\begin{array}{l}13764552 j \\
1366788\end{array}$ & 54 & $F$ & $\begin{array}{c}\text { Cripto } \\
H C M+O H\end{array}$ & ○ & $\begin{array}{l}30,1 \\
30,\end{array}$ & 1 & B8 & 11 & 0 & 2 & 1 & 1 & 580 & 1 & 7 & 1 & 1 & $>1000$ & 1 & 0 \\
\hline$\frac{4}{4}$ & 8 & 1301308080 & $\begin{array}{l}46 \\
44\end{array}$ & $\mathrm{~F}$ & $\begin{array}{l}\mathrm{HCM}+\mathrm{OH} \\
\mathrm{VHC}\end{array}$ & $\begin{array}{l}A \\
A\end{array}$ & $\begin{array}{l}30,1 \\
47,9\end{array}$ & 0 & $\begin{array}{l}\text { C10 } \\
\text { C11 }\end{array}$ & $\begin{array}{l}17 \\
19\end{array}$ & 1 & 2 & 1 & 1 & 580 & 1 & 1 & 1 & 1 & $>1000$ & 1 & $\begin{array}{l}1 \\
0\end{array}$ \\
\hline 5 & 1 & $13757423 \mathrm{~b}$ & 24 & $\mathrm{~F}$ & Cripto & A & 23,3 & 0 & B8 & 9 & 1 & & & & & 1 & & & & & 1 & 0 \\
\hline 5 & 2 & $13733137 \mathrm{f}$ & 49 & M & $\mathrm{OH}$ & A & 20,1 & 1 & C10 & 19 & 1 & & & & & 1 & & & & & 1 & 0 \\
\hline $\begin{array}{l}5 \\
5\end{array}$ & 3 & $\begin{array}{l}13747499 c \\
3304754\end{array}$ & 41 & $M$ & $\mathrm{OH}$ & 0 & $\begin{array}{l}27,6 \\
236\end{array}$ & 1 & B7 & 13 & 0 & 3 & 0 & 0 & 2 & 0 & 14 & 1 & 0 & 24 & 0 & 1 \\
\hline 5 & $\begin{array}{l}4 \\
5\end{array}$ & $\begin{array}{l}3304754 i \\
13\end{array}$ & $\begin{array}{l}51 \\
44\end{array}$ & $\mathrm{M}$ & $\mathrm{OH}$ & 0 & $\begin{array}{l}23,6 \\
305\end{array}$ & 1 & $\begin{array}{l}B 9 \\
\text { A5 }\end{array}$ & $\begin{array}{l}14 \\
11\end{array}$ & 1 & 2 & 1 & 0 & 24 & 1 & 7 & 1 & 0 & 33 & 1 & 0 \\
\hline 5 & 6 & $13774220 \mathrm{e}$ & 62 & $\mathrm{~F}$ & Cripto & 0 & 27,7 & 0 & $\begin{array}{l}\text { As } \\
\text { C10 }\end{array}$ & 17 & 0 & 2 & 0 & 0 & 4 & 0 & 6 & 1 & 1 & 461 & 0 & 1 \\
\hline 5 & 7 & 3328112d & 55 & M & $\mathrm{VHC}+\mathrm{OH}$ & 0 & 23,4 & 0 & A6 & 11 & 0 & 2 & 0 & 0 & 0 & 0 & 6 & 0 & 0 & 0 & 0 & 1 \\
\hline 5 & 8 & & 53 & M & 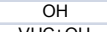 & 0 & & 0 & A6 & 9 & 1 & 2 & 1 & 0 & 25 & & 8 & 1 & 1 & 439 & 0 & 1 \\
\hline$\frac{6}{6}$ & 1 & $2576601 f$ & $\begin{array}{l}44 \\
58\end{array}$ & $M$ & $\begin{array}{l}\mathrm{VHC}+\mathrm{OH} \\
\mathrm{VHC}\end{array}$ & 0 & $\begin{array}{l}30,1 \\
274\end{array}$ & 1 & B7 & 13 & 0 & 2 & 0 & 0 & 0 & 0 & 7 & 0 & 0 & 3 & 0 & 1 \\
\hline $\begin{array}{l}6 \\
6\end{array}$ & $\begin{array}{l}3 \\
4\end{array}$ & $\begin{array}{l}13684522 c \\
13769949\end{array}$ & $\begin{array}{l}58 \\
41\end{array}$ & $\begin{array}{l}\mathrm{M} \\
\mathrm{M}\end{array}$ & $\begin{array}{l}\mathrm{VHC} \\
\mathrm{OH}\end{array}$ & ${ }_{A}^{A}$ & $\begin{array}{l}27,4 \\
28,6\end{array}$ & $\begin{array}{l}0 \\
1\end{array}$ & $\begin{array}{l}\text { A5 } \\
\text { C12 }\end{array}$ & $\begin{array}{c}6 \\
23 \\
23\end{array}$ & $\begin{array}{l}1 \\
0\end{array}$ & 2 & 0 & 0 & 1 & $\begin{array}{l}0 \\
1\end{array}$ & 7 & 1 & 0 & 60 & $\begin{array}{l}0 \\
1\end{array}$ & $\begin{array}{l}1 \\
0\end{array}$ \\
\hline 6 & 5 & $13760196 \mathrm{~h}$ & 65 & M & Cripto & B & 25,3 & 0 & C10 & 16 & 0 & & & & & 1 & & & & & 1 & 0 \\
\hline 6 & 6 & $13604779 \mathrm{j}$ & 61 & $\mathrm{~F}$ & VHC & 0 & 29,6 & 0 & B7 & 9 & 0 & 2 & 0 & 0 & 0 & 0 & & & & & 1 & 0 \\
\hline 6 & 7 & $13732269 \mathrm{~g}$ & 60 & $M$ & VHC & 0 & 30,1 & 1 & A6 & 6 & 1 & 4 & 0 & 0 & 0 & 0 & 10 & 0 & 0 & 0 & 0 & 1 \\
\hline $\begin{array}{l}6 \\
7 \\
7\end{array}$ & 8 & $\begin{array}{l}13700277 a \\
13750878\end{array}$ & $\begin{array}{l}44 \\
46\end{array}$ & $M$ & $\begin{array}{c}\mathrm{OH} \\
\mathrm{VHC+OH}\end{array}$ & A & $\begin{array}{l}37,0 \\
30,4\end{array}$ & $\begin{array}{l}0 \\
0\end{array}$ & $\begin{array}{l}\text { B7 } \\
\text { B8 }\end{array}$ & $\begin{array}{l}12 \\
17\end{array}$ & $\begin{array}{l}1 \\
0\end{array}$ & 3 & 1 & 0 & 18 & 0 & & & & & 1 & 0 \\
\hline 7 & $\begin{array}{l}1 \\
2\end{array}$ & $\begin{array}{l}13750878 \mathrm{a} \\
1371698 \mathrm{c}\end{array}$ & $\begin{array}{l}46 \\
60\end{array}$ & $\mathrm{M}$ & $\begin{array}{l}\mathrm{VHC+OH} \\
\mathrm{VHC}\end{array}$ & $\begin{array}{l}A \\
0\end{array}$ & $\begin{array}{l}30,4 \\
24,9\end{array}$ & 0 & $\begin{array}{c}\text { B8 } \\
\text { C12 }\end{array}$ & $\begin{array}{l}17 \\
19\end{array}$ & $\begin{array}{l}0 \\
0\end{array}$ & & & & & $\frac{1}{1}$ & & & & & $\begin{array}{l}1 \\
1\end{array}$ & 0 \\
\hline 78 & 3 & 137 & 64 & $\mathrm{~F}$ & VHC & A & $\begin{array}{l}24,9 \\
29,7\end{array}$ & 0 & B7 & 11 & 1 & & & & & 1 & & & & & 1 & 0 \\
\hline 7 & 4 & 137 & 54 & M & $\mathrm{OH}$ & A & 36,2 & 0 & $\mathrm{C} 10$ & 20 & 1 & 2 & 0 & 0 & 0 & 0 & 13 & 0 & 0 & 0 & 0 & \\
\hline 7 & 5 & $13771140 \mathrm{~g}$ & 56 & M & HCM & B & 22.5 & 0 & B9 & 18 & 0 & & & 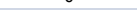 & & 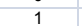 & & & & & 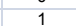 & 0 \\
\hline 7 & 6 & $13752629 b$ & 64 & M & $\mathrm{OH}$ & A & 32,0 & 0 & B7 & 14 & 0 & 5 & 0 & 0 & 0 & 0 & 10 & 0 & 0 & & 0 & 1 \\
\hline & 7 & $13686215 \mathrm{e}$ & 60 & M & 0 & 0 & 23,5 & 0 & A5 & 8 & 1 & & & & & 1 & 25 & 1 & 1 & $>1000$ & 0 & 0 \\
\hline 7 & 8 & 13754109g & 29 & M & CBS & A & 21,4 & 0 & B7 & 16 & 1 & 3 & 0 & 0 & 7 & 0 & 6 & 1 & 0 & 11 & 0 & 1 \\
\hline & & 4007381 & $44^{4}$ & $M$ & $\mathrm{OH}$ & A & 2 & & B8 & & & & & & & & & & & & 1 & \\
\hline
\end{tabular}


Continuação Anexo E

\begin{tabular}{|c|c|c|c|c|c|c|c|c|c|c|c|c|c|c|c|c|c|c|c|c|c|c|}
\hline Bloco & Envelope & RG & Idade & Sexo & Etiologia & TS & IMC & Tabagista & CTP & MELD & $\begin{array}{c}\text { Dose } \\
\text { dobrada }\end{array}$ & $\begin{array}{c}\text { Intervalo entre } \\
3 \text { doses } \\
\text { (meses) }\end{array}$ & $\begin{array}{c}\text { Soroconversão } \\
3 \text { doses } \\
(\geq 10 \mathrm{mll} / \mathrm{ml})\end{array}$ & $\begin{array}{l}\text { Soroconversão } \\
3 \text { doses } \\
(\geq 100 \mathrm{ml} \mid \mathrm{U} / \mathrm{ml})\end{array}$ & $\begin{array}{c}\text { Título após } \\
3 \text { doses }\end{array}$ & $\begin{array}{l}\text { Perdas } \\
3 \text { doses }\end{array}$ & $\begin{array}{l}\text { Intervalo entre } \\
4 \text { doses } 7 \mathrm{~m}\end{array}$ & $\begin{array}{c}\text { Soroconversão } \\
4 \text { doses } \\
(\geq 10 \mathrm{ml} / \mathrm{lml})\end{array}$ & $\begin{array}{l}\text { Soroconversão } \\
4 \text { doses } \\
(\geq 100 \mathrm{mlU} / \mathrm{ml})\end{array}$ & $\begin{array}{c}\text { Titulo após } \\
4 \text { doses }\end{array}$ & \begin{tabular}{|l|} 
Perdas \\
4 doses
\end{tabular} & $\begin{array}{l}\text { Colheu após } \\
3 \mathrm{e} 4 \text { doses }\end{array}$ \\
\hline 8 & 3 & $2396029 \mathrm{~g}$ ou & 68 & M & $\mathrm{OH}$ & 0 & 24,9 & 0 & C11 & 17 & 1 & 2 & 0 & 0 & 0 & 0 & 6 & 1 & 0 & 27 & 0 & 1 \\
\hline 8 & $\begin{array}{l}4 \\
5\end{array}$ & $13766727 \mathrm{~g}$ & & M & Cripto & 0 & 43,0 & 0 & C10 & & 1 & 2 & 1 & 0 & 18 & 0 & 6 & 1 & 0 & 22 & 0 & 1 \\
\hline $\begin{array}{l}8 \\
8\end{array}$ & $\begin{array}{l}5 \\
6\end{array}$ & $\begin{array}{l}\begin{array}{l}216292920 \mathrm{~b} \\
2301540 \mathrm{c}\end{array}\end{array}$ & $\begin{array}{l}49 \\
47\end{array}$ & $\mathrm{M}$ & VHC & A & 34,0 & 0 & A5 & 8 & 1 & 2 & 1 & 0 & 81 & 0 & 6 & 1 & 1 & 605 & 0 & 1 \\
\hline 8 & & $13758437 a$ & 64 & M & $\mathrm{OH}$ & A & $\begin{array}{l}20,6 \\
24,3\end{array}$ & 0 & $\begin{array}{l}\text { Ao } \\
\text { C10 }\end{array}$ & $\begin{array}{l}14 \\
12\end{array}$ & 0 & $\begin{array}{l}2 \\
2\end{array}$ & $\begin{array}{l}1 \\
0\end{array}$ & $\begin{array}{l}0 \\
0\end{array}$ & $\begin{array}{c}42 \\
0\end{array}$ & $\begin{array}{l}0 \\
0\end{array}$ & $\frac{6}{7}$ & 0 & $\begin{array}{l}0 \\
0\end{array}$ & $\frac{89}{4}$ & $\begin{array}{l}0 \\
0 \\
0\end{array}$ & $\frac{1}{1}$ \\
\hline 8 & 8 & $13756336 \mathrm{e}$ & 56 & $\mathrm{~F}$ & VHC & A & 34,1 & 0 & B9 & 17 & 0 & & & & & 1 & 19 & 0 & 0 & 0 & 0 & 0 \\
\hline 9 & 1 & $13733879 \mathrm{~h}$ & 51 & M & $\mathrm{OH}$ & A & 34,6 & 0 & A6 & 11 & 0 & 6 & 0 & 0 & 6 & 0 & 10 & 0 & 0 & 9 & 0 & 1 \\
\hline 9 & 3 & $13685051 \mathrm{j}$ & 53 & M & Cripto & A & 25,5 & 0 & B9 & 19 & 0 & & & & & 1 & & & & & 1 & 0 \\
\hline $\begin{array}{l}9 \\
9\end{array}$ & $\begin{array}{l}4 \\
5\end{array}$ & $\begin{array}{l}13783633 d \mathrm{~d} \\
13783448 \mathrm{q}\end{array}$ & 66 & $\begin{array}{l}M \\
\text { F }\end{array}$ & $\begin{array}{l}\mathrm{OH} \\
\mathrm{VHC}\end{array}$ & $\stackrel{0}{A}$ & $\begin{array}{l}24,0 \\
230\end{array}$ & $\begin{array}{l}0 \\
0\end{array}$ & B9 & 15 & 0 & 4 & 0 & 0 & 2 & 0 & & & & & 1 & 0 \\
\hline 9 & 6 & $13783642 b$ & $\begin{array}{l}04 \\
46\end{array}$ & $\mathrm{~F}$ & $\begin{array}{l}\text { VHe } \\
\text { Cripto }\end{array}$ & $A B$ & $\begin{array}{l}23,0 \\
31,2\end{array}$ & 0 & $\begin{array}{l}C 10 \\
B 9\end{array}$ & $\begin{array}{l}14 \\
10\end{array}$ & $\begin{array}{l}1 \\
1\end{array}$ & & & & & 1 & 12 & 0 & 0 & 0 & 1 & $\begin{array}{l}0 \\
0 \\
0\end{array}$ \\
\hline 9 & 7 & $13759325 \mathrm{e}$ & 39 & M & $\mathrm{OH}$ & A & 46,2 & 0 & $\begin{array}{l}\text { B9 } \\
\text { B9 }\end{array}$ & 17 & 1 & 2 & 0 & 0 & 0 & 0 & 12 & 0 & 0 & 4 & 0 & 1 \\
\hline 10 & 1 & $13736485 j$ & 55 & $\mathrm{~F}$ & Cripto & 0 & 25,4 & 0 & C10 & 21 & 0 & 2 & 0 & 0 & 0 & 0 & & & & & 1 & 0 \\
\hline & 2 & $\begin{array}{l}24968239 \\
\end{array}$ & 58 & $F$ & Cripto & 0 & 49,4 & 0 & A6 & 8 & 0 & 6 & 0 & 0 & 0 & 0 & 12 & 0 & 0 & 3 & 0 & 1 \\
\hline $\begin{array}{l}10 \\
10\end{array}$ & 3 & $\begin{array}{l}13708649 \mathrm{~g} \\
13777876\end{array}$ & 56 & $M$ & $\begin{array}{l}\mathrm{OH} \\
\mathrm{VHC}\end{array}$ & 0 & $\begin{array}{l}34,8 \\
356\end{array}$ & 0 & A5 & 10 & 1 & & & & & 1 & 12 & 1 & 0 & 16 & 0 & 0 \\
\hline & $\begin{array}{l}6 \\
7\end{array}$ & $13699478 \mathrm{j}$ & $\begin{array}{l}42 \\
42\end{array}$ & M & $\mathrm{VHC}+\mathrm{OH}$ & A & $\begin{array}{l}35,6 \\
26,6\end{array}$ & 1 & $\begin{array}{l}\mathrm{Bg} \\
\mathrm{C} 10\end{array}$ & $\begin{array}{l}21 \\
11\end{array}$ & 0 & 2 & 1 & 1 & 183 & 0 & 7 & 1 & 1 & $>1000$ & 0 & 1 \\
\hline 10 & 8 & $13700194 b$ & 59 & M & $\mathrm{OH}$ & A & 21,0 & 0 & B7 & 12 & 1 & & & & & 1 & 7 & 0 & 0 & 4 & 0 & 0 \\
\hline 11 & 1 & $13746561 j$ & 50 & M & CBP & 0 & 17,5 & 0 & B7 & 14 & 0 & & & & & 1 & & & & & 1 & 0 \\
\hline $\begin{array}{l}\frac{11}{11} \\
\end{array}$ & 2 & $\begin{array}{l}13530672 \mathrm{~h} \\
13772320\end{array}$ & 49 & M & $\mathrm{VHC}+\mathrm{OH}$ & 0 & 24,1 & 1 & B7 & 11 & 1 & 8 & 0 & 0 & 0 & 0 & & 1 & r & & 1 & 0 \\
\hline 11 & $\begin{array}{l}3 \\
4\end{array}$ & $\begin{array}{l}137724349 \mathrm{~g} \\
13732991 \mathrm{k}\end{array}$ & $\begin{array}{l}55 \\
57\end{array}$ & F & $\begin{array}{l}\text { VHC } \\
\mathrm{OH}\end{array}$ & $\begin{array}{c}0 \\
A B\end{array}$ & $\begin{array}{l}26,2 \\
247\end{array}$ & $\begin{array}{l}0 \\
0\end{array}$ & $\begin{array}{l}\text { C10 } \\
\text { B9 }\end{array}$ & $\begin{array}{l}15 \\
16\end{array}$ & $\begin{array}{l}0 \\
1\end{array}$ & $\begin{array}{l}4 \\
2\end{array}$ & $\begin{array}{l}1 \\
1\end{array}$ & $\begin{array}{l}0 \\
0\end{array}$ & 42 & $\begin{array}{l}0 \\
0 \\
0\end{array}$ & 10 & 1 & 0 & $\begin{array}{r}25 \\
453\end{array}$ & $\begin{array}{l}0 \\
0\end{array}$ & 1 \\
\hline 11 & 5 & $13737466 \mathrm{j}$ & $\begin{array}{l}59 \\
59\end{array}$ & $\mathrm{~F}$ & Cripto & $\begin{array}{l}A B \\
0\end{array}$ & 32,8 & 0 & $\begin{array}{l}\text { B9 } \\
\text { B7 }\end{array}$ & 6 & 0 & 17 & 1 & 0 & $\begin{array}{l}12 \\
19\end{array}$ & 0 & $r$ & 1 & 1 & 453 & 1 & 0 \\
\hline 11 & 6 & 3384793e & 55 & $F$ & VHC & B & 30,1 & 0 & C10 & 17 & 1 & 2 & 0 & 0 & 0 & 0 & 9 & 0 & 0 & 9 & 0 & 1 \\
\hline $\begin{array}{l}11 \\
11\end{array}$ & 7 & $2805575 \mathrm{~K}$ & 62 & M & $\mathrm{OH}$ & A & 28,0 & 0 & C10 & 18 & 0 & 2 & 0 & 0 & 0 & 0 & 7 & 0 & 0 & 0 & 0 & 1 \\
\hline $\begin{array}{l}11 \\
12\end{array}$ & 8 & $\begin{array}{l}13727507 \mathrm{~g} \\
13759121\end{array}$ & 40 & $M$ & OH & B & $\begin{array}{l}31,8 \\
257\end{array}$ & 0 & B9 & 20 & 1 & 2 & 0 & 0 & 3 & 0 & 8 & 1 & 1 & 510 & 0 & 1 \\
\hline $\begin{array}{l}12 \\
12\end{array}$ & $\begin{array}{l}1 \\
2\end{array}$ & $\begin{array}{l}137592121 \mathrm{f} \\
6023457 \mathrm{~h}\end{array}$ & $\begin{array}{l}45 \\
29\end{array}$ & $\begin{array}{l}M \\
M\end{array}$ & $\begin{array}{l}\text { Cripto } \\
\text { CBS }\end{array}$ & $\begin{array}{l}\text { A } \\
\text { B }\end{array}$ & $\begin{array}{l}25,7 \\
21,3\end{array}$ & $\begin{array}{l}0 \\
0\end{array}$ & $\begin{array}{l}\text { B9 } \\
\text { C10 }\end{array}$ & $\begin{array}{l}16 \\
20\end{array}$ & $\begin{array}{l}1 \\
1\end{array}$ & $\begin{array}{l}2 \\
5\end{array}$ & $\begin{array}{l}0 \\
0\end{array}$ & $\begin{array}{l}0 \\
0\end{array}$ & $\begin{array}{l}2 \\
0\end{array}$ & $\begin{array}{l}0 \\
0\end{array}$ & 7 & 1 & 0 & 56 & $\begin{array}{l}0 \\
1\end{array}$ & $\begin{array}{l}1 \\
0\end{array}$ \\
\hline 12 & 3 & $13747245 \mathrm{~h}$ & 31 & $\mathrm{~F}$ & Cripto & 0 & 23,5 & 0 & A5 & 6 & 0 & 2 & 1 & 1 & $>1000$ & 0 & 7 & 1 & 1 & $>1000$ & 0 & 1 \\
\hline 12 & 4 & 137079 & 29 & $\mathrm{~F}$ & $\mathrm{VHC}+\mathrm{HAI}$ & A & 34,9 & 0 & A5 & 7 & 0 & 2 & 0 & 0 & 0 & 0 & 8 & 1 & 0 & 18 & 0 & 1 \\
\hline $\begin{array}{l}12 \\
12\end{array}$ & 5 & $\begin{array}{l}13768702 \mathrm{~h} \\
13724863\end{array}$ & 50 & $F$ & CBP & A & 25,3 & 1 & B8 & 20 & 1 & 2 & 0 & 0 & 1 & 0 & & & & & 1 & 0 \\
\hline $\begin{array}{l}12 \\
12\end{array}$ & $\begin{array}{l}6 \\
7\end{array}$ & $\begin{array}{l}337746863 c \\
13568162\end{array}$ & $\begin{array}{l}48 \\
24\end{array}$ & $\begin{array}{l}\mathrm{M} \\
\mathrm{F}\end{array}$ & $\begin{array}{l}\mathrm{OH} \\
\mathrm{CBS}\end{array}$ & B & $\begin{array}{l}27,4 \\
24,1\end{array}$ & 0 & $\begin{array}{l}\text { C10 } \\
\text {. }\end{array}$ & 15 & 1 & 2 & 1 & 0 & 10 & 1 & 8 & 1 & 1 & 257 & 1 & 0 \\
\hline 12 & 8 & 137626759 & $\begin{array}{l}24 \\
51\end{array}$ & M & $\begin{array}{c}{ }^{C} \text { OS } \\
\mathrm{OH}\end{array}$ & A & $\begin{array}{l}24,1 \\
28,6\end{array}$ & 1 & $\begin{array}{l}\text { A5 } \\
\text { B8 }\end{array}$ & & 0 & & & & 10 & 1 & 8 & 1 & 1 & 201 & 1 & $\begin{array}{l}1 \\
0\end{array}$ \\
\hline 13 & 1 & $13625207 \mathrm{C}$ & 68 & M & VHC & A & 18,8 & 0 & C10 & 14 & 1 & & & & & 1 & & & & & 1 & 0 \\
\hline 13 & 2 & $13789027 \mathrm{~h}$ & 45 & M & $\mathrm{VHC}+\mathrm{OH}$ & B & 20.9 & 1 & B8 & 15 & 0 & 2 & 0 & 0 & 6 & 0 & 7 & 1 & 1 & 104 & 0 & 1 \\
\hline 13 & 3 & $13731255 \mathrm{~h}$ & 61 & M & $\mathrm{OH}$ & A & 27,3 & 0 & ${ }_{A 6}$ & 11 & 1 & 2 & 1 & 0 & 36 & 0 & 7 & 1 & 1 & 753 & 0 & 1 \\
\hline 13 & 5 & $13722641 \mathrm{k}$ & 56 & $\mathrm{~F}$ & VHC & B & $\begin{array}{l}23,7 \\
23\end{array}$ & 0 & B7 & 10 & 0 & 2 & 0 & 0 & 0 & 0 & 7 & 0 & 0 & 1 & 0 & 1 \\
\hline 13 & 6 & $3266719 \mathrm{j}$ & 34 & $\mathrm{~F}$ & Budd & 0 & 31,1 & 0 & B9 & 12 & 0 & & & & & 1 & 8 & 1 & 0 & 14 & 0 & 0 \\
\hline 13 & 7 & $13751102 \mathrm{~g}$ & 31 & M & $\mathrm{OH}$ & 0 & 23,0 & & B9 & 16 & 0 & 2 & 0 & 0 & 3 & 0 & 7 & 1 & 1 & 232 & 0 & 1 \\
\hline 13 & 8 & 135394 & 56 & M & VHC & A & 24,0 & 1 & A5 & 7 & 1 & & & & & 1 & & & & & 1 & 0 \\
\hline $\begin{array}{l}14 \\
14 \\
\end{array}$ & 1 & $\begin{array}{l}3388110 \mathrm{c} \\
13656792\end{array}$ & 38 & $F$ & Budd & A & 22,2 & 0 & B7 & 11 & 1 & 2 & 1 & 1 & 225 & 0 & 8 & 1 & 1 & $>1000$ & 0 & 1 \\
\hline $\begin{array}{l}14 \\
14\end{array}$ & 2 & $\begin{array}{l}13665972 a \\
5255555 i\end{array}$ & 65 & M & $\begin{array}{l}\mathrm{OH} \\
\mathrm{VHC}\end{array}$ & A & $\begin{array}{l}22,7 \\
33,8\end{array}$ & 0 & $\begin{array}{l}\text { B8 } \\
\text { A6 }\end{array}$ & 7 & 0 & 2 & 0 & 0 & 7 & 0 & 11 & 1 & 1 & $\begin{array}{l}224 \\
974\end{array}$ & $\begin{array}{l}0 \\
0 \\
0\end{array}$ & 1 \\
\hline 14 & 4 & $\begin{array}{l}52555575 \mathrm{j} \\
13475009 \mathrm{~d}\end{array}$ & 58 & F & $\begin{array}{l}\text { VHC } \\
\text { HAI }\end{array}$ & A & $\begin{array}{l}33,8 \\
22,4\end{array}$ & $\begin{array}{l}0 \\
0 \\
0\end{array}$ & $\begin{array}{l}\mathrm{A} 6 \\
\mathrm{Bg}\end{array}$ & $\begin{array}{l}9 \\
12\end{array}$ & $\begin{array}{l}1 \\
0\end{array}$ & 3 & $\begin{array}{l}0 \\
0\end{array}$ & $\begin{array}{l}0 \\
0 \\
0\end{array}$ & $\begin{array}{l}0 \\
0 \\
0\end{array}$ & $\begin{array}{l}0 \\
0\end{array}$ & $\begin{array}{l}7 \\
10\end{array}$ & $\begin{array}{l}1 \\
0\end{array}$ & $\begin{array}{l}1 \\
0\end{array}$ & 974 & $\begin{array}{l}0 \\
0 \\
0\end{array}$ & 1 \\
\hline 14 & $\begin{array}{l}4 \\
5\end{array}$ & $13720305 \mathrm{~h}$ & 63 & M & $\begin{array}{l}\text { RAA } \\
\text { VHC }\end{array}$ & B & $\begin{array}{l}2,4,4 \\
301\end{array}$ & 0 & $C_{10}$ & 18 & 0 & 2 & 0 & 0 & 0 & 0 & 7 & 0 & 0 & $\begin{array}{lll}2 & \end{array}$ & 0 & 1 \\
\hline 14 & 6 & 13596 & 63 & $\mathrm{~F}$ & 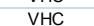 & 0 & 25.5 & 0 & C11 & 11 & 0 & 2 & 1 & 1 & 558 & 0 & 7 & 1 & 1 & $>1000$ & 0 & 1 \\
\hline 14 & 7 & 2811466 & 51 & M & $\mathrm{VHC}+\mathrm{OH}$ & A & 26.4 & 0 & B8 & 11 & 1 & 3 & 1 & 1 & 421 & 0 & 8 & 1 & 1 & $>1000$ & 0 & 1 \\
\hline 14 & 8 & $13740832 c$ & 62 & M & $\mathrm{OH}$ & $A B$ & 35,2 & 0 & B7 & 16 & 1 & 2 & 0 & 0 & 0 & 0 & 15 & 0 & 0 & 0 & 0 & 1 \\
\hline 15 & 1 & 137855 & 40 & M & $\mathrm{OH}$ & A & 24,2 & 0 & B8 & 19 & 1 & 2 & 0 & 0 & 7 & 0 & 7 & 1 & 1 & 233 & 0 & 1 \\
\hline 15 & 3 & 13794482i & 47 & M & Or & 0 & 28,7 & & B9 & 17 & 0 & 3 & 0 & 0 & 0 & 0 & 7 & 1 & 1 & 220 & 0 & 1 \\
\hline 15 & 4 & 321896 & 62 & M & 0 & A & 27,3 & 0 & B7 & 11 & 0 & 2 & 0 & 0 & 1 & 0 & 7 & 0 & 0 & 3 & 0 & 1 \\
\hline $\begin{array}{l}15 \\
15 \\
15\end{array}$ & 5 & $13707891 \mathrm{~h}$ & 26 & M & Cripto & 0 & 21,5 & 0 & A6 & 14 & 1 & 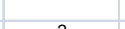 & & & & 1 & 8 & 1 & 1 & 316 & 0 & 0 \\
\hline $\begin{array}{l}15 \\
15\end{array}$ & $\begin{array}{l}6 \\
7\end{array}$ & $\begin{array}{l}13794552 \mathrm{c} \\
13654638 \mathrm{~h}\end{array}$ & $\begin{array}{l}61 \\
53\end{array}$ & $\begin{array}{l}\mathrm{M} \\
\mathrm{F}\end{array}$ & $\begin{array}{l}\text { VHC+OH } \\
\text { Cripto }\end{array}$ & $\begin{array}{l}\mathrm{O} \\
\mathrm{A}\end{array}$ & $\begin{array}{l}30,1 \\
23,7\end{array}$ & $\begin{array}{l}1 \\
0\end{array}$ & $\begin{array}{l}\text { C10 } \\
\text { B9 }\end{array}$ & $\begin{array}{l}18 \\
14\end{array}$ & $\begin{array}{l}0 \\
1\end{array}$ & 2 & $\begin{array}{l}0 \\
1\end{array}$ & $\begin{array}{l}0 \\
0\end{array}$ & $\begin{array}{c}0 \\
53 \\
53\end{array}$ & $\begin{array}{l}0 \\
0\end{array}$ & & & & & 1 & 0 \\
\hline & & & & & & & & & & & & & & & & & & & & & & \\
\hline
\end{tabular}


Continuação Anexo E

\begin{tabular}{|c|c|c|c|c|c|c|c|c|c|c|c|c|c|c|c|c|c|c|c|c|c|c|}
\hline Bloco & Envelope & RG & Idade & Sexo & Etiologia & TS & IMC & Tabagista & CTP & MELD & $\begin{array}{l}\text { Dose } \\
\text { dobrada }\end{array}$ & $\begin{array}{c}\text { Intervalo entre } \\
3 \text { doses } \\
\text { (meses) }\end{array}$ & $\begin{array}{c}\text { Soroconversão } \\
3 \text { doses } \\
(\geq 10 \mathrm{mll} / \mathrm{ml})\end{array}$ & $\begin{array}{l}\text { Soroconversão } \\
3 \text { doses } \\
(\geq 100 \mathrm{ml} / \mathrm{m} / \mathrm{ml})\end{array}$ & $\begin{array}{l}\text { Titulo após } \\
3 \text { doses }\end{array}$ & $\begin{array}{l}\text { Perdas } \\
3 \text { doses }\end{array}$ & $\begin{array}{l}\text { Intervalo entre } \\
4 \text { doses } 7 \mathrm{~m}\end{array}$ & $\begin{array}{c}\text { Soroconversão } \\
4 \text { doses } \\
(\geq 10 \mathrm{ml} / \mathrm{l} / \mathrm{ml})\end{array}$ & $\begin{array}{l}\text { Soroconversão } \\
4 \text { doses } \\
(\geq 100 \mathrm{~m} \mid \mathrm{U} / \mathrm{ml})\end{array}$ & $\begin{array}{c}\text { Titulo após } \\
4 \text { doses }\end{array}$ & $\begin{array}{l}\text { Perdas } \\
4 \text { doses }\end{array}$ & $\begin{array}{l}\text { Colheu após } \\
3 \text { e } 4 \text { doses }\end{array}$ \\
\hline 15 & 8 & $13682870 \mathrm{j}$ & 59 & M & $\mathrm{OH}$ & A & 25,8 & 1 & A5 & 7 & 0 & & & & & 1 & 7 & 0 & 0 & 3 & 0 & 0 \\
\hline 16 & 1 & 137887111 & 39 & $\mathrm{~F}$ & $\mathrm{OH}$ & 0 & 24,7 & & $\mathrm{C} 10$ & 16 & 0 & 2 & 1 & 1 & 349 & 0 & 8 & 1 & 1 & $>1000$ & 0 & 1 \\
\hline 16 & 2 & 13796652k & 40 & M & $\mathrm{VHC}+\mathrm{OH}$ & A & 28,7 & & B7 & 10 & 0 & & & & & 1 & & & & & 1 & 0 \\
\hline $\begin{array}{l}16 \\
16 \\
16\end{array}$ & 3 & $\begin{array}{l}13728196 c \\
135606\end{array}$ & 68 & M & $\mathrm{OH}$ & 0 & 24,1 & 0 & $\begin{array}{l}B 7 \\
{ }^{2}\end{array}$ & 12 & 0 & 2 & 0 & 0 & 0 & 0 & 7 & 1 & 0 & 36 & 0 & 1 \\
\hline $\begin{array}{l}16 \\
16 \\
16\end{array}$ & $\begin{array}{l}5 \\
6\end{array}$ & $\begin{array}{l}135600666 \\
13743868 f\end{array}$ & $\begin{array}{l}67 \\
62\end{array}$ & $\begin{array}{l}\mathrm{F} \\
\mathrm{F}\end{array}$ & $\begin{array}{l}\text { VHC } \\
\text { CBS }\end{array}$ & $\begin{array}{l}\mathrm{A} \\
\mathrm{O}\end{array}$ & $\begin{array}{l}28,4 \\
21,2\end{array}$ & $\begin{array}{l}0 \\
0\end{array}$ & $\begin{array}{l}\text { A5 } \\
\text { B8 }\end{array}$ & $\begin{array}{c}6 \\
16\end{array}$ & $\begin{array}{l}1 \\
1\end{array}$ & 2 & & & 317 & $\begin{array}{l}0 \\
1\end{array}$ & 7 & 1 & & $>1000$ & $\begin{array}{l}0 \\
1\end{array}$ & $\begin{array}{l}1 \\
0\end{array}$ \\
\hline 16 & 7 & $13734292 f$ & 46 & M & VHC & A & 32,7 & 0 & $\begin{array}{l}\text { Do } \\
\text { B8 }\end{array}$ & 16 & 1 & & & & & 1 & & & & & 1 & 0 \\
\hline 16 & 8 & $13760222 \mathrm{~g}$ & 53 & M & $\mathrm{OH}$ & B & 33,1 & 0 & B7 & 9 & 0 & & & & & 1 & & & & & 1 & 0 \\
\hline $\begin{array}{l}17 \\
17\end{array}$ & $\begin{array}{l}3 \\
4 \\
4\end{array}$ & $\begin{array}{l}13575374 \mathrm{~b} \\
13696726\end{array}$ & 52 & M & $\begin{array}{l}\text { VHC } \\
V H C\end{array}$ & $\begin{array}{l}0 \\
0\end{array}$ & $\begin{array}{l}26,9 \\
21,9\end{array}$ & 0 & B8 & 15 & 1 & 3 & 1 & 1 & 980 & 0 & & & & & 1 & 0 \\
\hline $\begin{array}{l}17 \\
17\end{array}$ & 4 & $\begin{array}{l}13696726 \mathrm{~h} \\
13668201\end{array}$ & 41 & $F$ & $\begin{array}{l}\text { VHC } \\
V H C\end{array}$ & O & $\begin{array}{l}21,9 \\
297\end{array}$ & 0 & $\begin{array}{l}\text { B7 } \\
\text { B7 }\end{array}$ & 13 & 0 & 2 & 0 & 0 & 0 & 1 & 7 & 1 & 1 & $>1000$ & 0 & 0 \\
\hline $\begin{array}{l}17 \\
17\end{array}$ & $\begin{array}{l}6 \\
7\end{array}$ & $\begin{array}{l}\text { 163668200k } \\
3007052 \mathrm{a}\end{array}$ & $\begin{array}{l}53 \\
53\end{array}$ & $\begin{array}{l}\mathrm{M} \\
\mathrm{F}\end{array}$ & $\begin{array}{l}\text { VHC } \\
\text { VHC }\end{array}$ & $\begin{array}{l}\text { A } \\
\text { A }\end{array}$ & 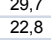 & $\begin{array}{l}0 \\
0\end{array}$ & $\begin{array}{l}\mathrm{B} 7 \\
\mathrm{C} 12\end{array}$ & $\begin{array}{l}11 \\
25\end{array}$ & $\begin{array}{l}1 \\
1\end{array}$ & 2 & 0 & 0 & 0 & $\begin{array}{l}0 \\
1\end{array}$ & 6 & 0 & 0 & 1 & $\begin{array}{l}0 \\
1\end{array}$ & $\begin{array}{l}1 \\
0\end{array}$ \\
\hline 17 & 8 & 33550651 & 41 & $\mathrm{~F}$ & CBS & A & & 0 & C11 & 26 & 0 & 3 & 1 & 0 & 18 & 0 & 8 & 1 & 0 & 43 & 0 & 1 \\
\hline 18 & 2 & 13800473a & 60 & $F$ & Cripto & 0 & 22,1 & & C11 & 17 & 1 & 3 & 0 & 0 & 8 & 0 & & & & & 1 & 0 \\
\hline 18 & 3 & 13608993d & 66 & M & $\mathrm{OH}$ & 0 & 23,7 & 1 & A6 & 18 & 0 & 2 & 0 & 0 & 0 & 0 & & & & & 1 & 0 \\
\hline $\begin{array}{l}18 \\
18\end{array}$ & $\begin{array}{l}4 \\
5\end{array}$ & $\begin{array}{l}137954344 \\
13700572 \mathrm{e}\end{array}$ & $\begin{array}{l}50 \\
54\end{array}$ & $\begin{array}{l}\mathrm{F} \\
\mathrm{F}\end{array}$ & $\begin{array}{l}\text { CBS } \\
\text { VHC }\end{array}$ & A & 26,3 & $\begin{array}{l}0 \\
0\end{array}$ & $\begin{array}{l}B 7 \\
B 8\end{array}$ & 15 & $\begin{array}{l}1 \\
0\end{array}$ & & & & & 1 & & & & & 1 & 0 \\
\hline $\begin{array}{l}18 \\
18\end{array}$ & 6 & $13644442 c$ & 58 & $\mathrm{~F}$ & Cripto & A & $\begin{array}{l}20,5 \\
25,2\end{array}$ & & C10 & 13 & 1 & 3 & 0 & 0 & 1 & 0 & 8 & 0 & 0 & 2 & 0 & 1 \\
\hline 18 & 7 & $13717171 \mathrm{C}$ & 59 & M & $\mathrm{OH}$ & A & 23,1 & 1 & A6 & 15 & 0 & 2 & 0 & 0 & 2 & 0 & & & & & 1 & 0 \\
\hline 18 & 8 & 13671523a & 54 & M & VHC & A & 31,9 & 0 & C12 & 18 & 0 & & & & & 1 & & & & & 1 & 0 \\
\hline $\begin{array}{l}19 \\
19\end{array}$ & 1 & $\begin{array}{l}13725318 \mathrm{j} \\
366379\end{array}$ & 59 & $M$ & $\mathrm{HCM}+\mathrm{OH}$ & A & $\begin{array}{l}24,8 \\
326\end{array}$ & 1 & A6 & 15 & 0 & 12 & 1 & 0 & 37 & 0 & 13 & 1 & 1 & & 1 & 0 \\
\hline $\begin{array}{l}19 \\
19\end{array}$ & $\begin{array}{l}2 \\
4\end{array}$ & $\begin{array}{l}33666379 a \\
1347461 h\end{array}$ & $\begin{array}{l}45 \\
59\end{array}$ & $\begin{array}{l}M \\
M\end{array}$ & $\begin{array}{l}\text { VHC } \\
\text { VHC }\end{array}$ & ${ }_{A}^{A}$ & $\begin{array}{l}32,6 \\
37,2\end{array}$ & $\begin{array}{l}0 \\
0\end{array}$ & $\begin{array}{l}\mathrm{A} 5 \\
\mathrm{~A} 6\end{array}$ & $\begin{array}{c}9 \\
10\end{array}$ & $\begin{array}{l}1 \\
1\end{array}$ & $\begin{array}{l}3 \\
3\end{array}$ & $\begin{array}{l}1 \\
0\end{array}$ & $\begin{array}{l}1 \\
0\end{array}$ & $\begin{array}{l}162 \\
0\end{array}$ & $\begin{array}{l}0 \\
0\end{array}$ & $\begin{array}{c}13 \\
8\end{array}$ & $\begin{array}{l}1 \\
0\end{array}$ & $\begin{array}{l}1 \\
0\end{array}$ & 462 & $\begin{array}{l}0 \\
0 \\
0\end{array}$ & $\begin{array}{l}1 \\
1\end{array}$ \\
\hline 19 & 5 & $13731259 \mathrm{~d}$ & 43 & M & VHC & A & 31,5 & 0 & B9 & 19 & 0 & 6 & 1 & 0 & 79 & 0 & & & & & 1 & 0 \\
\hline 19 & 6 & $13735684 \mathrm{~h}$ & 64 & $\mathrm{~F}$ & $\mathrm{OH}$ & A & 25,0 & 0 & B9 & 15 & 0 & 14 & 0 & 0 & 5 & 0 & & & & & 1 & 0 \\
\hline $\begin{array}{l}19 \\
20\end{array}$ & 7 & 13672193b & 60 & $F$ & VHC & A & $\begin{array}{l}25,8 \\
274\end{array}$ & 1 & B9 & 16 & 1 & & & & & 1 & & & & & 1 & 0 \\
\hline $\begin{array}{l}20 \\
20 \\
20\end{array}$ & 1 & $\begin{array}{l}13754180 \mathrm{c} \\
13721091\end{array}$ & $\begin{array}{l}52 \\
53\end{array}$ & $\begin{array}{l}M \\
M\end{array}$ & $\begin{array}{l}\mathrm{OH} \\
\text { Cripto }\end{array}$ & O & $\begin{array}{l}27,4 \\
34,8\end{array}$ & 0 & $\begin{array}{l}B 8 \\
A 5\end{array}$ & $\begin{array}{l}15 \\
8\end{array}$ & 0 & & & & & 1 & $\begin{array}{l}16 \\
12\end{array}$ & 0 & 0 & $\begin{array}{c}4 \\
557\end{array}$ & $\begin{array}{l}0 \\
0 \\
0\end{array}$ & 0 \\
\hline 20 & 3 & $13651444 j$ & 25 & $\mathrm{~F}$ & $\mathrm{HAl}$ & A & $\begin{array}{r}24,6 \\
24,6\end{array}$ & 0 & A6 & 11 & 0 & 2 & 1 & 1 & $>1000$ & 0 & 7 & 1 & 1 & $>>1000$ & 0 & 1 \\
\hline 20 & 4 & $13710095 j$ & 69 & M & $\mathrm{VHC}+\mathrm{OH}$ & A & 35,5 & 0 & B7 & 12 & 1 & 2 & 1 & 1 & 159 & 0 & & & & & 1 & 0 \\
\hline 20 & 6 & $5267396 f$ & 69 & $F$ & Nash & A & 22,5 & 0 & C10 & 18 & 1 & & & & & 1 & & & & & 1 & 0 \\
\hline $\begin{array}{l}20 \\
20\end{array}$ & 7 & $\begin{array}{l}13737309 \mathrm{~g} \\
1179087\end{array}$ & $\begin{array}{l}48 \\
50\end{array}$ & $M$ & $\begin{array}{l}\mathrm{OH} \\
\mathrm{VHC}\end{array}$ & O & 20,3 & 0 & B8 & 17 & 0 & 2 & 0 & 0 & 0 & 0 & & & & & 1 & 0 \\
\hline 21 & $\begin{array}{l}8 \\
1\end{array}$ & $\begin{array}{l}137908720 \\
13751104\end{array}$ & 50 & M & $\begin{array}{l}\text { VHC } \\
\text { OH }\end{array}$ & A & & 0 & $\begin{array}{l}\text { B8 } \\
\text { B7 }\end{array}$ & $\begin{array}{l}10 \\
13\end{array}$ & 1 & 2 & 1 & 0 & 26 & 1 & 6 & 1 & 1 & $>1000$ & 1 & $\begin{array}{l}0 \\
1\end{array}$ \\
\hline 21 & 2 & $2358304 i$ & 51 & M & $\mathrm{OH}$ & A & $\begin{array}{l}20,1 \\
23,8\end{array}$ & 1 & A6 & 11 & 1 & 3 & 0 & 0 & 0 & 0 & 7 & 0 & 0 & 1 & 0 & $\begin{array}{l}1 \\
1\end{array}$ \\
\hline 21 & 3 & $13753670 \mathrm{~b}$ & 50 & M & $\mathrm{OH}$ & B & 27,4 & 1 & B7 & 13 & 1 & 2 & 0 & 0 & 9 & 0 & 7 & 1 & 1 & 258 & 0 & 1 \\
\hline 21 & 4 & $3177515 \mathrm{~g}$ & 59 & M & $\mathrm{OH}$ & B & 28,0 & 0 & B7 & 7 & 0 & 2 & 1 & 0 & 71 & 0 & 7 & 1 & 1 & $>1000$ & 0 & 1 \\
\hline 21 & 5 & 13698253a & 64 & $\mathrm{~F}$ & VHC & B & 22,7 & 0 & A6 & 11 & 0 & 2 & 0 & 0 & 0 & 0 & & & & & 1 & 0 \\
\hline 21 & 6 & 13799407c & 60 & M & $\mathrm{OH}$ & B & 22,1 & 1 & A5 & 10 & 0 & & & & & 1 & & & & & 1 & 0 \\
\hline 21 & & $13651241 j$ & 64 & $\mathrm{~F}$ & VHC & B & 23,5 & 0 & B8 & 12 & 0 & & & & & 1 & & & & & 1 & 0 \\
\hline 21 & 8 & 3023056e & 29 & & CBS & 0 & 24,1 & 0 & B7 & 16 & 1 & & & & & 1 & 8 & 1 & 1 & 113 & 0 & 0 \\
\hline $\begin{array}{l}22 \\
22\end{array}$ & 1 & 13629370i & 41 & M & O & 0 & 23,7 & 1 & B7 & 14 & 1 & & & & & 1 & & & & & 1 & 0 \\
\hline $\begin{array}{l}22 \\
22\end{array}$ & 2 & $\begin{array}{l}3392702 \mathrm{e} \\
174843\end{array}$ & 53 & $\begin{array}{l}M \\
\text { F }\end{array}$ & $\begin{array}{l}\text { Nash } \\
\text { VHC }\end{array}$ & $\begin{array}{l}0 \\
B\end{array}$ & $\begin{array}{l}26,4 \\
27,6\end{array}$ & 0 & B8 & 12 & 1 & 2 & 0 & 0 & & 1 & 7 & 1 & 1 & $>1000$ & 0 & 0 \\
\hline $\begin{array}{l}22 \\
22 \\
22\end{array}$ & 3 & $\begin{array}{l}13748437 \mathrm{~g} \\
13690255\end{array}$ & 66 & $F$ & $\begin{array}{c}\mathrm{VHC} \\
\mathrm{VHC}+\mathrm{OH}\end{array}$ & B & $\begin{array}{l}27,6 \\
24,8\end{array}$ & 0 & $\begin{array}{l}\text { B7 } \\
\text { C10 }\end{array}$ & $\begin{array}{c}9 \\
18\end{array}$ & 1 & 2 & 0 & 0 & 0 & 0 & & & & & 1 & 0 \\
\hline 22 & 5 & $3338254 \mathrm{~b}$ & 58 & $M$ & VHC & 0 & $\begin{array}{l}24,6 \\
28,4\end{array}$ & 0 & A5 & $\begin{array}{l}18 \\
10\end{array}$ & 0 & 2 & 1 & 1 & $>1000$ & 0 & 8 & 1 & 1 & $>1000$ & 0 & 1 \\
\hline 22 & 6 & $55449475 \mathrm{~h}$ & 65 & $\mathrm{~F}$ & VHC & 0 & 21,9 & 0 & B7 & 13 & 0 & 2 & 0 & 0 & 0 & 0 & 7 & 1 & 0 & 32 & 0 & 1 \\
\hline 22 & 7 & $\begin{array}{l}13795257 e \\
117956909\end{array}$ & 58 & M & $\mathrm{OH}$ & A & & 0 & B9 & 13 & 1 & & & & & 1 & & & & & 1 & 0 \\
\hline $\begin{array}{l}22 \\
23 \\
23\end{array}$ & 8 & $\begin{array}{l}13786599 \mathrm{~b} \\
1381536\end{array}$ & $\begin{array}{l}47 \\
54\end{array}$ & $\mathrm{M}$ & $\mathrm{OH}$ & 0 & $\begin{array}{l}22,1 \\
2,0\end{array}$ & 0 & B8 & 13 & 0 & $?$ & & & 0 & 1 & & & 0 & & 1 & 0 \\
\hline $\begin{array}{l}23 \\
23 \\
23\end{array}$ & $\begin{array}{l}1 \\
2\end{array}$ & $\begin{array}{l}1381536000 \\
13650123 a\end{array}$ & $\begin{array}{l}54 \\
53\end{array}$ & $\begin{array}{l}M \\
M\end{array}$ & $\begin{array}{ll}\mathrm{OH} \\
\mathrm{VHC}+\mathrm{HAI}\end{array}$ & $\begin{array}{l}\mathrm{A} \\
\mathrm{O}\end{array}$ & $\begin{array}{l}23,9 \\
25,5\end{array}$ & 0 & $\begin{array}{l}\text { C10 } \\
\text { B7 }\end{array}$ & $\begin{array}{l}20 \\
11\end{array}$ & $\begin{array}{l}1 \\
0\end{array}$ & $\begin{array}{c}2 \\
19\end{array}$ & $\begin{array}{l}0 \\
1\end{array}$ & 0 & 29 & $\begin{array}{l}0 \\
0\end{array}$ & 21 & 1 & 0 & 39 & $\begin{array}{l}0 \\
0\end{array}$ & $\begin{array}{l}1 \\
1\end{array}$ \\
\hline 23 & 3 & 1381 & 51 & M & $\mathrm{OH}$ & 0 & 30,1 & & B9 & 19 & 0 & & & & & 1 & 7 & 1 & 0 & 52 & 0 & 0 \\
\hline $\begin{array}{l}23 \\
23 \\
23\end{array}$ & $\begin{array}{l}4 \\
5\end{array}$ & $\begin{array}{l}13662813 d d \\
13452445\end{array}$ & $\begin{array}{l}59 \\
53\end{array}$ & $\begin{array}{l}M \\
M\end{array}$ & $\begin{array}{l}\mathrm{OH} \\
\mathrm{OH}\end{array}$ & $\begin{array}{l}\mathrm{A} \\
\mathrm{O}\end{array}$ & $\begin{array}{l}26,4 \\
32,7\end{array}$ & $\begin{array}{l}1 \\
0\end{array}$ & $\begin{array}{l}\text { A6 } \\
\text { A5 }\end{array}$ & $\begin{array}{l}12 \\
9\end{array}$ & $\begin{array}{l}1 \\
0\end{array}$ & $\begin{array}{l}2 \\
3 \\
\end{array}$ & $\begin{array}{l}0 \\
1 \\
1\end{array}$ & $\begin{array}{l}0 \\
0 \\
0\end{array}$ & $\begin{array}{c}0 \\
32\end{array}$ & $\begin{array}{l}0 \\
0\end{array}$ & $\begin{array}{l}10 \\
8\end{array}$ & $\begin{array}{l}1 \\
1\end{array}$ & $\begin{array}{l}0 \\
1\end{array}$ & $\begin{array}{l}71 \\
788 \\
188\end{array}$ & $\begin{array}{l}0 \\
0\end{array}$ & $\begin{array}{l}1 \\
1\end{array}$ \\
\hline $\begin{array}{l}23 \\
23 \\
23\end{array}$ & 5 & $\begin{array}{l}13452445 \mathrm{~g} \\
13716168\end{array}$ & 53 & $\begin{array}{l}\mathrm{M} \\
\mathrm{F}\end{array}$ & $\begin{array}{l}\mathrm{OH} \\
\mathrm{OH}\end{array}$ & $\begin{array}{l}O \\
A\end{array}$ & $\begin{array}{l}32,7 \\
24,6\end{array}$ & 0 & $\begin{array}{l}\mathrm{A} 5 \\
\mathrm{~B} 8\end{array}$ & $\begin{array}{c}9 \\
11\end{array}$ & 0 & $\begin{array}{l}3 \\
7\end{array}$ & 1 & $\begin{array}{l}0 \\
0\end{array}$ & 32 & 0 & 8 & 1 & 1 & 188 & 0 & 1 \\
\hline 23 & & 13716168d & 44 & $\mathrm{~F}$ & $\mathrm{OH}$ & & 24,6 & & B8 & 11 & & 7 & 0 & 0 & & & & 1 & & & & \\
\hline
\end{tabular}


Conclusão Anexo E

\begin{tabular}{|c|c|c|c|c|c|c|c|c|c|c|c|c|c|c|c|c|c|c|c|c|c|c|}
\hline Bloco & Envelope & RG & Idade & Sexo & Etiologia & TS & IMC & Tabagista & CTP & MELD & $\begin{array}{c}\text { Dose } \\
\text { dobrada }\end{array}$ & 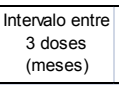 & 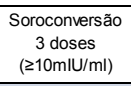 & 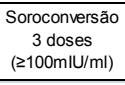 & $\begin{array}{c}\text { Titulo após } \\
3 \text { doses }\end{array}$ & $\begin{array}{l}\text { Perdas } \\
3 \text { doses }\end{array}$ & $\begin{array}{l}\text { Intervalo entre } \\
4 \text { doses } 7 \mathrm{~m}\end{array}$ & 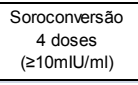 & $\begin{array}{c}\text { Soroconversão } \\
4 \text { doses } \\
(2100 \mathrm{mIU} / \mathrm{ml}) \\
\end{array}$ & $\begin{array}{c}\text { Titulo após } \\
4 \text { doses }\end{array}$ & $\begin{array}{l}\text { Perdas } \\
4 \text { doses }\end{array}$ & $\begin{array}{l}\text { Colheu após } \\
3 \text { e } 4 \text { doseses }\end{array}$ \\
\hline 23 & 7 & $\begin{array}{l}13450390 \mathrm{k} \\
13817563\end{array}$ & $\begin{array}{ll}60 \\
58\end{array}$ & M & $\mathrm{VHC}$ & A & $\begin{array}{l}177,7 \\
274\end{array}$ & 0 & $\begin{array}{l}77 \\
8\end{array}$ & 8 & 0 & 2 & 1 & 1 & $>1000$ & 0 & 7 & 1 & 1 & $>1000$ & 0 & 1 \\
\hline 23 & 8 & $\begin{array}{l}13817653 b \\
138336369\end{array}$ & 58 & M & $\mathrm{OH}$ & A & 27,4 & 1 & B8 & 12 & 1 & & & & & 1 & 7 & 0 & 0 & 0 & 0 & 0 \\
\hline $\begin{array}{l}24 \\
24\end{array}$ & $\begin{array}{l}1 \\
2\end{array}$ & $\begin{array}{l}338033699 \mathrm{i} \\
3354997 \mathrm{k}\end{array}$ & $\begin{array}{l}50 \\
40\end{array}$ & $\begin{array}{l}M \\
M\end{array}$ & $\begin{array}{l}\mathrm{OH} \\
\mathrm{OH}\end{array}$ & $\begin{array}{l}\mathrm{A} \\
\mathrm{O}\end{array}$ & $\begin{array}{l}24,0 \\
26,0\end{array}$ & $\begin{array}{l}0 \\
1\end{array}$ & $\begin{array}{l}\text { B8 } \\
\text { B8 }\end{array}$ & $\begin{array}{l}16 \\
17\end{array}$ & 1 & 2 & 0 & 0 & 4 & 1 & $\begin{array}{l}7 \\
7\end{array}$ & 0 & 0 & ${ }_{144}^{0}$ & 0 & 0 \\
\hline 24 & 3 & $13549378 \mathrm{~g}$ & 48 & M & Cripto & A & $\begin{array}{l}20,0 \\
34,9\end{array}$ & 0 & $\begin{array}{l}\text { B8 } \\
\text { B9 }\end{array}$ & $\begin{array}{l}17 \\
10\end{array}$ & $\begin{array}{l}0 \\
1\end{array}$ & $\begin{array}{l}2 \\
3\end{array}$ & $\begin{array}{l}0 \\
1\end{array}$ & $\frac{0}{1}$ & $\begin{array}{c}4 \\
524\end{array}$ & 0 & 8 & $\frac{1}{1}$ & $\frac{1}{1}$ & $\begin{array}{l}144 \\
>1000\end{array}$ & & 1 \\
\hline 24 & 4 & $13789296 \mathrm{~b}$ & 69 & M & VHC & 0 & 23,6 & 0 & $\mathrm{C} 13$ & 26 & 0 & 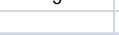 & r & 1 & $0<4$ & 1 & 0 & 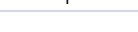 & 1 & T1000 & 1 & 0 \\
\hline 24 & 5 & $13808760 \mathrm{j}$ & 53 & $F$ & VHC & 0 & $\begin{array}{l}31,6 \\
215\end{array}$ & 0 & B9 & 17 & 1 & 2 & 0 & 0 & 0 & 0 & & & & & 1 & 0 \\
\hline 24 & 6 & $\begin{array}{l}13613173 f \\
13619184\end{array}$ & 47 & M & VHC & A & $\begin{array}{l}21,5 \\
253\end{array}$ & 1 & B7 & 12 & 0 & 2 & 0 & 0 & 6 & 0 & 8 & 1 & 1 & 183 & 0 & 1 \\
\hline $\begin{array}{l}24 \\
24\end{array}$ & $\begin{array}{l}7 \\
8\end{array}$ & $\begin{array}{l}\text { 3366191844e } \\
2907990 \mathrm{j}\end{array}$ & $\begin{array}{l}49 \\
62\end{array}$ & $\begin{array}{l}F \\
M\end{array}$ & $\begin{array}{l}\text { VHC } \\
\text { VHC }\end{array}$ & $\begin{array}{l}A B \\
0\end{array}$ & $\begin{array}{l}25,3 \\
25,9\end{array}$ & $\begin{array}{l}0 \\
0\end{array}$ & $\begin{array}{l}\mathrm{A} 6 \\
\mathrm{~B} 8\end{array}$ & $\begin{array}{l}10 \\
17\end{array}$ & $\begin{array}{l}1 \\
0\end{array}$ & 2 & 0 & 0 & 6 & 0 & $\begin{array}{l}11 \\
9\end{array}$ & 1 & $\begin{array}{l}1 \\
0\end{array}$ & $>1000$ & 0 & 1 \\
\hline 25 & 1 & $13792716 \mathrm{~b}$ & 62 & $\mathrm{~F}$ & Cripto & 0 & $\begin{array}{l}25,9 \\
28,3\end{array}$ & 0 & $\begin{array}{l}\text { B8 } \\
\text { B8 }\end{array}$ & 11 & 1 & 3 & 0 & 0 & 0 & $\begin{array}{l}1 \\
0\end{array}$ & 8 & $\begin{array}{l}1 \\
0\end{array}$ & 0 & 29 & 0 & 1 \\
\hline 25 & 2 & $13667148 \mathrm{~d}$ & 57 & M & VHC & 0 & (1) & 0 & A5 & 9 & 0 & & 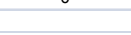 & 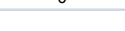 & 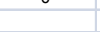 & 1 & 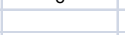 & & 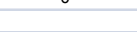 & 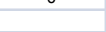 & 1 & 0 \\
\hline 25 & 3 & $13668459 \mathrm{e}$ & 67 & $F$ & VHC & B & 22,5 & 0 & B7 & 12 & 1 & & & & & 1 & & & & & 1 & 0 \\
\hline & $\begin{array}{l}4 \\
5\end{array}$ & $\begin{array}{l}13613694 a \\
1367453\end{array}$ & 34 & M & $\begin{array}{l}\text { VHC } \\
\mathrm{OH}\end{array}$ & 0 & $\begin{array}{l}30,1 \\
298\end{array}$ & 0 & $\begin{array}{l}B 7 \\
B 7\end{array}$ & $\begin{array}{l}12 \\
12\end{array}$ & 0 & & & & & 1 & & 1 & 1 & & 1 & 0 \\
\hline $\begin{array}{l}25 \\
25\end{array}$ & $\begin{array}{l}5 \\
6\end{array}$ & $\begin{array}{l}33674503 c \\
13815315 a\end{array}$ & $\begin{array}{l}67 \\
59\end{array}$ & $\begin{array}{l}M \\
M\end{array}$ & $\begin{array}{l}\mathrm{OH} \\
\mathrm{HCM} M+\mathrm{OH}\end{array}$ & $\begin{array}{l}0 \\
0\end{array}$ & $\begin{array}{l}29,8 \\
27,1\end{array}$ & $\begin{array}{l}0 \\
0\end{array}$ & $\begin{array}{l}\text { B7 } \\
\text { C11 }\end{array}$ & 12 & $\begin{array}{l}0 \\
1\end{array}$ & 3 & 0 & 0 & 0 & 1 & 7 & 1 & 1 & 447 & 0 & 0 \\
\hline 25 & 7 & $13689244 \mathrm{~d}$ & 49 & M & HAI & 0 & 30,5 & 0 & A5 & 11 & 0 & 7 & 1 & 0 & 29 & 0 & 10 & 1 & 1 & 104 & 0 & 1 \\
\hline 25 & 8 & $5252545 \mathrm{~A}$ & 70 & $F$ & $\mathrm{HAI}$ & B & 22,5 & 0 & B8 & 11 & 1 & & & & & 1 & 7 & 0 & 0 & 0 & 0 & 0 \\
\hline 26 & 1 & $\begin{array}{l}13462280 \mathrm{~b} \\
13482098\end{array}$ & 42 & M & $\mathrm{OH}$ & A & 29,5 & 0 & & 12 & 0 & 2 & 1 & 1 & 527 & 0 & & & & & 1 & 0 \\
\hline $\begin{array}{l}26 \\
26\end{array}$ & 2 & $\begin{array}{l}13482968 d \\
137323688\end{array}$ & $\begin{array}{l}62 \\
35\end{array}$ & $\begin{array}{l}\mathrm{M} \\
\mathrm{M}\end{array}$ & $\mathrm{OH}$ & A & 32,3 & $\begin{array}{l}0 \\
0\end{array}$ & $\begin{array}{l}\text { B9 } \\
{ }^{A} 6\end{array}$ & $\begin{array}{l}15 \\
14\end{array}$ & 1 & & & & & 1 & 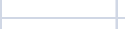 & 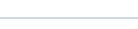 & 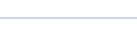 & & 1 & 0 \\
\hline 26 & 4 & $\begin{array}{l}13 / 323638 d \mathrm{~d} \\
13823326 \mathrm{a}\end{array}$ & $\begin{array}{l}35 \\
42 \\
42\end{array}$ & $\begin{array}{l}\text { M } \\
M\end{array}$ & $\begin{array}{l}\mathrm{OH} \\
\mathrm{OH}\end{array}$ & 0 & $\begin{array}{l}40,4 \\
25,4\end{array}$ & 0 & $\begin{array}{l}\text { A6 } \\
\text { B7 }\end{array}$ & $\begin{array}{l}14 \\
16\end{array}$ & $\begin{array}{l}1 \\
1\end{array}$ & 3 & 1 & 1 & $>1000$ & $\begin{array}{l}1 \\
0\end{array}$ & 8 & 1 & 1 & $>1000$ & $\begin{array}{l}1 \\
0\end{array}$ & $\begin{array}{l}0 \\
1\end{array}$ \\
\hline 26 & 5 & $13488124 k$ & 57 & M & VHC & 0 & 2,4 & 1 & A6 & 10 & 1 & 3 & 0 & 0 & 0 & 0 & 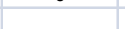 & & & 17000 & 1 & 0 \\
\hline 26 & $\begin{array}{l}6 \\
7\end{array}$ & $\begin{array}{l}13730108 g \\
13630243 c\end{array}$ & $\begin{array}{l}47 \\
56\end{array}$ & $M$ & $\begin{array}{l}\mathrm{VHC+OH} \\
\mathrm{VHHCOH}\end{array}$ & A & $\begin{array}{l}23,5 \\
279\end{array}$ & 0 & A6 & 13 & 0 & 2 & 0 & 0 & 0 & 0 & 7 & 0 & 0 & 3 & 0 & 1 \\
\hline 26 & 78 & $\begin{array}{l}13630243 c \\
13967413\end{array}$ & 56 & $\mathrm{M}$ & $\mathrm{VHC}+\mathrm{OH}$ & O & 27,9 & 0 & B9 & 13 & 0 & 2 & 1 & 1 & $>>1000$ & 0 & 7 & 1 & 0 & & 1 & 0 \\
\hline $\begin{array}{l}26 \\
27\end{array}$ & 8 & $\begin{array}{l}13697443 j \\
1344433\end{array}$ & 52 & $\begin{array}{l}\mathrm{M} \\
\mathrm{F}\end{array}$ & $\begin{array}{l}\mathrm{OH} \\
\mathrm{VHC}\end{array}$ & A & 32,4 & 0 & ${ }^{A 6}$ & 12 & 0 & 2 & 0 & 0 & 0 & 0 & 7 & 1 & 0 & 20 & 0 & 1 \\
\hline 27 & 2 & $\begin{array}{l}134444333 \mathrm{~h} \\
13732556 \mathrm{~h}\end{array}$ & 62 & $\begin{array}{l}F \\
F\end{array}$ & $\begin{array}{l}\text { VHC } \\
\text { VHC }\end{array}$ & $\begin{array}{c}A B \\
B\end{array}$ & $\begin{array}{l}22,0 \\
28,8\end{array}$ & 1 & $\begin{array}{l}A 6 \\
B 7\end{array}$ & $\begin{array}{l}11 \\
15\end{array}$ & $\begin{array}{l}1 \\
0\end{array}$ & & & & & $\begin{array}{l}1 \\
1\end{array}$ & 8 & 0 & 0 & 4 & $\begin{array}{l}0 \\
1\end{array}$ & 0 \\
\hline 27 & 3 & $13622999 \mathrm{~g}$ & 66 & M & $\mathrm{OH}$ & A & 28,3 & 0 & B8 & 10 & 0 & 2 & 0 & 0 & 0 & 0 & 7 & 0 & 0 & 0 & 0 & 1 \\
\hline 27 & 4 & $13823313 \mathrm{~g}$ & 47 & $\mathrm{~F}$ & Cripto & A & 33,3 & 0 & C10 & 22 & 1 & & & & & 1 & 7 & & & & 1 & 0 \\
\hline $\begin{array}{l}27 \\
27\end{array}$ & 5 & $\begin{array}{l}13711786 \mathrm{a} \\
13713727\end{array}$ & 40 & M & $\mathrm{OH}$ & A & $\begin{array}{l}29,6 \\
23\end{array}$ & 0 & B8 & 12 & 1 & & & & & 1 & 7 & 1 & 1 & 154 & 0 & 0 \\
\hline 27 & $\begin{array}{l}6 \\
7\end{array}$ & $\begin{array}{l}33773272 \mathrm{~g} \\
13478018 \mathrm{i}\end{array}$ & $\begin{array}{l}46 \\
49\end{array}$ & $\begin{array}{l}\text { M } \\
F\end{array}$ & $\begin{array}{l}\mathrm{OH} \\
\mathrm{VHC}\end{array}$ & $\begin{array}{l}\text { B } \\
\text { B }\end{array}$ & $\begin{array}{l}23,3 \\
32,0\end{array}$ & $\begin{array}{l}0 \\
0\end{array}$ & $\begin{array}{l}\text { B8 } \\
\text { B8 }\end{array}$ & $\begin{array}{l}12 \\
15\end{array}$ & $\begin{array}{l}0 \\
0\end{array}$ & 3 & 0 & 0 & 0 & $\begin{array}{l}1 \\
0\end{array}$ & 8 & 0 & 0 & 0 & 1 & $\begin{array}{l}0 \\
1\end{array}$ \\
\hline 27 & 8 & $13824958 \mathrm{e}$ & 52 & M & $\mathrm{OH}$ & 0 & 29,0 & 0 & A6 & 10 & 1 & 2 & 0 & 0 & 0 & 0 & 6 & 1 & 0 & 10 & 0 & 1 \\
\hline 28 & 1 & 1372831 & 52 & $\mathrm{~F}$ & HAI & A & $\begin{array}{l}3,0 \\
3,0\end{array}$ & 1 & C10 & 8 & 0 & 2 & 0 & 0 & 0 & 0 & 7 & 0 & 0 & 0 & 0 & 1 \\
\hline 28 & 2 & & & $\mathrm{~F}$ & CBS & 0 & $\begin{array}{l}26,5 \\
\end{array}$ & 0 & A5 & 9 & 1 & 2 & 1 & 0 & 50 & 0 & 8 & 1 & 1 & $>1000$ & 0 & 1 \\
\hline $\begin{array}{l}28 \\
28\end{array}$ & $\begin{array}{l}3 \\
4 \\
\end{array}$ & $\begin{array}{l}33827245 b \\
13798888 k\end{array}$ & $\begin{array}{l}50 \\
19\end{array}$ & $\begin{array}{l}M \\
\text { F }\end{array}$ & $\begin{array}{l}\mathrm{OH} \\
\mathrm{HAI}\end{array}$ & $\begin{array}{l}\text { A } \\
\text { A }\end{array}$ & $\begin{array}{l}28,1 \\
25,3\end{array}$ & 0 & $\begin{array}{l}\text { B7 } \\
\text { B7 }\end{array}$ & $\begin{array}{l}12 \\
12\end{array}$ & 1 & 6 & 1 & 0 & 78 & 0 & 12 & 1 & 1 & $>1000$ & 0 & 1 \\
\hline 28 & $\begin{array}{l}4 \\
5\end{array}$ & $\begin{array}{l}137988888 \mathrm{k} \\
13812985 \mathrm{~d}\end{array}$ & 45 & $\begin{array}{l}F \\
M\end{array}$ & $\begin{array}{l}\text { HAI } \\
\text { OH }\end{array}$ & $\begin{array}{l}\text { A } \\
\text { B }\end{array}$ & $\begin{array}{l}25,3 \\
26,0\end{array}$ & 1 & $\begin{array}{l}\text { B7 } \\
\text { B8 }\end{array}$ & $\begin{array}{l}f_{12} \\
11\end{array}$ & $\begin{array}{l}0 \\
1\end{array}$ & 2 & 0 & 0 & 0 & 1 & & & & & 1 & 0 \\
\hline 28 & 6 & $13773450 \mathrm{~d}$ & 52 & $\mathrm{~F}$ & VHC & 0 & 40,2 & 0 & B7 & 11 & 0 & 2 & 0 & 0 & 0 & 0 & & & & & 1 & 0 \\
\hline 28 & & $2910146 \mathrm{c}$ & 57 & & Cripto & 0 & 28,1 & 0 & B8 & 19 & 1 & 7 & 1 & 0 & 73 & 0 & & & & & 1 & 0 \\
\hline $\begin{array}{l}28 \\
29\end{array}$ & 8 & $\begin{array}{l}338242120 j \\
132848114\end{array}$ & $\begin{array}{l}22 \\
54 \\
\end{array}$ & F & $\begin{array}{l}\text { HAA } \\
\text { OH }\end{array}$ & $\begin{array}{l}0 \\
B\end{array}$ & $\begin{array}{l}20,5 \\
33,7\end{array}$ & $\begin{array}{l}0 \\
0\end{array}$ & $\begin{array}{l}\text { C11 } \\
\text { B9 }\end{array}$ & $\begin{array}{l}17 \\
17\end{array}$ & 0 & 5 & 0 & 0 & 0 & 0 & 9 & 1 & 0 & 11 & 0 & 1 \\
\hline $\begin{array}{l}29 \\
29\end{array}$ & $\begin{array}{l}1 \\
2\end{array}$ & $\begin{array}{l}13824811 \mathrm{ft} \\
13814671 \mathrm{~b}\end{array}$ & $\begin{array}{l}54 \\
48\end{array}$ & $\begin{array}{l}\mathrm{M} \\
\mathrm{F}\end{array}$ & Cripto & $\begin{array}{l}B \\
B\end{array}$ & $\begin{array}{l}33,1 \\
27.9\end{array}$ & 0 & $\begin{array}{l}\text { B9 } \\
\text { B8 }\end{array}$ & $\begin{array}{l}11 \\
7\end{array}$ & $\begin{array}{l}1 \\
1\end{array}$ & 3 & 0 & 0 & 0 & $\begin{array}{l}1 \\
0\end{array}$ & $\begin{array}{l}6 \\
8\end{array}$ & $\begin{array}{l}1 \\
1 \\
\end{array}$ & 1 & 36 & 0 & 1 \\
\hline 29 & 3 & $3074375 \mathrm{~h}$ & 57 & M & $\mathrm{OH}$ & B & 25,8 & 0 & B7 & 21 & 1 & 2 & 0 & 0 & 0 & 0 & 6 & 0 & 0 & 2 & 0 & 1 \\
\hline 29 & 4 & 138 & 45 & M & VHC & B & 27,7 & 0 & C10 & 12 & 1 & 3 & 0 & 0 & 0 & 0 & & & & & 1 & 0 \\
\hline 29 & 5 & $3287923 j$ & 54 & $\mathrm{~F}$ & VH & $A B$ & 19,8 & 1 & A6 & 8 & 0 & & & & & 1 & & & & & 1 & 0 \\
\hline $\begin{array}{l}29 \\
29\end{array}$ & 6 & $\begin{array}{l}338228626 \mathrm{~K} \\
13841033 \mathrm{~K}\end{array}$ & $\begin{array}{l}55 \\
42\end{array}$ & $\begin{array}{l}\mathrm{F} \\
\mathrm{F}\end{array}$ & $\begin{array}{l}\mathrm{OH} \\
\mathrm{VHC}\end{array}$ & A & 24,7 & 1 & $\begin{array}{r}\text { B9 } \\
\end{array}$ & 15 & 0 & 2 & 0 & 0 & 0 & 0 & 7 & 0 & 0 & 0 & 0 & 1 \\
\hline $\begin{array}{l}29 \\
29\end{array}$ & 8 & $\begin{array}{l}1384173033 K \\
13769702 C\end{array}$ & $\begin{array}{l}42 \\
21\end{array}$ & M & $\begin{array}{l}\text { VHC } \\
\text { HAI }\end{array}$ & $\begin{array}{l}\text { A } \\
0\end{array}$ & $\begin{array}{l}29,4 \\
26,0\end{array}$ & & $\begin{array}{l}\text { A6 } \\
\text { A6 }\end{array}$ & $\begin{array}{l}21 \\
14\end{array}$ & 0 & 4 & 0 & 0 & 0 & $\begin{array}{l}1 \\
0\end{array}$ & 9 & 0 & 0 & 1 & $\begin{array}{l}1 \\
0\end{array}$ & 1 \\
\hline
\end{tabular}

${ }^{*} \mathrm{~F}=$ Sexo feminino; $M=$ Sexo masculino

${ }^{*}$ Cripto=Criptogênica; $\mathrm{VHC}=$ Hepatite C; $\mathrm{OH}=$ Álcool; $\mathrm{CBS}=$ Cirrose biliar secundária;

$\mathrm{CBP}=$ Cirrose biliar primária; $\mathrm{HMC}=\mathrm{Hemocromatose} ; \mathrm{HAl}=$ Hepatite auto-imune

Budd= Budd-Chiari; Nash= Esteato-hepatite não alcoólica. 
Anexo F: Secretaria do Estado da Saúde: Ofício para utilização da Butang

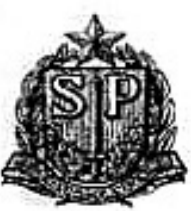

\author{
SECRETARIA DE ESTADO DA SAÜDE \\ COORDENADORIA DE CONTROLE DE DOENÇAS - CCD \\ CENTRO DE VIGILĀNCIA EPIDEMIOLÓGICA \\ "PROF. ALEXANDRE VRANJAC"
}

AV. DR. ARNALDO, 351 - $6^{\circ}$ ANDAR SALA 619 - SP/SP - CEP: 01246-000

FONE: (11) 3082-8780 - FAX: 3062-2136

E-MAlL: dvimuni@saude.sp.gov.br

OFICIO CIRC. IMUNI N $12 / 08$

São Paulo, 4 de junho de 2008.

Prezado(a) Senhor(a):

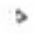

Após discussăo no Comitê Técnico Assessor em Imunizaçōes (CTAl) do Programa Nacional de Imunizações dos estudos cientificos realizados nestes últimos dez anos ${ }^{1,2.3,4,5,6}$ utilizando a vacina contra hepatite B (BUTANG (8), produzida pelo Instituto Butantan, informamos que:

- a vacina BUTANG@ poderá ser utilizada para todas as pessoas que a vacina contra hepatite B estiver indicada, incluindo os grupos de risco e pacientes imunodeprimidos.

- é importante informar que $25 \mu \mathrm{g}(1 \mathrm{ml})$ da vacina BUTANG (B) corresponde a $20 \mu \mathrm{g}$ das vacinas dos outros laboratórios

- a dose permanece a mesma: 0 a 19 anos de idade: $0,5 \mathrm{ml}(12,5 \mu \mathrm{g}), 20$ anos ou mais: $1,0 \mathrm{ml}(25 \mu)$

- é importante salientar que a idade máxima para vacinação nas açōes de rotina contra hepatite B, permanece a mesma, isto é até 19 anos, 11 meses e 29 dias.

\title{
Referência:
}

1 - Costa AA, Inenami M, Juarez E, Llacen PD, Raw I., Preliminary report of the use adults of a recombinant yeast-derived hepatitis $B$ vaccine manufactured by Instituto Butantan. Rev Inst Med Trop S Paulo 39:39-42, 1997.

2 - loshimoto LM, Rissato ML, Bonilha VSJ, Miyaki C, Raw I, Granovski N. Safety and immunogenicity of hepatitis B vaccine Butang in adults. Rev inst Med Trop S Paulo 41:191-3, 1999.

3 - Martins RM, Bensabath G, Arraes LC, Oliveira MLA, Miguel JC, Barbosa GG, Camacho LA, Multicenter study on the immunogenicity and safety of two recombinant vaccines against hepatitis B. Mem Inst Oswaldo Cruz 99 (8):86571,2004 . 
4 - Baldy JLS, Lima GZ, Morimoto HK, Reiche EMV, Matsuo T, Mattos ED, Sudan LCP, Immunogenicity of three recombinant hepatitis $B$ vaccines administered to students in three doses contaning half the antigen amount routinely used for adult yaccination. Rev. Inst. Med. Trop. S. Paulo 46 (2): 103-7, 2004.

5 - Moraes JC et al. Avaliaçăo de imunogenicidade e segurança da vacina recombinante contra hepatite $B$ do Instituto Butantan (Buta-NG) em adultos de 31 a 40 anos de idade. Relatório de pesquisa. Centro de Estudos Augusto Leopoldo Ayrosa Galvão (CEALAG). Faculdade de Ciências Médicas da Santa Casa de São Paulo, março de 2006 (mimeo).

6 - Moraes JC et al. Avaliaçăo de imunogenicidade e segurança da vacina recombieante contra hepatite B do Instituto Butantan (Buta-NG) em crianças na Regiăo Metropolitana de Săo Paulo, Relatório de pesquisa. Departamento de Medicina Social, Faculdade de Ciências Médicas da Santa Casa de São Paulo, maio de 2006 (mimeo).

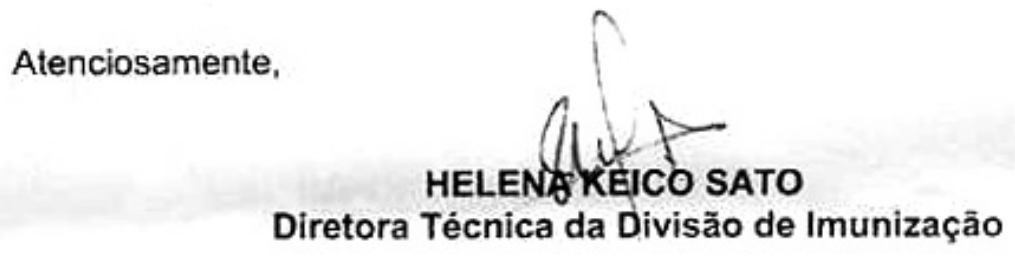

Visto,

DRA. ANA FREITAS RIBEIRO

Diretora Técnica do CVE/CCD/SES

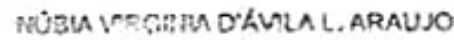

Assist. TAcritio Vig. Epidem. III

IImo.(a) Senhor(a)

AOS RESPONSÁVEIS PELA GVES I A XXXIII 


\section{Referências}


1. Poland GA, Jacobson RM. Prevention of hepatitis B with the hepatitis B vaccine. $N$ Engl J Med. 2004;351:2832-8.

2. Liaw YF, Chu CM. Hepatitis B virus infection. Lancet. 2009;373:582-92.

3. Shepard CW, Simard EP, Finelli L, Fiore AE, Bell BP. Hepatitis B virus infection: epidemiology and vaccination. Epidemiol Rev. 2006;28:112-25.

4. Berk PD, Lok A. Epidemiology and Prevention of Hepatitis B. Sem Liver Disease. 2003:23:39-46.

5. Manual dos centros de referência para imunobiológicos especiais. Secretaria de Vigilância Epidemiológica, Brasil. 3a Ed. 2006. Disponível em: http://portal.saude.gov.br/portal/arquivos/pdf/livro_cries_3ed1.pdf.

6. Mast EE, Ward JW. Hepatitis B vaccines. In: Plotkin SA, Orenstein WA, Offit PA. Vaccines. 5a ed. Philadelphia, Pennsylvania: Elsevier Inc; 2008. p.205-41.

7. Engler SH, Sauer PW, Golling M, Klar EA, Benz C, Stremmel W, et al. Immunogenicity of two accelerated hepatitis B vaccination protocols in liver transplant candidates. Eur J Gastroenterol Hepatol. 2001;13:363-7.

8. Nota Técnica No 13/2208/PNHV/DEVEP/SVS/MS. Proposta do dia nacional/ mundial das hepatites virais. Ministério da Saúde, Brasil [on line]. Janeiro de 2008. Disponível em: http://portal.saude.gov.br/portal/arquivos/pdf/nota_hepatites.pdf.

9. Situação da Prevenção e Controle das Doenças Transmissíveis. Secretaria de Vigilância em Saúde, Brasil [on line]. 2004. Disponível em: http://portal.saude.gov.br/portal/arquivos/pdf/capitulo6_sb.pdf. 
10. Programa Estadual de Imunizações. Boletim Epidemiológico Paulista [on line]. Março de 2006. Disponível em: http://www.cve.saude.sp.gov.br/agencia/bepa27_imuni.htm.

11. Hepatites Virais $B$ e $C-$ Gráficos. Centro de Vigilância Epidemiológica de São Paulo, Brasil. Dados de 30/06/2009 [on line]. Disponível em: http://www.cve.saude.sp.gov.br/htm/hepatite/hepa_graficos.htm.

12. Silva LC, Pinho JRB. Hepatite B. In: Doenças do fígado e vias biliares. Silva LC, Strauss E, Carrilho FJ, Porta G. São Paulo: Atheneu; 2001. P442-67.

13. Mahoney FJ. Update on diagnosis, management, and prevention of hepatitis B virus infection. Clin Microbiol Rev. 1999;12:351-66.

14. Oliveira LCM, Silva TE, Alves MH. Resposta à vacinação contra a hepatite B em alcoolistas sem cirrose hepática clinicamente evidente. Arq Gastroenterol. 2007;44:195-200.

15. Martins RM, Bensabath G, Arraes LC, Oliveira MLA, Miguel JC, Barbosa GG, et AL. Mem Inst Oswaldo Cruz. 2004;99:865-71.

16. Baldy JLS, Lima GZ, Morimoto HK, Reiche EMV, Matsuo T, Mattos ED, et al. Immunogenicity of three recombinant hepatitis B vaccines administered to students in three doses containing half the antigen amount routinely used for adult vaccination. Rev Inst Med Trop Sao Paulo. 2004;46:103-7.

17. Arguedas MR, McGuire BM, Fallon MB. Implementation of vaccination in patients with cirrhosis. Dig Dis Sci. 2002; 47:384-7.

18. Siegrist CA. Vaccine Immunology. In: Plotkin SA, Orenstein WA, Offit PA. Vaccines. 5a ed. Philadelphia, Pennsylvania: Elsevier Inc; 2008. p.17-36. 
19. Abbas AK, Lichtman AH, Pillai S. Imunologia celular e molecular. California São Francisco: Elsevier;2008. Cap.1, p3-17: Propriedades gerais das respostas imunológicas.

20. Banatvala J, Damme PV, Oehen S. Lifelong protection against hepatitis B: the role of immunogenicity in immune memory. Vaccine. 2001; 19:877-85.

21. Lopes MH, Gutierrez EB. Profilaxia Vacinal. In: Focaccia R. Tratado de Hepatites Virais. 2a ed. São Paulo: Atheneu; 2007. p.171-174.

22. Koff RS. Immunogenicity of hepatitis B vaccines: implications of immune memory. Vaccine. 2002; 20:3695-3701.

23. De Maria, Idilman, Calantoni, Van Thiel. Increased effective immunogenicity to high-dose and short-interval hepatitis B vírus vaccination in individuals with chronic hepatitis without cirrhosis. J Viral Hepat. 2001;8:372-6.

24. Koff RS. Review article: vaccination and viral hepatitis - current status and future prospects. Aliment Pharmacol Ther. 2007;26: 1285-92.

25. Winter AP, Follet EAC, McIntyre J, Stewart J, Symington IS. Influence of smoking immunological responses to hepatitis B vaccine. Vaccine. 1994;12:771-2.

26. Shaw FE, Guess HA, Roets JM, Mohr FE, Coleman PJ, Mandel EJ, et al. Effect of anatomic injection site, age and smoking on the immune response to hepatitis B vaccination. Vaccine. 1989;7:425-30.

27. Charest AF, McDougall J, Goldstein MB. A randomized comparison of intradermal and intramuscular vaccination against hepatitis B virus in incident chronic hemodialysis patients. Am J Kidney Dis. 2000;36:976-82. 
28. Fonseca MO, Pang LW, de Paula Cavalheiro N, Barone AA, Lopez MH. Randomized trial of recombinant hepatitis B vaccine in HIV infected adult patients comparing a standard dose to a double dose. Vaccine. 2005;23:2902-8.

29. Idilman R, Colantoni A, De Maria N, Ustun C, Sam R, Ing TS, et al. Impaired antibody response rates after high dose short interval hepatitis B virus vaccination of immunosuppressed individuals. Hepatogastroenterology. $2003 ; 50: 217-21$.

30. El-Reshaid K, Al-Mufti S, Johny KV, Sugathan TN. Comparison of two immunization schedules with recombinant hepatitis B vaccine and natural immunity acquired by hepatitis $\mathrm{B}$ infection in dialysis patients. Vaccine. 1994;12:223-8.

31. Strauss E, Sá Ribeiro MFG. Cirrose hepática-Aspectos gerais. In: Doenças do fígado e vias biliares. Silva LC, Strauss E, Carrilho FJ, Porta G. São Paulo: Atheneu; 2001. p591-601.

32. Bruguera M, Rodés J. Cirrosis hepática compensada. In: Lapuerta JB, Bengoechea MB, Bengoechea MG, Sáez LR. Tratamiento de las enfermedades hepáticas y biliares. Madrid: Elba; 2001. p.99-104.

33. Lallée MP, Quintela E, Mies S. Transplante de fígado e a realidade brasileira. In: Focaccia R. Tratado de Hepatites Virais. 2a ed. São Paulo: Atheneu; 2007. p.689-714.

34. Valla D, Durand F. Assessment of the prognosis of cirrhosis: Child-Pugh versus MELD. J Hepatol. 2005; 42(Suppl):100-7.

35. Freeman RB, Wiesner RH, Edwards E, Harper A, Merion R, Wolfe R, et al. Results of the first year of the new liver allocation plan. Liver Transplant. 2004;10:7-15. 
36. Fica A. Diagnóstico, manejo y prevención de infecciones en pacientes con cirrosis hepática. Rev Chilena Infectol. 2005;22:63-74.

37. Ferreira Filho RP, Almeida D. Sistema imunológico da doença parenquimatosa crônica do fígado. In: Focaccia R. Tratado de Hepatites Virais. $2^{\mathrm{a}}$ ed. São Paulo: Atheneu; 2007. p.399-401.

38. Cheong HJ, Song JY, Park JW, Yeon JE, Byun KS, Lee CH, et al. Humoral and cellular immune responses to influenza vaccine in patients with advanced cirrhosis. Vaccine. 2006;24:2417-22.

39. Arguedas MR, Johnson A, Eloubeidi MA, Fallon MB. Immunogenicity of hepatitis A vaccination in decompensated cirrhotic patients. Hepatology. 2001;34:28-31.

40. Brasil. Portaria n. ${ }^{\circ}$ 541/GM. Em 14 de março de 2002. Aprovar, na forma do Anexo desta Portaria, os Critérios para Cadastramento de Candidatos a Receptores de Fígado - Doador Cadáver, no Cadastro Técnico de Receptores de Fígado - “lista única” -das Centrais de Notificação, Captação e Distribuição de Órgãos - CNCDO. Ministério da Saúde, Brasil. Disponível em: http://dtr2001.saude.gov.br/sas/PORTARIAS/Port2002/Gm/GM-541.htm.

41. Brasil. Portaria $\mathrm{N}^{\circ} 1160$ de 29 de maio de 2006. Modifica os critérios de distribuição de fígado de doadores cadáveres para transplante, implantando o critério de gravidade de estado clínico do paciente. Ministério da Saúde, Brasil. Disponível em: http://dtr2001.saude.gov.br/sas/PORTARIAS/Port2006/GM/GM-1160.htm.

42. Lista de espera para transplantes. Primeiro Semestre 2009 [on line]. Ministério da Saúde, Brasil. Disponível em: http://portal.saude.gov.br/portal/arquivos/pdf/ Lista_de_Espera.pdf. 
43. Transplantes realizados no Brasil. Primeiro semestre de 2009 [on line]. Ministério da Saúde, Brasil. Disponível em: http://portal.saude.gov.br/portal/ arquivos/pdf/TRANSPLANTES_2009.pdf.

44. Garcia VD. Registro Brasileiro de Transplantes. Veículo oficial da Associação Brasileira de Transplantes de Órgãos [on line]. Janeiro/junho 2009. Disponível em: http://www.abto.org.br/abtov02/portugues/populacao/rbt/anoXV_n2/index.aspx? idCategoria $=2$.

45. Horlander JC, Boyle N, Manam R, Manam R, Schenk M, Herring S, et al. Vaccination against hepatitis $\mathrm{B}$ in patients with chronic liver disease awaiting liver transplantation. Am J Med Sci. 1999;318:304-7.

46. Reiss G, Keeffe EB. Review article: hepatitis vaccination in patients with chronic liver disease. Aliment Pharmacol Ther. 2004;19: 715-27.

47. Chalasani N, Smallwood G, Halcomb HJ. Is vaccination against hepatitis B infection indicated in patients waiting for or after orthotopic liver transplantation? Liver Transpl Surg. 1998;4:128-32.

48. Mattos AA, Gomes EB, Tovo CV, Alexandre COP, Remião JOR. Hepatitis B vaccine efficacy in patients with chronic liver disease by hepatitis $\mathrm{C}$ virus. Gastroenterology. 2004;41:180-4.

49. Dominguez M, Barcena R, Garcia M. Vaccination against hepatitis B vírus in cirrhotic patients on liver transplant waiting list. Liver Transpl. 2000;6:440-2.

50. Macedo G, Maia JC, Gomes A. Efficacy of a reinforced protocol of HBV vaccination in cirrhotic patients waiting for a orthotopic liver transplantation. Transplant Proc. 2000;32:2641. 
51. Idilman R, De Maria N, Colantoni A, Nadir A, Van Thiel DH. The effect of high dose and short interval HBV vaccination in individuals with chronic hepatitis $\mathrm{C}$. Am J Gastroenterol. 2002;97:435-9.

52. Arslan M, Wiesner RH, Sievers C, Egan K, Zein NN. Double-dose accelerated hepatitis B vaccine in patients with end-stage liver disease. Liver Transpl. 2001;7:314-20.

53. Kallinowski B, Benz C, Buchholz L, Stremmel W. Accelerated schedule of hepatitis B vaccination in liver transplant candidates. Transplant Proc. 1998;30:797-9.

54. Bonazzi PR, Bacchella T, Freitas AC, Osaki KT, Lopes MH, Freire MP, et AL. Double-dose hepatitis B vaccination in cirrhotic patients on a liver transplant waiting list. Braz J Infect Dis. 2008;12:306-9.

55. Rosman AS, Basu P, Galvin K, Lieber CS. Efficacy of a high and accelerated dose of hepatitis B vaccine in alcoholic patients: a randomized clinical trial. Am J Med. 1997;103:217-22.

56. Ni $\mathrm{YH}$, Chang $\mathrm{MH}$. The ways paved prophylaxis against de novo hepatitis $\mathrm{B}$ virus infection after liver transplantation: still many stones left unturned. Pediatr Transplant. 2006;10:405-7.

57. Chang SH, Suh KS, Yi NJ, Choi SH, Lee HJ, Seo JK, et al. Active immunization against de novo of hepatitis $\mathrm{B}$ virus infection in pediatric patients after liver transplantation. Hepatology. 2003;37:1329-34.

58. Jankowska I, Pawlowska J, Teisseyre M, Kalicin'ski P, Kamin'ski A, Czubkowski $\mathrm{P}$, et al. Prevention of de novo hepatitis $\mathrm{B}$ virus infection by vaccination and high hepatitis B surface antibodies level in children receiving hepatitis B virus core antibody-positive living related donor liver: Case reports. Transplant Proc. 2007;39:1511-2. 
59. Su WJ, Ho YC, Ni YH, Chen HL, Hu YH, Wu YM, et al. High-titer antibody to hepatitis $\mathrm{B}$ surface antigen before liver transplantation can prevent de novo hepatitis B infection. J Pediatr Gastroenterol Nutr. 2009; 48:203-8.

60. Lin CC, Chen CL, Concejero A, Wang CC, Wang SH, Liu YW, et al. Active immunization to prevent de novo hepatitis $\mathrm{B}$ infection in pediatric live donor liver recipients. Am J Transplant. 2007;7:195-200.

61. Yoshida EM, Ramji A, Erb SR, Davis JE, Steinbrecher UP, Sherlock CH, et al. De novo acute hepatitis $\mathrm{B}$ infection in a previously vaccinated liver transplant recipient due to a strain of $\mathrm{HBV}$ with a Met $133 \mathrm{Thr}$ mutation in the "a" determinant. Liver. 2000;20:411-4.

62. Moradela G, Bárcena R, Del Campo S, Otón E, Moreno J, Foruni R. De novo $\mathrm{HBV}$ infection caused by an anti-HBc positive donor in a vaccinated liver transplant recipient in spite of anti-HBs response [letter]. Am J Transplant. 2006;6:438-40.

63. Barcena R, Moraleda G, Moreno J, Martín MD, Vicente E, Nuño J, et al. Prevention of de novo $\mathrm{HBV}$ infection by the presence of anti-HBs in transplanted patients receiving core antibody positive livers. World $J$ Gastroenterol. 2006;12:2070-4.

64. Ni YH, Ho MC, Wu JF, Chen HL, Wu YM, Hu RH, et al. Response to booster hepatitis B vaccines in liver transplanted children primarily vaccinated in infancy. Transplantation. 2008;86:1531-5.

65. CDC. A comprehensive immunization strategy to eliminate transmission of hepatitis $B$ virus infection in the United States. Recommendations of ACIP. MMWR. 2006;55:RR16. Disponível em: http://www.cdc.gov/mmwR/PDF/rr/rr5516.pdf. 
66. Wendel S, Levi JE, Torezan Filho, M. Epidemiologia da hepatite B póstransfusional. In: Focaccia R. Tratado de Hepatites Virais. $2^{\mathrm{a}}$ ed. São Paulo: Atheneu; 2007. p.43-63.

67. Bruguera M, Rodicio JL, Alcazar JM, Oliver A, Del Rio G, Esteban-Mur R. Effects of different dose levels and vaccination schedules on immune response to a recombinant DNA hepatitis B vaccine in haemodialysis patients. Vaccine. 1990;8:S47-9.

68. Goldwater PN. Randomized, comparative trial of $20 \mu \mathrm{g}$ vs $40 \mu \mathrm{g}$ Engerix B vaccine in hepatitis B vaccine non-responders. Vaccine. 1997;15:353-356.

69. Fisman DN, Agrawal D, Leder K. The effect of age on immunologic response to recombinant hepatitis B vaccine: a meta-analysis. Clin Infect Dis. 2002;35:1368-76.

70. Caly WR, Strauss E, Carrilho FJ, Laudanna AA. Different degrees of malnutrition and immunological alterations according to the aetiology of cirrhosis: a prospective and sequencial study. Nutr J. 2003;2:2-9.

71. Kramer ES, Hofmann C, Smith PG, Shiffman ML, Sterling RK. Response to hepatitis $\mathrm{A}$ and $\mathrm{B}$ vaccine alone or in combination in patients with chronic hepatitis C virus and advanced fibrosis. Dig Dis Sci. 2009;54:2016-25.

72. Lin HH, Liao HWC, Lin SK, Wang LY. HLA and response to booster hepatitis $B$ vaccination in anti-HBs seronegative adolescents who had received primary infantile vaccination. Vaccine. 2008;26:3414-20.

73. Wang C, Tang J, Song W, Lobashevisky E, Wilson CM, Kaslow RA. HLA and cytokine gene polymorphisms are independently associated with responses to hepatitis B vaccination. Hepatology. 2004;39:978-88. 
74. Buchta C, Körmöczi G, Heinze G, Puhr R, Kompatscher M, Jüngling G, et al. Lack of impact of $\mathrm{ABO}$ blood group or corresponding isoantibodies on the immune response after rabies vaccination [abstract]. Wien Klin Wochenschr. 2005;117:412-6.

75. Zanetti AR, Damme PV, Shouval D. The global impact of vaccination against hepatitis B: a historical overview. Vaccine. 2008;26:6266-73. 